\title{
eNeuro
}

Review / Disorders of the Nervous System

\section{Volume and connectivity differences in brain networks associated with cognitive constructs of binge eating}

https://doi.org/10.1523/ENEURO.0080-21.2021

Cite as: eNeuro 2022; 10.1523/ENEURO.0080-21.2021

Received: 2 March 2021

Revised: 14 November 2021

Accepted: 29 November 2021

This Early Release article has been peer-reviewed and accepted, but has not been through the composition and copyediting processes. The final version may differ slightly in style or formatting and will contain links to any extended data.

Alerts: Sign up at www.eneuro.org/alerts to receive customized email alerts when the fully formatted version of this article is published.

Copyright (c) 2022 Hartogsveld et al.

This is an open-access article distributed under the terms of the Creative Commons Attribution 4.0 International license, which permits unrestricted use, distribution and reproduction in any medium provided that the original work is properly attributed. 
1 1. Volume and connectivity differences in brain networks associated with cognitive constructs

2 of binge eating

3

$4 \quad 2$. Brain network differences in binge eating

5

6 3. Bart Hartogsveld ${ }^{\mathrm{a} *}$, Conny W.E.M Quaedflieg ${ }^{\mathrm{b}}$, Peter van Ruitenbeek ${ }^{\mathrm{b}}, \&$ Tom Smeets $^{\mathrm{a}, \mathrm{c}}$

8 a Department of Clinical Psychological Science, Faculty of Psychology and Neuroscience,

9 Maastricht University, P.O. Box 616, 6200 MD, Maastricht, The Netherlands

b Department of Neuropsychology \& Psychopharmacology, Faculty of Psychology and Neuroscience, Maastricht University, P.O. Box 616, 6200 MD, Maastricht, The Netherlands

$c$ CoRPS - Center of Research on Psychological and Somatic disorders, Department of Medical and Clinical Psychology, Tilburg School of Social and Behavioral Sciences, Tilburg University, P.O. Box 90153, 5000 LE, Tilburg, The Netherlands

4. BH, CWEMQ, PVR, TS wrote the paper, BH, CWEMQ, PVR analyzed data and performed research

5. Correspondence should be addressed to Bart Hartogsveld, Department of Clinical Psychological Science, Faculty of Psychology and Neuroscience, Maastricht University, P.O. Box 616, 6200 MD, Maastricht, The Netherlands. Tel. +31 (0)43 38 82468, Fax +31 (0)43 38 84196, E-mail address: bart.hartogsveld@maastrichtuniversity.nl

6. Number of Figures: 5

7. Number of Tables: 2

8. Number of Multimedia: 0

9. Number of words for Abstract: 149

10. Number of words for Significance Statement: 119

11. Number of words for Introduction: 860

12. Number of words for Discussion: 934

13. Acknowledgements: N/A

14. Conflict of Interest: Authors report no conflict of interest

15. Funding sources: This work was supported by the Dutch Research Council (Nederlandse Organisatie voor Wetenschappelijk Onderzoek, NWO) to T.S. [grant number 452-14-003] and to C.Q. [grant number 446-15-003]. 
37 16. Due to the double-blind review process, we removed one sentence from Quality 38 Assessment, "(volumetric, functional-, and structural connectivity: BH and PvR; reward 39 sensitivity, cognitive control, and negative affect: BH and CWEMQ)". This was originally 40 part of the following section:

42 "Quality assessment was performed independently by two researchers (volumetric,

43 functional-, and structural connectivity: BH and PvR; reward sensitivity, cognitive control, 44 and negative affect: BH and CWEMQ). There were no major discrepancies in overall quality 45 rating between the assessors (poor, fair, good).”. 


\section{Abstract}

48 Bulimia nervosa $(\mathrm{BN})$ and binge eating disorder (BED) are characterized by episodes of eating large amounts of food whilst experiencing a loss of control. Recent studies suggest that the underlying causes of BN/BED consist of a complex system of environmental cues, atypical processing of food stimuli, altered behavioral responding, and structural/functional brain differences compared with healthy controls (HC). In this narrative review, we provide an integrative account of the brain networks associated with the three cognitive constructs most integral to BN and BED, namely increased reward sensitivity, decreased cognitive control, and altered negative affect and stress responding. We show altered activity in $\mathrm{BED} / \mathrm{BN}$ within several brain networks, specifically in the striatum, insula, prefrontal and orbitofrontal cortex, and cingulate gyrus. Numerous key nodes in these networks also differ in volume and connectivity compared with HC. We provide suggestions for how this integration may guide future research into these brain networks and cognitive constructs.

\section{Significance statement}

61 Binge eating disorder and bulimia nervosa are common eating disorders and remain a major problem due to the association with a variety of health risks. This review shows that three cognitive constructs that underlie these disorders, namely reward sensitivity, cognitive control, and negative affect, can be explained in terms of brain activity differences in key brain networks. These activity differences are interpreted in light of differences in brain volume and connectivity, observed in different studies. cortex, and cingulate gyrus, are interpreted by means of the current understanding of their function and mechanisms. Finally, suggestions for further research integrating brain function and structure in binge eating are made. 
71

72

73

74

75

76

77

\section{Introduction}

Despite widespread attention from the general public and the scientific community, bulimia nervosa $(\mathrm{BN})$ and binge eating disorder $(\mathrm{BED})$ remain a major societal problem, with an estimated prevalence of 2-3\% (Stice et al., 2013). Due to unhealthy eating behavior and a strong association with obesity, these disorders are associated with a number of diseases, such as type II diabetes, cancer, cardiovascular diseases, and higher mortality rates (Guh et al., 2009; Hudson et al., 2007; Kessler et al., 2013; Patel et al., 2018; Smink et al., 2012). Both BN and BED are characterized by binge eating episodes, which have to meet two requirements (American Psychiatric Association, 2013). Firstly, a certain amount of food has to be consumed within a 2-hour period that is definitely larger than what most individuals would eat in a similar time period under similar circumstances. Secondly, the person has to experience a feeling that they cannot stop eating or control what or how much they are eating during the binge eating episode. Both BED and BN diagnosis require a frequency of these episodes of once a week on average, lasting for at least 3 months. In addition, stress regarding binging is a criterion for the diagnosis of both BN and BED (American Psychiatric Association, 2013). The disorders are also associated with several changes in eating patterns, such as eating much more rapidly than normal. However, only $\mathrm{BN}$ is accompanied by inappropriate compensatory behaviors to prevent weight gain, such as fasting, laxative use, or excessive exercise (American Psychiatric Association, 2013).

Given the numerous health risks, research into the mechanics of BN and BED is essential to improve our understanding of these disorders. Recent studies suggest that the underlying causes consist of a complex system of environmental cues, altered processing of food stimuli and behavioral responding, and brain differences. In particular, the literature indicates that three major cognitive constructs play a large role in $\mathrm{BN}$ and $\mathrm{BED}$, namely reward sensitivity, cognitive control, and negative affect (for an overview see, for example, Appelhans, 2009; Vainik et al., 2019). Reward sensitivity includes alterations in cue reactivity and hypo-responsiveness to food consumption (in which craving toward food is heightened but food liking when consumed is reduced), and serves as a motivational basis for impulsive behavior and engaging in binge eating (Giel et al., 2017). Cognitive control is 
highly connected to instrumental behavior and goal-directed behavior in particular, and reduced cognitive control may form the basis of losing control over ones eating behavior (e.g. Kar et al., 2019; O’Doherty et al., 2017; Quaedflieg et al., 2019; Ridderinkhof et al., 2004; Voon et al., 2017). Negative affect, or increased sensitivity to negative emotions (Vainik et al., 2019), is shown to be important in the development of BN and BED (e.g. Allison et al., 2007; Grilo and Masheb, 2002; Rojo et al., 2006; Striegel-Moore et al., 2007) and the frequency of binge eating episodes (Haedt-Matt and Keel, 2012; Berner et al., 2017). Particularly, an increase in negative affect is shown to be strongly connected to and typically caused by stress (e.g. Wemm and Wulfert, 2017; Mendonça-de-Souza et al., 2007). Stress-induced changes in appetite related hormones and reward brain circuitry are an important factor in BN and BED (Wierenga et al., 2018; Gluck, 2009; for animal model see Hardaway et al., 2015). Specifically, in BN and BED several physical differences in the stress response can be observed, such as hypothalamic-pituitary-adrenal (HPA) axis hyperactivity, elevated cortisol awakening response, and blunted responses to acute stressors compared with HC (Culbert et al., 2016; Naishe et al., 2018; Wierenga et al., 2018). We will demonstrate that functional imaging studies show differences in BN/BED specifically in brain areas associated with reward sensitivity, cognitive control, and negative affect as cognitive constructs underlying the disorders and that these overlap with gray matter (GM) volume and structural and functional connectivity differences.

To our knowledge no review has integrated the findings of the three major cognitive constructs underlying $\mathrm{BN}$ and $\mathrm{BED}$ with structural and task-based neuroimaging studies in these disorders. The current narrative review is intended to supply an integrative account to identify key brain networks that are affected to aid further research. To do so, we will discuss 1) the differences between $\mathrm{BN} / \mathrm{BED}$ and $\mathrm{HC}$ in brain networks associated with the three aforementioned cognitive constructs, and 2) differences in brain organization in BN/BED, including differences in GM volume and connectivity. Specifically, we will first give an overview of prominent studies related to the three cognitive constructs in BN/BED (e.g. food tasting, instrumental learning tasks, acute stress exposure).

We will explore behavioral differences, their relation to physical measurements (e.g. cortisol response), and the connection to task-based brain activation studies. Subsequently, we will give an overview of differences in GM and white matter (WM) volume compared with HC, structural 
connectivity (diffusion weighted imaging studies) and functional connectivity (resting state studies). In the last section, we will integrate task-independent and task-dependent brain differences, discuss the potential function of these areas, and give suggestions for future research. As will be shown in this review, neuroimaging studies can help in understanding the neurobiological underpinnings of $\mathrm{BN}$ and BED, and so may aid in early detection or serve as a potential biomarker (Val-Laillet et al., 2015).

\section{Cognitive constructs associated with binging behavior}

Binge eating disorders are, as previously mentioned, associated with differences in three major cognitive constructs (e.g. Vainik et al., 2019): reward sensitivity (2.1), cognitive control (2.2), and negative affect (2.3.1 and 2.3.2). In the sections below these three cognitive constructs are discussed, first in the context of binging behavior and subsequently in a neural context.

\subsection{Reward sensitivity}

\subsubsection{Concepts and behavioral studies}

Reward sensitivity is the propensity to seek out rewards and encompasses both the anticipation of the reward and the actual affective experience during receiving the reward (Loxton and Tipman, 2017; Vainik et al., 2019). High reward-sensitive individuals are thought to more often seek out high palatable foods (e.g. Nansel et al., 2016), and thus reward sensitivity may have similar behavioral effects in BN/BED. The two aspects of reward anticipation and the affective experience are represented in the distinction between 'wanting' (i.e. anticipation) and 'liking' (i.e. during receiving the reward; Robinson and Berridge, 1993). Berridge (1996) proposed that this distinction could affect the processing of food rewards, represented in two separate brain networks, although others have argued that this distinction cannot be easily made (Rogers, 2017; Rogers and Hardman, 2015). BN/BED could be explained by an increase in initial reward anticipation (i.e. wanting or craving), and repeated ingestion of that food could diminish its rewarding effects (i.e. liking) (Berridge, 1996). 
Changes in wanting and liking operates through Pavlovian conditioning, where food-related environmental cues (e.g. seeing a bag of crisps), elicit a learned response (i.e. wanting/anticipation). This response seems to be stronger in BN and BED compared with HC (Meule et al., 2018). Several aspects of the learning process can be affected in BN/BED, such as enhanced learning of stimuliresponse associations, responses generalizing more easily to novel food stimuli, or an increased difficulty to extinguish craving (wanting; for an overview see, for example, van den Akker et al., 2018).

Not only Pavlovian conditioning but also instrumental conditioning is likely to play a large role in $\mathrm{BN} / \mathrm{BED}$, operating mainly through behavioral responses (e.g. binge eating). In instrumental conditioning, responses to stimuli that lead to positive outcomes are reinforced, thereby increasing the probability of that response being repeated. In the literature this association between a stimulus, response (e.g. pressing a button), and outcome (e.g. a food reward) is often abbreviated to S-R-O. If this sequence is repeated several times, the outcome $(\mathrm{O})$ is thought to lose its functional role and the stimulus will thus automatically come to elicit the response (S-R). In the example, a food reward is no longer necessary to elicit the response $(\mathrm{R})$, the stimulus $(\mathrm{S})$ is sufficient to generate a response, leading to a S-R association (for a complete overview, see O'Doherty et al., 2017). These association-based behaviors are also known as goal-directed (S-R-O) and habitual behavior (S-R), respectively, and are related to differences in cognitive control in BN/BED, the second important cognitive construct (Vainik et al., 2019). Patients with BED appear to rely more often on habitual behavior compared with HC (Voon et al., 2015). Thus, the insensitivity to reward value (i.e. outcome) in habitual behavior may explain the behavioral hypo-responsiveness for the reward value experienced during binge eating episodes, even though large quantities of food are consumed (Berner et al., 2017). Most studies that investigated reward sensitivity experimentally suggest higher reward sensitivity on a subjective level and in food-related tasks (Loxton and Tipman, 2017; Schag et al., 2013; for a systemic review see Harrison et al., 2010). However, this effect does not correspond well with studies using non-foodrelated tasks where often no differences between BN/BED and HC are found (Appelhans, 2009; Balodis et al., 2019; Giel et al., 2017; Hutson et al., 2018; Kessler et al., 2016; Rogers, 2017; Simon et al., 2016; Wierenga et al., 2018). From the behavioral results it seems clear that reward sensitivity is 
not consistently higher in BN/BED across all reward types and that it might be limited to food rewards alone (Appelhans, 2009)

\subsubsection{Functional imaging studies}

Using a variety of reward sensitivity tasks, several differences in brain activation are observed between BN and BED and HC (see Table 1 and Figure 1). Brain areas where differences in activation were found were the anterior cingulate cortex (ACC) and posterior cingulate cortex (PCC), the ventral striatum, and the insula, all of which are involved in reward sensitivity (Oberndorfer et al., 2013; Schienle et al., 2009; Simon et al., 2016; Weygandt et al., 2012; Balodis et al., 2013a; Balodis et al., 2014). The ACC has been associated with reward learning and outcome prediction (Alexander \& Brown, 2019), and the PCC with storing and retrieving reward values (Rolls, 2019). The ventral striatum is thought to compare these predicted reward values with the outcome (Wang et al., 2016). Finally, the insula is typically implicated in the actual somatosensory experiences such as taste and touch (Rolls, 2016).

In more detail, in the insula and $\mathrm{ACC}$, food cue exposure increases brain activation in $\mathrm{BN}$, BED, and HC (Schienle et al., 2009; Wang et al., 2011). Yet in BED and particularly in BN, this increase appears larger compared with HC (Oberndorfer et al., 2013; Schienle et al., 2009; Weygandt et al., 2012). In contrast, activation of the PCC in BN and BED was decreased in an anticipatory task compared with HC, while it was increased in a consummatory task (Simon et al., 2016). Using a monetary incentive delay task, obese BED showed lower activity in ventral striatum during anticipation of reward, and in the prefrontal cortex (PFC) and insula in the outcome phase compared with obese non-BED and HC (Balodis et al., 2013a). The regional specific responses again point to differences in anticipating and receiving rewards. While the role of the cingulate cortex and insula are not domain-specific, the ventral striatum has a specific role in the reward network.

All in all, research shows clear differences in food-specific reward sensitivity in BN and BED.

This is supported by the results of a study demonstrating that subjects could be successfully identified as $\mathrm{BED}, \mathrm{BN}, \mathrm{HC}$, and obese with an accuracy of $59-90 \%$ based on activity patterns of the insula, ventral striatum, ACC, and the orbitofrontal cortex (OFC) (Weygandt et al., 2012). In the future this 
could add further specificity to diagnosis of BN or BED. This seems to be partially associated with post-treatment outcome. BED patients who continued to report binge eating after treatment, were shown to have lower activity of ventral striatum and inferior frontal gyrus (IFG) during anticipation phase, and lower medial PFC activation during the outcome phase versus recovered patients (Balodis et al., 2014).

Insert Figure 1 around here

\subsection{Cognitive control}

\subsubsection{Concepts and behavioral studies}

Cognitive control is multi-dimensional in that it covers various aspects of cognitions and behavior, such as planning, attention/distraction, motoric impulsivity, non-planning impulsivity or lack of concern for the future (Fineberg et. al., 2014; Fischer et al., 2003; Kessler et al., 2013; Rosval, 2006). Not all of these cognitive components are unambiguously affected in BN/BED compared with HC. The most notable differences are found in impulsivity during food-related tasks (Fischer et al., 2003; Waxman, 2009; Wu et al., 2014). However, some authors (e.g. Neveu et al., 2018) have emphasized that BN/BED patients cannot be fully identified by their loss of control. Because binges can be planned in advance, BN subjects are able to postpone a binge if conditions such as food availability are not met, and subjects often choose food that is often consumed outside binges. Thus, in $\mathrm{BN} / \mathrm{BED}$ loss of cognitive control is not a domain-general failure, but seems specific to the binging episodes (Neveu et al., 2018). However, in BED subjects planned binges are often longer and larger than initially intended by the subject (Curtis and Davis, 2014). This indicates that a deficit in cognitive control, resulting in a behavioral loss of control, was found to be primarily present during the binge itself (also see Adams et al., 2019). Crucial to both BN and BED is the specific, food-related loss of control during the binge eating episode itself, as illustrated by an increase in intake, even if the episode is planned beforehand (Curtis and Davis, 2014). This loss of control could be explained through a switch from goal-directed to habitual behavior, where direct S-R associations are able to drive 
behavior (Watson et al., 2017; Cartoni et al., 2016; Watson et al., 2014). Of course, it is not necessary that this loss of control always leads to an increase in intake, as seen in subjective binge eating (where there is only an experience of loss of control).

Since cognitive control is multi-dimensional it is measured by a variety of tasks and selfreported questionnaires (e.g. stop-signal task, Stroop, Go/noGo, memory paradigms, Simon tasks, delay discounting; see for example Bartholdy et al., 2016; Lavagnino et al., 2016). Using self-reported questionnaires, BED patients show increased impulsivity, elevated compulsivity, decreased selfcontrol, impaired set-shifting reflective of compulsive behavior, motoric impulsivity, attention impulsivity, and a higher tendency to seek out novel experiences and stimuli (Claes et al., 2002; Danner et al., 2012; Fahy and Eisler, 1993; Favaro et al., 2005; Galanti et al., 2007; Hege et al., 2015; Kessler et al., 2016; Rosval, 2006). Self-reported cognitive control was positively associated with task performance or amount of food eaten during the experiment (Galanti et al., 2007; Hege et al., 2015; Kessler et al., 2016). Other studies, including two meta-analyses, confirm the important role of selfreported cognitive control, but also report that not all components are consistently found (Fischer et al., 2003; Waxman, 2009; Wu et al., 2014). In particular, while planning does not seem to be impaired, acting rashly, general impulsivity, and impairments in set-shifting do seem present in both BED and $\mathrm{BN}$ in these studies.

These diversely affected subcomponents of cognitive control further demonstrate that it is not a solitary cognitive construct. Evidence of cognitive control impairments in BN and BED obtained from experimental paradigms is equally inconsistent. Several systematic reviews and meta-analyses (e.g. Kittel et al., 2015; Lavagnino et al., 2016) demonstrate that differences in inhibitory responding in $\mathrm{BN}$ and BED are often task-dependent. Only around half of the studies included in these metaanalyses showed impaired performance on relevant tasks by patients compared with HC matched on BMI (body mass index) (e.g. stop-signal task, Stroop task; Bartholdy et al., 2016; Kittel et al., 2015; Lavagnino et al., 2016). Results of the stop-signal task (SST) indicate that the observed impairments are due to reduced inhibitory control and not to motor response deficits. Overall SST scores correlate with eating pathology in BED but not in BN. Two other studies showed that the impairment in inhibitory responding (using a Simon and go/no-go task) might be related to symptoms of BN (Bruce 
et al., 2003; Marsh et al., 2009). Symptom severity (e.g. number of binge eating and vomiting episodes) was inversely correlated with task accuracy and activation of the frontostriatal network (Marsh et al., 2009). A systematic review showed that inhibition and delay gratification deficits might actually be limited to food related tasks (Kittel et al., 2015). Similarly, Svaldi and colleagues (2014) found that inhibition was more impaired for food stimuli (however, see Manasse et al., 2016).

\subsubsection{Functional imaging studies}

Compared to the inconsistent findings in self-reported and behavioral tasks assessing cognitive control, imaging studies do show a consistent reduction in task-related brain activity in the associated PFC network. As proposed by the schematic control theory (Badre \& Nee, 2018), the frontal areas can be divided into three subnetworks. This network consists of anterior PFC areas involved in schematic control (organizing features and relations), rostral mid-lateral PFC areas involved in contextual control (implementing behavioral strategies), and caudal frontal areas involved in sensory-motor control (executing behavior and sensory feedback) (Badre \& Nee, 2018). The reduced task-related brain activity has been found in all three networks for both $\mathrm{BN}$ and BED compared with $\mathrm{HC}$, using a variety of paradigms (tasks are for example the SST, Simon, and Stroop; see Table 1 and Figure 2). A metaanalysis (Lavagnino et al., 2016) reported two studies investigating BED subjects. In one, obese BED subjects showed lower activation of the dorsolateral prefrontal cortex (dlPFC) and IFG compared with obese non-BED in a food-specific Go/No-go task (Hege et al., 2015). Obese BED subjects also scored higher on a self-reported impulsiveness measure, and in both obese BED and obese non-BED this score was negatively correlated with response inhibition and activity in the prefrontal networks. BED subjects showed reduced activity in OFC, IFG, superior temporal gyrus, ventromedial prefrontal cortex (vmPFC), and insula compared with HC and obese subjects during a Stroop task (Balodis et al., 2013b), whilst no differences were found in task performance. In addition, BED showed the highest self-reported dietary restraint scores, and this was negatively correlated with activation in vmPFC, OFC, IFG, and insula. In obese subjects, however, these scores were positively correlated with IFG and insula activation in obese subjects (Balodis et al., 2013b). This shows that there is a strong relation 
between measures of cognitive control and activation patterns during a task involving cognitive control. During the Simon task, BN patients showed decreased activation compared with HC in the bilateral IFG, lenticular and caudate nuclei, and ACC when responding correctly to incongruent stimuli (Marsh et al., 2011). In short, these studies show an overall reduction in activity in cognitive control networks, particularly several frontal areas.

As mentioned before, instrumental conditioning is highly related to cognitive control. Indeed, some authors have proposed that instrumental conditioning is implicated in many of the tasks used to measure cognitive control (e.g., Liefooghe, \& de Houwer, 2016). It is indeed possible that a shift from goal-directed to habitual control likely precedes or occurs during a binge eating episode. One fMRI study directly assessed this possibility in obese BED and obese non-BED (Voon et al., 2015). Using a two-step sequential learning task, Voon et al. (2015) showed that obese BED had a lower engagement of a model-based strategy compared with obese non-BED and lean HC. This demonstrates a shift away from goal-directed toward habitual responses. In BED, higher scores on a binge eating scale were negatively associated with the amount of goal-directed responding during the task. In other words, the more severe BED was, the more likely the person was to respond in a habitual fashion. A subsample of the BED subjects in the Voon et al. (2015) study showed reduced volume in the left ventral striatum, left lateral OFC, bilateral medial OFC, and bilateral caudate compared with non-BED obese. When adding the goal-directed/habitual score as a covariate, Voon et al. (2015) found that the differences in medial OFC, caudate, and ventral striatum disappeared, indicating that the structural differences likely drive the differences in habitual and goal-directed responding between these groups. This is likely to be associated with a reduction in activation of networks associated with goal-directed responding, rather than a simple increased activation in networks associated with habitual responding. Overall then, habit formation in BED could very well be mediated by the medial OFC-caudate-striatal network. These findings are consistent with those in BN. A recent study by Neveu and colleagues (2018) did demonstrate the involvement of vmPFC and dlPFC in a cognitive conflict task in BN, where subjects had to choose between healthy and tasty food. The authors proposed that the results of this study demonstrated increased goal-directed responding in BN. However, it is important to note 
that vmPFC activity can also be illustrative of value estimation (Wunderlich et al., 2012), rather than goal-directed responding.

Taken together, whilst differences on a behavioral level are limited and inconsistent, information processing in the brain is consistently different in subjects with $\mathrm{BN}$ or BED. Both seem to be characterized by an overall hypoactivity in frontal regions (OFC, vmPFC, dlPFC, IFG), ventral striatum, and insula in a variety of tasks measuring cognitive control. Additionally, decreased activation in the caudate nucleus in the aforementioned Simon task (Marsh et al., 2011) corresponds well with the interpretation that behavior could be biased toward habitual and away from goal-directed control (Voon et al., 2015). This is particularly likely since the caudate nucleus is hypothesized to be part of the goal-directed network together with frontal areas such as OFC, and the insula (Watson et al., 2018). These fMRI paradigms indicate that whilst there may not always be a behavioral difference between $\mathrm{BN}, \mathrm{BED}$, obese, and $\mathrm{HC}$, differences in activation are often present. This illustrates a difference in processing that together with increased reward sensitivity, plays a large role in eating behavior in $\mathrm{BN}$ and BED.

\subsubsection{Concepts and behavioral studies}

Insert figure 2 around here

Negative affect refers to increased sensitivity to negative stimuli and increased likelihood to experience negative emotions (Vainik et al., 2019) and is also highly related to the balance between habitual and goal-directed behavior. Heightened negative affect is typically the result of stress (e.g. Wemm and Wulfert, 2017; Mendonça-de-Souza et al., 2007), alters this balance in instrumental learning tasks, rendering behavior more habitual (Schwabe et al., 2012; Schwabe and Wolf, 2010, 2009; Wirz et al., 2018; Smeets et al., 2019; Hartogsveld et al., 2020; Quaedflieg et al., 2019). Negative affect and stress are also closely related to the concept of 'comfort eating', the idea that some people have an increased tendency to consume food when stressed, in order to relieve stress and improve affect (Gibson, 2012). Whilst support is inconsistent, several studies demonstrate that stressed 
(HC) subjects show a clear preference for food high in sugar and fat (but see Bongers and Jansen, 2016). Some authors have therefore suggested that bulimic episodes could be a form of learned behavior through negative reinforcement (Berner et al., 2017; Wierenga et al., 2018; Racine and Martin, 2017). One proposed model to explain this further is the acquired preparedness model of binge eating (Racine and Martin, 2017). This model poses that certain high-risk personality traits, such as impulsivity, can alter learning through reward value and make it more likely that food is seen as a positive stimulus that can temporarily alleviate negative affect. Indeed, it has been shown that impulsivity under stress is associated with a greater risk for dysregulated eating in people with $\mathrm{BN}$ symptoms (Fischer et al., 2018). This association is contingent on the belief that food can alleviate negative affect, body dissatisfaction, and dietary restraint (Racine and Martin, 2017). It also might be connected to overall self-reported difficulties in emotion regulation in BN/BED compared with HC (Brockmeyer et al., 2014; Troop et al., 1998). Lastly, sensitivity to negative effect has also been associated with a higher frequency of binge eating episodes, greater severity of the disorder (Carrard et al., 2012), and playing a role in the development of BN/BED (Razzoli et al., 2016). For example, a meta-analysis revealed that negative affect increased before binge eating episodes compared with diurnal affect and affect before normal meals (Haedt-Matt and Keel, 2012). After this increase, negative affect decreases following the binge eating episode (Berner et al., 2017; Crosby et al., 2009; Johnson and Larson, 1982; Kaye et al., 1986).

Stress may also be considered a form of negative affect. In support of the role of stress in BN/BED are the multiple alterations in stress hormone levels that are observed in BN/BED. Stress exposure causes a rapid release of catecholamines (e.g. adrenalin and noradrenalin) and activates the slower-acting HPA axis that results in the release of glucocorticoids (e.g. cortisol) in the blood. Collectively, these fast and slow stress hormones alter the responding of numerous circuits in the brain and other aspects of homeostasis (Ulrich-Lai and Herman, 2009). BN and BED are associated with differences in these hormones and circuits, namely long term HPA axis hyperactivity, elevated cortisol awakening response, ultimately resulting in a blunted response to acute stressors (Culbert et al., 2016; Naish et al., 2018; Wierenga et al., 2018). 
In a lab setting, several studies have experimentally investigated acute stress-induced changes in eating behavior in BED, since acute stress is relatively easily and reliably inducible (Klatzkin et al., 2018; Laessle and Schulz, 2009; Lyu and Jackson, 2016; Schulz and Laessle, 2012). Acute stress mostly seems to affect eating rate, with a faster initial eating rate and smaller decrease in eating rate over time in BED (Laessle and Schulz, 2009; Schulz and Laessle, 2012). Effects of acute stress on overall food intake in BED are inconsistent, with some studies showing increased overall intake compared with non-BED after acute stress (e.g. Lyu and Jackson, 2016) but with most studies finding no differences (Klatzkin et al., 2018; Laessle and Schulz, 2009; Schulz and Laessle, 2012). A possible explanation for the inconsistent results in food intake might be the lab setting and the stress tasks used. Whilst it has not been investigated in BN/BED, overweight subjects eat less in social settings compared with being alone, this could be more pronounced in BN/BED because of negative emotions such as shame (Krantz, 1979; Salvy et al., 2007). The stress tasks also differed between studies. Physical and psychological stressors activate the various stress systems to different degrees (McRae et al., 2006). A physical stressor results in rapid activation of the autonomic nervous system via reflexive mechanisms in brainstem and hypothalamus, while a psychological stressor requires processing in the PFC and in turn activates the slower HPA-axis via connections with limbic structures. Related to this, the timing of the food consumption after stress was also different between studies with some measuring before and other during the cortisol peak (i.e. 20-40 minutes after stress onset; Dickerson \& Kennedy, 2004).

Many studies have also investigated heart-rate variability (HRV), blood pressure, salivary alpha-amylase, and cortisol responses to acute stress (Carroll et al., 2017; Culbert et al., 2016; Naish et al., 2018; Peschel et al., 2016; Wierenga et al., 2018). HRV responses in BN/BED are not affected by acute stress and seem to not display the decrease during acute stress and increase post-stress normally found in HC, even though baseline levels are higher in BN/BED (Het et al., 2015a; Hilbert et al., 2011; Messerli-Bürgy et al., 2010; Murialdo et al., 2007). Blood pressure increase in response to acute stress was shown to be blunted in BN subjects compared to HC (Koo-Loeb et al., 1998; Ginty et al., 2012). Similarly, the majority of studies report a blunted cortisol response in BN and BED following acute stress (Carnell et al., 2018; Culbert et al., 2016; Ginty et al., 2012; Het et al., 2015b; Koo-Loeb 
et al., 1998; Naish et al., 2018; Rosenberg et al., 2013; Vaz-Leal et al., 2018; Wierenga et al., 2018), but not all do (Coutinho et al., 2007; Vannucci et al., 2015). Interestingly, the blunted cortisol reactivity was positively associated with binge-eating severity in BED (Coutinho et al., 2007) and an increase in desire to eat after acute stress exposure (Rosenberg et al., 2013). Some have hypothesized that the blunted cortisol reactivity could be caused by long-term HPA axis activation (Culbert et al., 2016; Het et al., 2015b) due to high levels of chronic stress. Baseline HRV differences largely point to increased parasympathetic activity (Peschel et al., 2016), suggesting a blunted influence of the HPA axis. In addition, this idea is supported by the findings of increased baseline cortisol levels in BN (e.g. Monteleone et al., 2017; see Culbert et al., 2016 for an overview). Though, baseline cortisol results are rather inconclusive, with only some suggesting a decrease in baseline cortisol levels and cortisol awakening response (e.g. Rosenberg et al., 2013; Vaz-Leal et al., 2018).

To summarize, most studies suggest an overall blunted physiological effect of stress in BN and BED, both after acute stress induction and in resting baseline measurements. This largely seems to be related to higher chronic stress levels and negative affect in these disorders. Even though lab studies do not show a behavioral link between food intake and acute stress, they are related physiologically. Acute stress elicits an increase in salivary ghrelin, a peptide that promotes food intake in BN compared with non-BN (Gluck et al., 2014; Monteleone et al., 2012; Monteleone and Maj, 2013). Other studies confirm the importance of hormonal responses in eating behavior, including insulin, leptin, and extrahypothalamic corticotrophin releasing factor (CRF; for an overview, see Sinha, 2018; Schepers and Markus, 2015). Similar to the effects of acute stress, it is proposed that in healthy individuals CRF suppresses appetite during and directly after a stressful event. Subsequently, glucocorticoids stimulate feelings of hunger to offset the expanded energy. Chronic stress on the other hand appears to be able to expose the individual to long-term heightened levels of glucocorticoids, thereby increasing ghrelin levels and stimulating eating behavior of high caloric foods through reward sensitivity (Sominsky and Spencer, 2014; Sinha, 2018; Schepers and Markus, 2015). These effects on reward sensitivity by metabolic state can also potentially drive individuals to make more risky (variable outcome) choices when hungry (see for example Symmonds et al., 2010). 


\subsubsection{Functional imaging studies}

Acute stress and the processing of food stimuli appear to be associated, as reward sensitivity is shown to be altered in BN and BED after acute stress exposure (see Table 1 and Figure 3; Collins et al., 2017; Fischer et al., 2017; Lyu and Jackson, 2016; Wonderlich et al., 2018). Relevant brain areas seem to largely overlap with the network involved in reward sensitivity when not under acute stress. As mentioned previously, the cingulate cortex and insula are involved in processing reward values (e.g. Alexander \& Brown, 2019; Rolls, 2019) and have been observed to be affected by acute stress (van Ruitenbeek et al., 2021). Other areas like the amygdala and hippocampus are commonly known to regulate stress. Specifically, the hippocampus is associated with inhibition of the HPA-axis (UlrichLai and Herman, 2009) and the amygdala is well-known to respond during stress (e.g., Marle et al., 2009; for an overview see Zhang et al., 2018). In addition, these areas project to several relevant areas for reward sensitivity (Abivardi and Bach, 2017; Salzman and Fusi, 2010). In support of the overlap, they have been implicated in reward sensitivity tasks without acute stress manipulation (e.g., Filbey et al., 2012).

When comparing pre- with post-stress reward processing in $\mathrm{BN}$ compared with $\mathrm{HC}$, a decrease in activation is predominantly reported in the vmPFC, ACC, precuneus, and amygdala in BN patients (Collins et al., 2017; Fischer et al., 2017; Smith et al., 2018). Furthermore, the decrease in activity preto post-stress in the bilateral precuneus, ACC, and dlPFC during a reward sensitivity task was associated with higher subjective stress prior to binge eating episodes in daily life (Fisher et al., 2017). On the other hand, amygdala and the vmPFC activation did not moderate subjective stress levels prior to binge eating episodes (Fischer et al., 2017). However, another study showed that activation in the bilateral vmPFC and right amygdala moderated negative affect pre- and post-binge episode in BN (Wonderlich et al., 2018). Larger decreases in activity in these areas were associated with larger increases in negative affect before a binge eating episode. Conversely, positive affect pre- and postbinge eating episode was moderated by activation in the right ACC and bilateral vmPFC, with larger decreases in activity also being associated with larger increases in positive affect after a binge eating episode. Combined, these results suggest that the vmPFC, ACC, amygdala, precuneus, and dlPFC play 
451 a role in regulating negative and positive affect before and after a binge eating episode. Indeed, the

452 role of the vmPFC in successfully regulating negative affect has also been demonstrated in healthy

453 samples; with larger decreases in activation following acute stress being reflective of a reduced coping

454 and a higher frequency of maladaptive coping behaviors, including emotional eating (Sinha et al.,

455 2016). Two independent samples of $B N$ showed reduced activity in the precuneus, paracingulate

456 gyrus, and anterior vermis of the cerebellum, whilst healthy controls showed an increased activity

457 from pre- to post-stress on reward sensitivity (Collins et al., 2017). Furthermore, decreased activation

458 in the hippocampus in BED compared with non-BED was found for showing high-caloric and low-

459 caloric foods compared with neutral images, and the decrease was largest in response to high-caloric

460 food images (Lyu and Jackson, 2016). Interestingly, reduced hippocampal activation predicted larger

461 amounts of chocolate intake after the fMRI scans in the entire sample (Lyu and Jackson, 2016).

Taken together, these results show that several networks are affected pre- to post-stress in

463

464

465

466

467

$\mathrm{BN} / \mathrm{BED}$ during reward processing. In $\mathrm{BN}$, there is support for a decrease in activation post-stress in the vmPFC, amygdala, precuneus, and ACC. Decrease in these areas are also associated with increased negative affect pre-stress, and positive affect post-stress. So far, only one study has investigated reward sensitivity after acute stress exposure in BED (Lyu and Jackson, 2016), suggesting that the hippocampus may play an inhibitory role in reward sensitivity after acute stress. Overall then, the results from these studies suggest that the vmPFC and ACC are likely to be involved in regulating negative affect, in addition to their role in reward sensitivity and cognitive control. Crucially, the ventral striatum and OFC, which are involved in processing of reward values, do not seem to be affected in reward processing post-stress in BED/BD. A blunted stress response is confirmed by a number of different measures, including salivary cortisol, blood pressure and brain activity. The blunted stress response might disproportionally be associated with an increased drive for binging and is likely reflective of prolonged activation of the HPA axis and autonomic nervous system. Several studies (e.g. Fischer et al., 2018; Carrard et al., 2012; Haedt-Matt and Keel, 2012) suggest that the link between acute stress, negative affect, and eating behavior outside the lab is strong, even though lab studies could not find differences in food intake. 


\section{Brain differences in BN/BED}

\subsection{Volumetric differences in Gray Matter (GM)}

Neuroscientific studies investigating volumetric GM differences between BN subjects and HC reveal specific volume reductions and increases in cortical and subcortical structures (please see Figure 4 and Table 2 for an overview), which reflect those part of the networks associated with the three cognitive constructs discussed in section 2. In both BN and BED, several structures associated with reward processing were shown to be affected, such as the ventral and dorsal striatum (Amianto et al., 2013a; Coutinho et al., 2015; Frank et al., 2013; Voon et al., 2015; Schäfer et al., 2010). Both the ventral and dorsal striatum comprise multiple substructures that are associated with processing different kinds of information. Therefore, identifying which structures are affected is important to determine potential functional roles. The ventral striatum is comprised of the olfactory tubercle and nucleus accumbens, the dorsal striatum is comprised of the putamen and caudate nucleus (Meredith et al., 2008). For the dorsal striatum, GM volume in the bilateral caudate was shown to be reduced in BN compared with HC, with a larger reduction in the right hemisphere (Amianto et al., 2013a; Coutinho et al., 2015) and particularly in the dorsal caudate nucleus (Frank et al., 2013). Differences in GM of the putamen seem even more lateralized, with BN showing increased volume in the left putamen compared with HC (Amianto et al., 2013a) but reduced volume in the right dorsal putamen (Frank et al, 2013). Slightly different patterns are observed in BED (Voon et al., 2015; Schäfer et al., 2010), but the number of studies is limited. A reduction in GM volume was only observed in the bilateral caudate nucleus, no differences between BED and HC were found in putamen volume (Coutinho et al., 2015; Frank et al., 2013; Voon et al, 2015; Schäfer et al., 2010). A study directly comparing BED, BN, and HC subjects showed that BN subjects had greater GM volume in the dorsal striatum than BED 
subjects, suggesting that it might be more affected in BN (Schäfer et al., 2010). For the ventral striatum, specifically for the nucleus accumbens, differences in volume seem to be relatively inconsistent. Some studies indicate an increase in accumbal volume in BN compared with HC and BED (Schäfer et al., 2010; but see Coutinho et al., 2015), while one study indicated that GM volume was reduced in BED in the bilateral nucleus accumbens (Voon et al., 2015).

Differences in volume of cortical areas have also been reported (e.g. Frank et al., 2013; Berner et al., 2019; Wagner et al., 2006; Wallace et al., 2020), although findings are not always consistent with each other (e.g. Amianto et al., 2013a; Marsh et al., 2015). One of these areas is the insula, which is associated with a large number of functions (e.g. perception, self-reflection, cognitive functioning, emotion, homeostasis) and is shown to be involved in a wide variety of tasks (e.g. Uddin et al., 2017). Insula GM volume seems particularly affected in BN, with studies predominantly showing an increase in GM volume compared with HC (Amianto et al., 2013a; Frank et al., 2013). These differences seem to persist to some extent after recovery, with recovered BN subjects showing an increase in volume when age was controlled for (Wagner et al., 2006). However, larger insula volume might be limited to patients only, as a large subclinical group with limited BN symptoms showed a negative association between BN subscale scores (Eating Disorder Inventory, EDI-3) and GM thickness of the bilateral insula and the left inferior parietal cortex (Wallace et al., 2020). Indeed, parts of the parietal cortex are also affected in $\mathrm{BN}$ with most consistent findings in the inferior parietal cortex. Reduction in volume is observed of the right inferior parietal lobule (Marsh et al., 2015), but also in the right superior parietal cortex (Berner et al., 2018; Marsh et al., 2015), and both an increase and reduction in volume in the precuneus (Amianto et al., 2013a; Marsh et al., 2015). In addition, BN symptom severity (Eating Disorder Examination Questionnaire, EDE-Q) was shown to be negatively associated with cortical thickness in parts of the inferior parietal cortex and temporal cortex (Westwater et al., 2018). The ACC seems uniquely increased in GM volume in BED compared with HC (Schäfer et al., 2010), although the PCC was found to be reduced in GM volume in BN (Berner et al., 2019; Marsh et al., 2015).

Frontal areas, and in particular the OFC, are associated with reward processing and show GM differences between BN and HC, and BED and HC. Several studies show an increase in GM volume in BN compared with HC, in particular in the bilateral medial OFC (Frank et al., 2013; Schäfer et al., 
2010; Cyr et al., 2017). In contrast, OFC GM thickness was shown to be negatively associated with bulimia subscale scores (EDI-3) and BN symptoms (EDE-Q) in subclinical populations (Westwater et al., 2018; Wallace et al., 2020), and the number of vomiting episodes in BN subjects was negatively associated with lateral OFC GM volume (Cyr et al., 2017). Some studies showed that several other parts of the prefrontal cortex were also affected, such as the inferior frontal gyrus (Marsh et al., 2015; Cyr et al., 2017). Likewise, BN symptoms (EDE-Q) were found to be negatively associated with cortical thickness in caudal and rostral parts of the middle frontal gyrus and the superior frontal gyrus (Westwater et al., 2018). In addition, BED patients also showed reduced left lateral OFC volume compared with HC (Schäfer et al., 2010; Voon et al., 2015). Results concerning medial OFC volume are however inconsistent, with one study finding an increase in volume, and another finding a reduction in volume (Voon et al., 2015, Schäfer et al., 2010).

To summarize, GM volumetric differences between BED and $\mathrm{HC}$ and especially between BN and $\mathrm{HC}$ are consistently found in the OFC, striatum, and insula (see Figure 4). These are associated with a number of functions that are associated with BN and BED pathology (Uddin et al., 2017; Yan et al., 2016; Setogawa et al., 2019; Stalnaker et al., 2018). Specifically, these areas show considerable overlap with those presented in the previous section; areas associated with reward sensitivity, cognitive control, and negative affect (see section 2). We will intergrate these findings in section 4. Interestingly, some of the discussed studies (e.g., Frank et al., 2013; Marsh et al., 2015) indicate that GM volumetric differences in a number of cortical areas are related to the underlying WM connectivity, particularly in the parietal cortex. In further support, Westwater et al. (2018) observed that while BN symptoms were negatively associated with cortical thickness in a number of areas (e.g. OFC, frontal gyrus, superior parietal cortex), the areas also showed an increase in estimation of WM connectivity (Westwater et al., 2018). In general, brain areas and their connections are organized into networks, and this connectivity plays a crucial role in information processing in the brain. Volumetric differences in the WM that connects these areas likely affect the functioning of these connections. Subsequently, connectivity studies will be informative to determine whether these are also affected in $\mathrm{BN}$ and $\mathrm{BED}$, and what role they might play in these pathologies. 
562 563

564

565

566

567

568

569

570

571

572

573

574

575

576

577

578

579

580

581

582

\subsection{Structural connectivity}

Brain regions are physically connected via white matter tracts, typically measured using diffusion weighted imaging (e.g. Fields, 2008). Differences in this structural connectivity between BN and $\mathrm{HC}$ reflect the GM volumetric differences, as the connectivity between these areas is particularly affected (see Table 2; i.e. connections between parts of the ventral and dorsal striatum, insula, (pre)frontal cortex, amygdala). For example, compared with $\mathrm{HC}$, BN patients showed reduced connectivity in the bilateral corona radiata extending in the posterior and anterior limb of the internal capsule (Mettler et al., 2013; He et al., 2016), which lies between the caudate nucleus and putamen. Connections of the ventral striatum with both cortical and subcortical areas are also affected. For example, connectivity between the ventral striatum and the insula and the frontal cortex (inferior and medial OFC) was shown to be increased in BN compared with HC (Frank et al., 2016; Wang et al., 2019), while connectivity between the ventral striatum and the right basolateral amygdala was reduced (Frank et al., 2016). Network analysis in BN compared with HC shows that mesocorticolimbic pathways and other subcortical connections in the right hemisphere might be negatively affected in global efficiency (Wang et al., 2019), a measure associated with parallel information processing (Bullmore \& Sporns, 2012). Pathways in the left hemisphere seem largely unaffected or even increased (Wang et al., 2019). This fits with the volumetric differences discussed in section 3.1, which show reductions in volume in the right hemisphere but some increases in the left hemisphere. Connectivity of the insula also seems affected in BN. Overall the left insula shows increased connectivity (Wang et al., 2019), corresponding with the increase in volume. However, depending on the projection, some white matter tracts are increased in connectivity, and others decreased.

Particularly, white matter tracts between the anterior insula and cortical areas show increased connectivity, whilst decreased connectivity is observed between the anterior insula and subcortical areas (Frank et al., 2016). Specifically, connectivity was increased between the bilateral anterior insula and the medial PFC and the middle OFC, but was reduced between the right anterior insula and the basolateral amygdala, and the left anterior insula to the central nucleus of the amygdala and the 
inferior OFC (Frank et al., 2016). Some other areas show differences in connectivity as well, such as reduced connectivity from the left ACC, right precuneus, hypothalamus, but increased connectivity from the temporal cortex, hippocampus, and thalamus (Wang et al., 2019; Frank et al., 2016). One exception is the study by Canna et al. (2017) that found no differences in structural connectivity between $\mathrm{BN}$ and $\mathrm{HC}$.

In long-range white matter association fiber tracts that connect the frontal lobe with other lobes and subcortical areas, a reduction in connectivity was found in BN compared with HC (Mettler et al., 2013; He et al., 2016). Namely, connectivity differences were observed in the superior longitudinal fasciculus (SLF) (Mettler et al., 2013; He et al., 2016), which predominantly connects the frontal cortex to the parietal cortex, whilst passing through the insula and around the putamen.

Similarly, reduced connectivity was observed in BN in the bilateral inferior fronto-occipital fasciculus that connects the (pre)frontal cortex to the occipital cortex, and the uncinate fasciculus that connects the prefrontal cortex to the amygdala, parahippocampus, and anterior temporal cortex (Mettler et al., 2013; He et al., 2016). This was also the case for numerous long range connections between the two hemispheres, with connectivity being reduced in $\mathrm{BN}$ compared with $\mathrm{HC}$ in the major and minor forceps, bilateral corpus callosum, and cingulate gyrus (Mettler et al., 2013; He et al., 2016). In contrast, a recent paper (Estella et al., 2020) showed that connectivity in some of these white matter tracts appears to be increased in BED compared to HC and obese controls. Compared to obese controls, BED subjects showed increased connectivity in the minor forceps, corpus callosum, and cingulate gyrus (connecting the two hemispheres) and the SLF (connecting the frontal to parietal cortex). Some of the same results (forceps, SLF) were found when comparing BED and normal-weight HC (see Table 2), and when comparing obese controls to normal-weigh HC (Estella et al., 2020). This suggests that some of these differences might be related to obesity, rather than BED per se. To summarize, the observed WM tract differences echo those in GM volume and correspond to the networks associated with the three cognitive constructs. Differences in volume of the OFC, insula, and striatum fit well with the consistent differences in connection strength and/or microstructure between these areas. Indeed, the nature of some of the parameters that are affected (see Table 2) suggests that the differences might be relatively specific to myelin loss (although a loss of 
axons and/or a reduced density of axons is also possible; Aung et al., 2013; Solowij et al., 2017).

Myelin forms a protective sheath around the axons of neurons, and by speeding up axon potentials, ensures normal cognitive and sensory function, being involved in several other psychiatric disorders as well (Fields, 2008). Compared to BN, BED subjects show an increase in connectivity rather than a decrease (Estella et al., 2020). More research is needed to confirm these findings and to elucidate the functional consequences for BN and BED.

\subsection{Functional connectivity}

Functional connectivity is a measure of the functional association between brain areas operationalized by the temporal correlation or covariation of activity between those brain areas. Instead of structural images, functional connectivity uses functional magnetic resonance imaging (fMRI) i.e. blood oxygenation level dependent (BOLD) imaging to do so. Differences between $\mathrm{BN} / \mathrm{BED}$ and $\mathrm{HC}$ in functional connectivity measures (see Table 2) largely overlap with those of structural connectivity, although not all do. Connectivity from the right dorsal caudate nucleus and putamen to other subcortical structures (putamen, globus pallidus, thalamus) was increased in $\mathrm{BN}$ compared with HC, compared to connectivity from the ventral striatum and putamen to cortical areas (central gyrus, occipital gyrus, superior frontal gyrus), which was shown to be reduced (Wang et al., 2020).

Connectivity of the parietal cortex seems to be largely reduced. For example, BN is shown to be characterized by a reduction in volume of GM and structural connectivity of the parietal cortex. Similarly, functional connectivity was reduced compared with HC within the inferior parietal cortex (Stopyra et al., 2019), within the temporo-parietal junction (TPJ; Spalatro et al., 2019), and between the parietal lobes and the cerebellum (Amianto et al., 2013b). In contrast, functional connectivity was shown to be increased in $\mathrm{BN}$ between the precuneus and cerebellum (Amianto et al., 2013b). BED subjects showed a similar pattern, with reduced connectivity strength compared with HC within the inferior parietal cortex (Stopyra et al., 2019) and less connectivity to the right superior parietal cortex 
(Oliva et al., 2019). Reduced connectivity compared with BN in the angular gyrus (Stopyra et al., 2019), and a reduction in connectivity to the right insula was also reported (Oliva et al., 2019).

In general, functional connectivity within and between frontal regions was found to be reduced in BN and BED compared with HC (Stopyra et al., 2019; Spalatro et al., 2019; Canna et al., 2017). Namely, reduced connectivity within the IFG (Spalatro et al., 2019) was found in BN compared with HC. Similarly, BN showed reduced connectivity within and between a cluster extending from the OFC to the dlPFC (Canna et al., 2017). Connectivity between the two hemispheres for this cluster was reduced as well (e.g. between the left IFG and right IFG) (Canna et al., 2017). Interestingly, BN showed an increase in functional connectivity within the dorsomedial prefrontal cortex (dmPFC), while BED showed a reduction in the dmPFC connectivity compared with HC (Stopyra et al., 2019). Moreover, when comparing $\mathrm{BN}$ and $\mathrm{BED}$ directly, BED also showed a reduction in functional connectivity compared with BN within the middle frontal gyrus (MFG) (Stopyra et al., 2019), showing that areas in the frontal cortex are differently affected in BN and BED. Compared to HC, BED similarly showed less connectivity to the MFG and reduced connectivity strength from the right MFG to the right anterior insula and right IFG (Oliva et al., 2019). In the cingulate cortex, BED showed increased functional connectivity within the dorsal part of the PCC compared with BN (Stopyra et al., 2019). However, no differences for the PCC were found when comparing BED or BN with HC. For the ACC, BN and BED did show similar reductions in functional connectivity compared with HC (Stopyra et al., 2019). Connections between the ACC and left OFC, right precuneus, and cerebellum were only increased in BN (Lee et al., 2014; Amianto et al., 2013b). Connectivity between the ACC and parahippocampal gyrus was reduced compared with HC.

To summarize, numerous functional connectivity differences can be observed in BN and BED compared with HC. Most of these areas are also affected in terms of GM volume and structural connectivity, such as parietal areas, frontal areas (particularly the OFC), insula, and cingulate cortex. Only in $\mathrm{BN}$ an increase in functional connectivity between the insula and cerebellum was observed (Amianto et al., 2013b). It has to be mentioned that structural and functional connectivity are not always connected in a straightforward manner, even though they are often positively correlated (see for example Uddin, 2013). This was confirmed by an animal study where severing connections 
670

671 Nevertheless, the overall patterns reflect similar differences between BED/BN and HC in GM volume,

672

673

674

675

676

677

678

679

680

681

682

683

684

685

686

687

688

689

690

691

692

693

694

695

696

between areas did not always lead to a change in functional connectivity (O'Reilly et al., 2013). structural and functional connectivity.

Insert Table 2 around here

\section{Concluding remarks}

In this review, we gave an overview of the brain networks associated with the three cognitive constructs most integral to BN and BED. Subsequently, we showed how these networks show an atypical brain organization, both in volume and connectivity compared with HC. We will now shortly summarize the findings presented in these sections, and explain how these differences in volume and connectivity may explain BED and BN symptomatology, and how this is likely involved in eliciting and maintaining binge eating.

\subsection{Reward sensitivity}

Activation differences between $\mathrm{BN} / \mathrm{BED}$ patients and $\mathrm{HC}$ evoked by tasks assessing reward sensitivity are not uniform. A distinction has to be made between passive viewing (anticipatory) tasks and actively receiving or consuming food (consummatory tasks). Both patient groups show a difference in activity in passive viewing tasks in the cingulate cortex (ACC and PCC), the ventral striatum, ventral tegmental area (VTA), and the insula (e.g., Filbey et al., 2012; Oberndorfer et al., 2013; Balodis et al., 2013a; Balodis et al., 2014; Schienle et al., 2009; Simon et al., 2016). Generally, activity in the $\mathrm{PCC}$ is lower compared with $\mathrm{HC}$, whilst activation is shown to be higher in the other areas (see Figure 1). Activity differences in the medial OFC, that connects to the ventral striatum (nucleus accumbens), seem largely limited to BED in passive viewing tasks (Schienle et al., 2009). As mentioned previously, the ventral striatum is thought to play a role in reward prediction error, by 
comparing expected with received outcome values (e.g., Wang et al., 2016). The role of the medial OFC has been more controversial, especially when comparing it to the lateral OFC (e.g., Noonan et al., 2012). The medial OFC has been suggested to be involved value estimation (Sescousse et al., 2010; Setogawa et al., 2019; Stalnaker et al., 2018). However, it has been suggested that it is involved in a broader evaluation of value-guided decision making (Noonan et al., 2012), in particular in a working memory role when comparing previous to current choices (Wallis \& Kennerley, 2011). The ACC in comparison has been implicated in action-outcome learning, choice predictions, prediction errors and surprise signals, more in line with ventral striatum function (Alexander \& Brown, 2019; Wallis \& Kennerley, 2011). The PCC on the other hand is associated with memory and encoding/retrieval of reward values (for an overview, see Rolls, 2019). Additionally, the insula has been more implicated in the somatosensory experience of rewards, such as taste and touch (Rolls, 2016). This makes it likely that reward sensitivity is different in BED and BN in multiple aspects of reward processing, namely altered reward prediction error, perception of rewards, reward memory, value-guided decision making, and reward-based learning.

Some care must be taken when interpreting the function of areas, the roles of all aforementioned areas in reward prediction and estimation are still not completely clear. Some seem related to the reward value directly (i.e., ventral striatum), others (i.e., medial OFC, ACC, and insula) mostly to somewhat broader processes like attention elicited by reward (Uddin et al., 2017; Yan et al., 2016; Roefs et al., 2018). The cingulate cortex and insula in particular show activation patterns during presentation of both negative and positive outcomes (Liu et al., 2011). It is of course not necessary that each area has only one specific role. Rather, it is more likely that several loops in this network are involved in the same aspect, for example reward value estimation. Taken together, these results show that differences in this network associated with reward sensitivity in passive viewing tasks are more complex than an unequivocal increase in activity associated with increased processing of rewardrelated information. It is thus important to investigate the precise function of areas within this network further.

Activity differences in the medial OFC also show up in consummatory tasks (e.g., Simon et al., 2016) both in BED and BN, which is consistent with studies in HC (Liu et al., 2011). Activation 
differences in the dorsal striatum, angular gyrus, and anterior medial PFC seem unique to consummatory tasks (Wang et al., 2011; Simon et al., 2016; Filbey et al., 2012). The dorsal striatum has been mostly associated with learning from rewards, including in instrumental conditioning (e.g., O’Doherty et al., 2004; Tricomi \& Lempert, 2015; Chen et al., 2015). It is important to note that differences in dorsal striatum activation were only found in a study comparing the effects of methylphenidate with placebo on reward sensitivity, and in a study without a matched control group (Wang et al., 2011; Filbey et al., 2012). The absence of a control group makes determining any differences with HC difficult. Similar to the dorsal striatum, parts of the medial PFC have been implicated in reward learning and implementing behavioral strategies (e.g., Alexander \& Brown, 2011; Badre \& Nee, 2018). This strengthens the case for altered reward learning in BN and BED. Although the angular gyrus shows up in both BN and BED, it is unlikely that it is specific to reward sensitivity. The angular gyrus is a multimodal area that shows activation in a large variety of tasks, and integrates input from across the brain (e.g., from the cingulate cortex, precuneus, insula, prefrontal cortex; Seghier, 2013). Difference in activation in this area is thus more likely to be a result of difference in activation in other areas in the reward sensitivity network. Lastly, BN patients show in general an overall decrease in activity, while BED patients mostly show an increase in activity compared with HC. Differences in activity direction (negative/positive) in BN and BED could very well be related to a different way of processing received rewards, but not the anticipation of rewards. One possible difference between BN and BED is that the insular cortex has also been associated with body image distortion in BN (Mohr et al., 2011; Yan et al., 2016). Care must however be taken when making inferences, since brain activity does not map onto behavior or experiences directly.

Nevertheless, a difference in overall activity in this network is promising in possibly explaining differences between the two disorders.

Regarding the findings of volumetric and connectivity studies, in the current review they show considerable overlap with the reward sensitivity networks. To summarize, in BN, GM in the left insula, left OFC, and ventral PCC is larger in volume, whilst right OFC, ventral striatum, and dorsal PCC show smaller volumes (e.g., Amianto et al., 2013a; Berner et al., 2018; Coutinho et al., 2015; Frank et al., 2013; Westwater et al., 2018). This suggests that reward processing in the OFC might be 
753

somewhat lateralized and that the PCC has two separately implicated subregions. Functional connectivity similarly shows increased connectivity between the insula and PFC/OFC (Frank et al., 2016), the ACC and OFC (Lee et al., 2014), and between the caudate nucleus and putamen (Wang et al., 2020). In BED, left ventral striatum volume was also reduced, while ACC volume was found to be increased, and OFC volume seems ambiguously affected (Voon et al., 2015; Shafer et al., 2010). No related connectivity differences were found, although connectivity in the medial dorsal PCC was shown to be increased in BED compared with BN. Indeed, the dorsal PCC, but not ventral PCC, also showed a decrease in GM in BN (Berner et al., 2018). Together with a positive difference in PCC activity in BED during consummatory tasks, this indicates that the PCC could play a different role in reward encoding or attentional processes in BED. Further research into the specific contexts reward sensitivity might be altered in, will help in determining its exact role in BN/BED.

\subsection{Cognitive control}

In cognitive control tasks, both $\mathrm{BN}$ and BED patients show a reduction in activity in frontal areas compared with HC, including the IFG, OFC, dlPFC, superior frontal gyrus, and medial PFC (Marsh et al., 2011; Balodis et al., 2013b; Neveu et al., 2018; Hege et al., 2015; Voon et al., 2015). These are to be expected, as these areas play a large role in controlling our actions (for an overview see Badre \& Nee, 2018). In BED and BN patients, activity differences can be observed throughout the anterior, rostral mid-lateral, and caudal frontal cortex during cognitive control paradigms, including during food-related tasks. Altered processing of food-based decisions is thus likely not limited to decision making, but perception and sensory feedback of food as well. This could also explain activity differences in the occipital gyrus in BED (Balodis et al., 2013b) through top-down processing. The caudate nucleus and putamen show activity differences in BED and BN, respectively (Voon et al., 2015; Marsh et al., 2011). The caudate is thought to be crucial for goal-directed control (de Wit et al., 2012; Gasbarri et al., 2014; Watson et al., 2018), and decreased activity along with volumetric and connectivity differences within these areas could explain why a general increase in habitual responding in BED was found (Voon et al., 2015). This has been hypothesized to play a role 
in the loss of control during binge eating episodes (Voon et al., 2015). The dorsal putamen is shown to be decreased in activity in BN (Marsh et al., 2011) and receives projections from the dorsal posterior insula (Postuma and Dagher, 2006). Activity in medium spiny neurons in the putamen appear to be critical for instrumental learning in primates (Laquitaine et al., 2013). Different parts of the putamen (the posterolateral in humans and caudo-ventral parts in rats) have been associated with habitual responding and habit learning (Balleine and O'Doherty, 2010; de Wit et al., 2012). Reductions in activity during cognitive control tasks could therefore indicate impaired instrumental learning and integration of reward value rather than diminished cognitive control per se. A larger volume of the left putamen in BN may suggest a potential increase in habitual control. Increased functional connectivity of the putamen to subcortical areas, but decreased connectivity with frontal areas (Wang et al., 2020), supports the hypothesis of impaired instrumental learning deficits in BN. However, more studies are needed to confirm whether differences are unique to BN and BED, not only for the striatum but for other areas as well.

Overall, cognitive control is impaired in both BN and BED. Particularly in BN this is illustrated by a reduction of activity in frontal areas such as the OFC, IFG, medial PFC, medial, and superior frontal gyri and is potentially associated with diminished GM volume in these brain areas. The impaired performance is possibly reflective of a decreased influence of the goal-directed network and increased influence of networks associated with habitual responding, potentially creating a bias toward seeking unhealthy eating behaviors.

\subsection{Negative affect}

Stress-related negative affect has been shown to influence reward sensitivity through activation differences in several areas (Lyu \& Jackson, 2016; Collins et al., 2017; Fischer et al., 2017; Wonderlich et al., 2018). BED and BN differ in IFG activation while insula activity differences are unique to BED (Lyu \& Jackson, 2016), and right ACC, paracingulate gyrus, precuneus, vmPFC and IFG activity differences are unique to BN (Balodis et al., 2014; Collins et al., 2017; Fischer et al., 2017; Wonderlich et al., 2018). However, since the results in BED are only based on a single study, it 
is currently not warranted to conclude that BN and BED differ completely as more data is needed to assess the existence of potentially unique activation differences. Activity differences in the ACC, insula, precuneus, and vmPFC have been extensively implicated in similar reward sensitivity and cognitive control tasks outside of acute stress manipulation (e.g., Simon et al., 2016; Schienle et al., 2009; Neveu et al., 2018). It is likely that these are not unique to stress-related negative affect, although they could be a result of it.

Differences in activation of the hippocampus in BED and anterior vermis of the cerebellum in $\mathrm{BN}$ seem unique to these paradigms that measure reward sensitivity under acute stress. Differences in activation of the anterior vermis are somewhat difficult to evaluate since they have not been typically associated with acute stress or reward processing. As mentioned previously, differences in the amygdala and hippocampal projections to areas associated with reward sensitivity (Abivardi and Bach, 2017; Salzman and Fusi, 2010) can also be observed through structural and functional connectivity studies in BN/BED. BN subjects showed reduced connectivity between the central nucleus of the amygdala $(\mathrm{CeA})$ and the hypothalamus in the right hemisphere, and the ventral anterior insula in the left hemisphere (Frank et al., 2016). Connectivity between the CeA and insula has been associated with feeding behaviour in rats (Zhang-Molina et al., 2020), with activation of this pathway suppressing food intake. Projections of the $\mathrm{CeA}$ and insula also converge in the parasubthalamic nucleus, which together with the $\mathrm{CeA}$ and insula modulate feeding behaviour of palatable food (Barbier et al., 2020). Through these connections, the insula suppresses activity in the CeA associated with satiety and plays an important role in overfeeding behavior (Stern et al., 2021; for a comprehensive overview of the connections, see Barbier et al., 2020). Aside from the CeA, BN subjects also showed reduced connectivity in the right hemisphere between the basolateral amygdala (BLA) and the dorsal anterior insula (dAI), and ventral striatum. It has been shown that the BLA-dAI connections are crucial for reward learning through memory (Gil-Lievana et al., 2020). In particular, the BLA in rats is specifically involved in encoding changes in outcome value, but not the hedonic experience gained from rewards (e.g., Parkes et al., 2013; for an overview see Wassum \& Izquierdo et al., 2015). Crucially, lesions in rat BLA disrupted R-O learning (Balleine et al., 2003), and primate BLA neurons show similar involvement by future-oriented activity to gain rewards (Hernádi et al., 
2015). Disrupted BLA-dAI structural connectivity could leave BN (and possibly BED) subjects more reliant on S-R learning mechanisms. Indeed, a similar case can be made for the BLA-ventral striatum connections. Connectivity between the BLA and core of the nucleus accumbens was also necessary for R-O learning in rats (Shiflett \& Balleine, 2010), although it is facilitated by a reduction of dopamine release (Jones et al., 2010). Compared to the reward history function of BLA-dAI connectivity, BLAventral striatum connectivity is thus more reliant on the current hedonic value of the reward (Wassum \& Izquierdo et al., 2015). Incidentally, BLA connectivity to the lateral and medial OFC have also been shown to be necessary in reward encoding (Malvaez et al., 2019), however this has not yet been shown to be affected in BN/BED.

It is important to mention that interpretations of these studies on stress and reward sensitivity are complicated by not including or reporting cortisol values. One disadvantage of this is that it makes responder classification (Miller et al., 2013) impossible, as this is shown to be a boundary condition in a number of tasks, in particular for the shift from goal-directed to habitual control (e.g. Smeets et al., 2019). Indeed, responder classification is also an important factor for food intake in healthy participants. High cortisol reactivity after acute stress exposure was tied to greater food consumption (Epel et al., 2001). It would be interesting to test whether there is an association between cortisol reactivity in $\mathrm{BN} / \mathrm{BED}$, and the amount of food intake and the above-described hippocampus activation and amygdala connectivity.

Taken together, these results show that the HPA axis and reward networks are closely connected and differentially affected in BN/BED. Hippocampal activity, which has an inhibitory function on the HPA-axis, is affected, and both the CeA and BLA likely play crucial roles in feeding behavior and reward learning. Specifically, this is likely associated with disrupted R-O learning habitual control, which has been shown in humans with BED directly (Voon et al., 2015). This fits well with research showing that after acute stress, healthy participants show a shift from goal-directed to habitual responding in instrumental learning tasks (e.g. Schwabe and Wolf, 2009; Wirz et al., 2018; Smeets et al., 2019; Quaedflieg et al., 2019; Hartogsveld et al., 2020). Stress could therefore make BN/BED subjects more likely to rely on S-R associations, whilst impairing reward values and reducing cognitive control, connecting the three cognitive constructs. 


\subsection{Future directions}

It is crucial to use a multimodal approach that will lead to a better understanding of BN/BED.

Such an approach could compromise assessing neural activation during the task itself and combine volumetric and connectivity approaches, which could then establish associations between affected brain areas/connectivity and cognitive processes and ultimately brain network functioning and maladaptive behavioral output. Based on the present review, the three major cognitive constructs affected in BN and BED provide key elements in this approach. There is a number of promising ways that future research could pursue to more precisely delineate the association between brain function and these cognitive constructs. To model mechanisms underlying binges more accurately, future studies could integrate more than just a single of these three cognitive constructs in their paradigm to examine the potential interactive influences they may have. Pavlovian-to-instrumental-transfer (Cartoni et al., 2016; Mahlberg et al., 2019; Watson and de Wit, 2018) is a good example of a paradigm that combines reward sensitivity and cognitive control. Indeed, this review shows that the networks involved in Pavlovian conditioning show considerable overlap with those responsible for the transfer to instrumental learning and reward sensitivity (Corbit and Balleine, 2016). Another promising approach is to investigate how stress influences the balance between brain networks involved in instrumental learning in BN/BED, as stress could make subjects more likely to rely on stimulus-response associations (model-free) whilst also impairing reward value attribution to an outcome. It is likely that the balance between goal-directed (model-based) and habitual (model-free) behavior is affected in BN/BED and associated with structural brain differences, but unfortunately there is only one study (Voon et al., 2015) investigating this in patients. However, Voon and coworkers (2015) only investigated volumetric GM associations of a subsample of all the subjects performing the instrumental learning task. To establish a more complete understanding of these disorders, associations between GM volume, brain activation, structural and functional connectivity as well as impaired cognitive functioning needs to be determined in larger samples. Advanced designs and analyses such as multivariate pattern analysis for both activity and connectivity (Anzellotti et al., 
2018) and algorithmic network approaches (Bielczyck et al., 2019) show considerable promise and could be very effective in providing unambiguous results.

BN and BED seem to affect men and women equally (Guerdjikova et al., 2017; Hudson et al., 2007). Thus, future research also has to specifically address the lack of research on men with BN and BED, as most studies discussed in this review only involved women. This may be problematic, since there appears to be sexual dimorphism of the mesocorticolimbic system, particularly involving stress responses (Douma and de Kloet, 2020; Gillies et al., 2014). Moreover, sex hormones influence glucocorticoid secretion and functioning of ventrotegmental dopamine neurons. The ventrotegmental area is in turn connected to the ventral striatum and prefrontal cortex, which makes this network very likely to play a central role in reward sensitivity, particularly after acute stress exposure. This potentially could increase reward values for certain foods and the likelihood of binge eating. It has also been shown that the effects of acute stress are different for men and women, both when influencing decision making and the way it is involved in certain psychiatric disorders (Bale and Epperson, 2015; Bangasser and Valentino, 2014; Georgiou et al., 2017; Wellman et al., 2018). Therefore, stress may differentially affect decision making and binge eating in men and women with BN and BED. More refined research is needed to confirm these findings in male samples to identify their exact role in $\mathrm{BN}$ and BED.

Taken together, we show in this review that BN and BED are characterized by differences in three networks, involving the prefrontal and cingulate cortex, insula, striatum, amygdala and hippocampus. Each of these networks is associated with different cognitive constructs, namely reward sensitivity, cognitive control, and negative affect. Numerous key nodes in these networks are also different in volume and connectivity compared with HC. Moreover, some of the studies discussed indicate that alterations in volume are present in current, but not in recovered, patients, and that these alterations correlate positively with symptom severity (Cyr et al., 2017; Wagner et al., 2006). Nevertheless, the number of studies on BN and BED is still limited. Therefore, caution must be taken when drawing strong conclusions about these disorders based on the available evidence. A related issue is caused by the relatively small samples in the studies with BN/BED patients (even though studies investigating subclinical subjects have included larger samples). Especially in smaller samples, 
917 smaller differences that may be present might not be substantial enough to be detected due to a lack of

918 statistical power. This leaves the possibility of smaller, but relevant structural or functional differences

919 in brain organization still undiscovered in BN and BED. There are some differences found in

920 volumetric and connectivity studies that do not map onto the three cognitive constructs proposed in

921 this review. These are the inferior parietal cortex (Marsh et al., 2015; Westwater et al., 2018; Wallace

922 et al., 2020), middle/inferior temporal gyrus (Westwater et al., 2018; Marsh et al., 2015), paracentral

923 lobule (Amianto et al., 2013a), lingual gyrus (Marsh et al., 2015; Stopyra et al., 2019), and the

924 fusiform gyrus (Marsh et al., 2015). These areas might be associated with other constructs not

925 discussed here (e.g., body image distortion, other psychiatric comorbidities such as depression or

926 anxiety disorder), or they might not map onto any construct at all. In addition, most of these

927 differences are only confirmed by a limited number of studies with relatively small sample sizes. It is

928 therefore essential that more high-powered multimodal studies are performed to improve our

929 understanding of the brain-behavior connection in BN/BED. 
930

931

932

933

934

935

936

937

938

939

940

941

942

943

944

945

946

947

948

949

950

951

952

953

954

955

956

\section{Search strategy and selection criteria}

A literature search was performed for this narrative review in PubMed and Google Scholar. We used the following search terms: ((bulimia nervosa) OR (binge eating disorder)) AND ((volumetric) OR (cortical thickness) OR (diffusion) OR (resting state)) OR (((reward sensitivity) OR (cognitive control) OR (impulsivity) OR (decision making) OR (instrumental learning) OR (negative affect) OR (stress) OR (cortisol) OR (HPA axis) AND (fMRI)). The reference lists of the included articles were also searched for additional potentially relevant articles. The final search was conducted on the $10^{\text {th }}$ of November 2020, yielding a total of 463 articles. Our exclusion criteria for this narrative research were: 1) not including participants that are either BED or BN patients or experienced BED or BN symptoms, 2) not including measures of brain structure, connectivity, or activity during relevant tasks, 3) the article scores poor on our quality assessment (see below) and/or includes extremely small samples, 4) review articles not reporting original data, 5) conference proceedings without full report publication. After removing excluded articles and duplicates, the final number of eligible studies was 45 . Results were extracted from both the main paper and supplementary materials available online, and all tests are reported in Table 1 and 2.

\section{Quality assessment}

Quality of the studies was evaluated based on the nine criteria described in Wolters et al. (2019): (1) description of participants; (2) description of imaging procedure and instructions; (3) description of psychological task; (4) description of spatial normalization procedure; (5) specification of regions of interest; (6) suitability of imaging pipeline for analyzing imaging data; (7) multiple testing problem; (8) support of all empirical claims by statistical tests; (9) quality of tables and figures. We added three criteria that were particularly relevant in evaluating the quality of studies using BN and BED samples: (10) quality of assessment of BN/BED status (e.g. formal diagnosis, questionnaire); (11) correct matching of control group to patient group; and (12) the size of sample within each subgroup. Each criterion could be scored with 1 point (+), 0.5 points $( \pm)$ or 0 points (-). Total score was calculated and corrected for number of applicable criteria (total score/number of applicable criteria*10). A score of 
9577.5 or higher was considered as good quality, a score between 4 and 7.5 as fair quality, and a score of

9584 or less as poor quality (Wolters et al., 2019). Quality of papers was considered while interpreting and

959 discussing the results of the data synthesis. Quality assessment was performed independently by two

960 researchers. There were no major discrepancies in overall quality rating between the assessors (poor,

961 fair, good). Differences between the assessors for individual criteria (e.g. 9. quality of tables and

962 figures) also did not exceed 0.5 points. The average score between the two researchers is reported in

963 the figure below.

964

965

Insert Figure 5 around here

966

967

968 


\section{References}

Abivardi, A., Bach, D.R., 2017. Deconstructing white matter connectivity of human amygdala nuclei with thalamus and cortex subdivisions in vivo. Hum. Brain Mapp. 38, 3927-3940. https://doi.org/10.1002/hbm.23639

Adams, R.C., Sedgmond, J., Maizey, L., Chambers, C.D., Lawrence, N.S., 2019. Food addiction: Implications for the diagnosis and treatment of overeating. Nutrients 11. https://doi.org/10.3390/nu11092086

Alexander, W. H., Brown, J. W., 2011. Medial prefrontal cortex as an action-outcome predictor. Nat Neurosci. 14(10), 1338-1344. https://doi.org/ 10.1038/nn.2921

Alexander, W. H., Brown, J. W., 2019. The Role of the Anterior Cingulate Cortex in Prediction Error and Signaling Surprise. Top Cogn Sci. 11(1), 119-135. https://doi.org/10.1111/tops.12307

Allison, K.C., Grilo, C.M., Masheb, R.M., Stunkard, A.J., 2007. High self-reported rates of neglect and emotional abuse, by persons with binge eating disorder and night eating syndrome. Behav. Res. Ther. 45, 2874-2883. https://doi.org/10.1016/j.brat.2007.05.007

American Psychiatric Association., 2013. Diagnostic and statistical manual of mental disorders (5th ed.). Washington, DC.

Amianto, F., Caroppo, P., D’Agata, F., Spalatro, A., Lavagnino, L., Caglio, M., Righi, D., Bergui, M., Abbate-Daga, G., Rigardetto, R., Mortara, P., Fassino, S., 2013a. Brain volumetric abnormalities in patients with anorexia and bulimia nervosa: A Voxel-based morphometry study. Psychiatry Res. - Neuroimaging 213, 210-216. https://doi.org/10.1016/j.pscychresns.2013.03.010

Amianto, F., D’Agata, F., Lavagnino, L., Caroppo, P., Abbate-Daga, G., Righi, D., Scarone, S., Bergui, M., Mortara, P., Fassino, S., 2013b. Intrinsic connectivity networks within cerebellum and beyond in eating disorders. Cerebellum 12, 623-631. https://doi.org/10.1007/s12311-0130471-1

Appelhans, B.M., 2009. Neurobehavioral inhibition of reward-driven feeding: Implications for dieting and obesity. Obesity 17, 640-647. https://doi.org/10.1038/oby.2008.638

Aung, W.Y., Mar, S., Benzinger, T.L.S., 2013. Diffusion tensor MRI as a biomarker in axonal and myelin damage. Imaging Med., 5(5), 427-440. https://doi.org/10.2217/iim.13.49

Anzellotti, S., Coutanche, M. N., 2018. Beyond functional connectivity: Investigating networks of multivariate representations. Trends Cogn Sci. 22(3), 258-269. https://doi.og/10.1016/j.tics.2017.12.002

Badre, D., Nee, D. E., 2018. Frontal Cortex and the Hierarchical Control of Behavior. Trends Cogn Sci. 22(2), 170-188. https://doi.org/10.1016/j.tics.2017.11.005

Bale, T.L., Epperson, C.N., 2015. Sex differences and stress across the lifespan 18, 35-42. https://doi.org/10.1038/nn.4112

Balleine, B. W., Killcross, A. S., Dickinson, A., 2003. The effect of lesions of the basolateral 
1006

1007

1008

1009

1010

1011

1012

1013

1014

1015

1016

1017

1018

1019

1020

1021

1022

1023

1024

1025

1026

1027

1028

1029

1030

1031

1032

1033

1034

1035

1036

1037

1038

1039

1040

1041

1042

amygdala on instrumental conditioning. J Neurosci. 23(2), 666-675. https://doi.org/10.1523/JNEUROSCI.23-02-00666.2003

Balleine, B.W., O’Doherty, J.P., 2010. Human and rodent homologies in action control: corticostriatal determinants of goal-directed and habitual action. Neuropsychopharmacology 35, 48-69. https://doi.org/10.1038/npp.2009.131

Balodis, I.M., Grilo, C.M., Kober, H., Worhunsky, P.D., White, M.A., Stevens, M.C., Pearlson, G.D., Potenza, M.N., 2014. A pilot study linking reduced fronto-Striatal recruitment during reward processing to persistent bingeing following treatment for binge-eating disorder. Int. J. Eat. Disord. 47, 376-384. https://doi.org/10.1002/eat.22204

Balodis, I.M., Grilo, C.M., Potenza, M.N., 2019. Neurobiological features of binge eating disorder. CNS Spectr. 20, 557-565. https://doi.org/10.1017/S1092852915000814

Balodis, I.M., Kober, H., Worhunsky, P.D., White, M.A., Stevens, M.C., Pearlson, G.D., Sinha, R., Grilo, C.M., Potenza, M.N., 2013a. Monetary reward processing in obese individuals with and without binge eating disorder. Biol. Psychiatry 73, 877-886.

https://doi.org/10.1016/j.biopsych.2013.01.014

Balodis, I.M., Molina, N.D., Kober, H., Worhunsky, P.D., White, M.A., Sinha, R., Grilo, C.M., Potenza, M.N., 2013b. Divergent neural substrates of inhibitory control in binge eating disorder relative to other manifestations of obesity. Obesity $21,367-377$. https://doi.org/10.1002/oby.20068

Bangasser, D.A., Valentino, R.J., 2014. Sex differences in stress-related psychiatric disorders: Neurobiological perspectives. Front. Neuroendocrinol. https://doi.org/10.1016/j.yfrne.2014.03.008

Barbier, M., Chometton, S., Pautrat, A., Miguet-Alfonsi, C., Datiche, F., Gascuel, J., Fellmann, D., Peterschmitt, Y., Coizet, V., Risold, P. Y. 2020. A basal ganglia-like cortical-amygdalarhypothalamic network mediates feeding behavior. Proc Natl Acad Sci U S A. 117(27), 1596715976. https://doi.org/10.1073/pnas/2004914117

Bartholdy, S., Dalton, B., O’Daly, O.G., Campbell, I.C., Schmidt, U., 2016. A systematic review of the relationship between eating, weight and inhibitory control using the stop signal task. Neurosci. Biobehav. Rev. 64, 35-62. https://doi.org/10.1016/j.neubiorev.2016.02.010

Berner, L.A., Crosby, R.D., Cao, L., Engel, S.G., Lavender, J.M., Mitchell, J.E., Wonderlich, S.A., 2017. Temporal associations between affective instability and dysregulated eating behavior in bulimia nervosa. J. Psychiatr. Res. 92, 183-190. https://doi.org/10.1016/j.jpsychires.2017.04.009

Berner, L.A., Stefan, M., Lee, S., Wang, Z., Terranova, K., Attia, E., Marsh, R., 2018. Altered cortical thickness and attentional deficits in adolescent girls and women with bulimia nervosa. J. Psychiatry Neurosci. 43, 151-160. https://doi.org/10.1503/jpn.170070

Berner, L.A., Wang, Z., Stefan, M., Lee, S., Huo, Z., Cyr, M., Marsh, R., 2019. Subcortical shape abnormalities in bulimia nervosa. Biol. Psychiatry Cogn. Neurosci. Neuroimaging. 
1043

1044

1045

1046

1047

1048

1049

1050

1051

1052

1053

1054

1055

1056

1057

1058

1059

1060

1061

1062

1063

1064

1065

1066

1067

1068

1069

1070

1071

1072

1073

1074

1075

1076

1077

1078

1079 https://doi.org/10.1016/j.bpsc.2018.12.011

Berner, Laura A, Winter, S.R., Matheson, B.E., Benson, L., Lowe, M.R., 2017. Behind binge eating: A review of food-specific adaptations of neurocognitive and neuroimaging tasks. Physiol Behav 176, 59-70. https://doi.org/10.1016/j.physbeh.2017.03.037

Berridge, K.C., 1996. Food Reward: Brain substrates of wanting and liking. Neurosci. Biobehav. Rev. 20, 1-181. https://doi.org/10.1016/0149-7634(95)00033-B

Bielczyk, N. Z., Uithol, S., van Mourik, T., Anderson, P., Glennon, J. C., Buitelaar, J. K., 2019. Disentangling causal webs in the brain using functional magnetic resonance imaging: A review of current approaches. Netw Neurosci.3(2), 237-273. https://doi.org/10.1162/netn_a_00062

Bongers, P., Jansen, A., 2016. Emotional eating is not what you think it is and emotional eating scales do not measure what you think they measure. Front. Psychol. 7, 1-11. https://doi.org/10.3389/fpsyg.2016.01932

Brockmeyer, T., Skunde, M., Wu, M., Bresslein, E., Rudofsky, G., Herzog, W., Friederich, H.C., 2014. Difficulties in emotion regulation across the spectrum of eating disorders. Compr. Psychiatry 55, 565-571. https://doi.org/10.1016/j.comppsych.2013.12.001

Bruce, K.R., Koerner, N.M., Steiger, H., Young, S.N., 2003. Laxative misuse and behavioral disinhibition in bulimia nervosa. Int. J. Eat. Disord. 33, 92-97. https://doi.org/10.1002/eat.10116

Bullmore, E., Sporns, O., 2012. The economy of brain network organization. Nat. Rev. Neurosci., 13(5), 336-349. https://doi.org/10.1038/nrn3214

Canna, A., Prinster, A., Monteleone, A.M., Cantone, E., Monteleone, P., Volpe, U., Maj, M., Di Salle, F., Esposito, F., 2017. Interhemispheric functional connectivity in anorexia and bulimia nervosa. Eur. J. Neurosci. Neuroimaging and obesity: current knowledge and future directions. Obes. Rev. 13, 43-56. https://doi.org/10.1111/j.1467-789X.2011.00927.x

Carnell, S., Grillot, C., Ungredda, T., Ellis, S., Mehta, N., Holst, J., Geliebter, A., 2018. Morning and afternoon appetite and gut hormone responses to meal and stress challenges in obese individuals with and without binge eating disorder. Int. J. Obes. 42, 841-849. https://doi.org/10.1038/ijo.2017.307

Carrard, I., Crépin, C., Ceschi, G., Golay, A., van der Linden, M., 2012. Eating Behaviors Relations between pure dietary and dietary-negative affect subtypes and impulsivity and reinforcement sensitivity in binge eating individuals. Eat. Behav. 13, 13-19. https://doi.org/10.1016/j.eatbeh.2011.10.004

Carroll, D., Ginty, A.T., Whittaker, A.C., Lovallo, W.R., de Rooij, S.R., 2017. The behavioural, cognitive, and neural corollaries of blunted cardiovascular and cortisol reactions to acute psychological stress. Neurosci. Biobehav. Rev. 77, 74-86. https://doi.org/10.1016/j.neubiorev.2017.02.025

Cartoni, E., Balleine, B., Baldassarre, G., 2016. Appetitive Pavlovian-instrumental Transfer : A review. Neurosci. Biobehav. Rev. 71, 829-848. https://doi.org/10.1016/j.neubiorev.2016.09.020 
1080

1081

1082

1083

1084

1085

1086

1087

1088

1089

1090

1091

1092

1093

1094

1095

1096

1097

1098

1099

1100

1101

1102

1103

1104

1105

1106

1107

1108

1109

1110

1111

1112

1113

1114

1115

1116

Chen, C., Omiya, Y., Yang, S., 2015. Dissociating contributions of ventral and dorsal striatum to reward learning. J Neurophysiol. 114(3), 1364-1366. https://doi.org/10.1152/jn.00873.2014

Claes, L., Vandereycken, W., Vertommen, H., 2002. Impulsive and compulsive traits in eating disordered patients compared with controls. Pers. Individ. Dif. 32, 707-714. https://doi.org/10.1016/S0191-8869(01)00071-X

Collins, B., Breithaupt., L., McDowell, J. E., Miller, L. S., Thompson, J., \& Fischer S., 2017. The impact of acute stress on the neural processing of food cues in bulimia nervosa: Replication in two samples. J. Abnorm. Psychol., 126(5), 540-551. https://doi.org/1037/abn0000242

Corbit, L. H., \& Balleine, B. W., 2016. Learning and motivational processes contributing to pavlovian-instrumental transfer and their neural bases: dopamine and beyond. Curr. Top. Behav. Neurosci., 27, 259-289. https://doi.org/10.1007/7854_2015_388

Coutinho, J.F.P., Ramos, A.F., Maia, L., Castro, L., Conceic, ão, E., Geliebter, A., Machado, P.P.P., Gonc salves, Ó., Sampaio, A., 2015. Volumetric alterations in the nucleus accumbens and caudate nucleus in bulimia nervosa: A structural magnetic resonance imaging study. Int. J. Eat. Disord. 48, 206-214. https://doi.org/10.1002/eat.22273

Coutinho, W.F., Moreira, R.O., Spagnol, C., Appolinario, J.C., 2007. Does binge eating disorder alter cortisol secretion in obese women? Eat. Behav. 8, 59-64. https://doi.org/10.1016/j.eatbeh.2006.01.002

Crosby, R.D., Wonderlich, S.A., Engel, S.G., Simonich, H., Smyth, J., Mitchell, J.E., 2009. Daily mood patterns and bulimic behaviors in the natural environment. Behav. Res. Ther. 47, 181-188. https://doi.org/10.1016/j.brat.2008.11.006

Culbert, K.M., Racine, S.E., Klump, K.L., 2016. Hormonal Factors and Disturbances in Eating Disorders. Curr. Psychiatry Rep. 18. https://doi.org/10.1007/s11920-016-0701-6

Curtis, C., Davis, C., 2014. A Qualitative Study of Binge Eating and Obesity From an Addiction Perspective. Eat. Disord. 22, 19-32. https://doi.org/10.1080/10640266.2014.857515

Cyr, M., Kopala-Sibley, D.C., Lee, S., Chen, C., Stefan, M., Fontaine, M., Terranova, K., Berner, L.A., Marsh, R., 2017. Reduced inferior and orbital frontal thickness in adolescent bulimia nervosa persists over two-year follow-up. J. Am. Acad. Child. Adolesc. Psychiatry, 56(10), 866874.e7. https://doi.org/10.1016/j.jaac.2017.08.008

Danner, U.N., Ouwehand, C., Van Haastert, N.L., Hornsveld, H., De Ridder, D.T.D., 2012. Decisionmaking impairments in women with binge eating disorder in comparison with obese and normal weight women. Eur. Eat. Disord. Rev. 20. https://doi.org/10.1002/erv.1098

de Houwer, J., Tanaka, A., Moors, A., Tibboel, H., 2018. Kicking the habit: why evidence for habits in humans might be overestimated. Motiv. Sci. 4, 50-59. https://doi.org/10.1037/mot0000065

de Wit, S., Watson, P., Harsay, H.A., Cohen, M.X., van de Vijver, I., Ridderinkhof, K.R., 2012. Corticostriatal connectivity underlies individual differences in the balance between habitual and goal-directed action control. J. Neurosci. 32, 12066-75. 
1117

1118

1119

1120

1121

1122

1123

1124

1125

1126

1127

1128

1129

1130

1131

1132

1133

1134

1135

1136

1137

1138

1139

1140

1141

1142

1143

1144

1145

1146

1147

1148

1149

1150

1151

1152

1153
https://doi.org/10.1523/JNEUROSCI.1088-12.2012

Dickerson, S.S., Kemeny, M.E., 2004. Acute stressors and cortisol responses: a theoretical integration and synthesis of laboratory research. Psychol Bull, 130(3), 355-391. https://doi.org/10.1037/0033-2909.130.3.355

Douma, E.H., de Kloet, E.R., 2020. Stress-induced plasticity and functioning of ventral tegmental dopamine neurons. Neurosci. Biobehav. Rev. https://doi.org/10.1016/j.neubiorev.2019.10.015

Epel, E., Lapidus, R., McEwen, B., Brownell, K., 2001. Stress may add bite to appetite in women: A laboratory study of stress-induced cortisol and eating behavior. Psychoneuroendocrinology 26, 37-49. https://doi.org/10.1016/S0306-4530(00)00035-4

Estella, N.M., Sanches, L.G., Maranhão, M.F., Hoexter, M.Q., Schmidt, U., Campbell, I.C., Amaro Jr., E., Claudino, A.M., 2020. Brain white matter microstructure in obese women with binge eating disorder. European Eating Disorders Review, 28(5), 525-535. https://doio.org/10.1002/erv.2758

Fahy, T., Eisler, I., 1993. Impulsivity and eating disorders. Br. J. Psychiatry 162, 193-197. https://doi.org/10.1192/bjp.162.2.193

Favaro, A., Zanetti, T., Tenconi, E., Degortes, D., Ronzan, A., Veronese, A., Santonastaso, P., 2005. The relationship between temperament and impulsive behaviors in eating disordered subjects. Eat. Disord. 13, 61-70. https://doi.org/10.1080/10640260590893647

Fields, D.R., 2008. White matter in learning, cognition and psychiatric disorders. Trends Neurosci., 31(7), 361-370. https://doi.org/10.1016/j.tins.2008.04.001

Fineberg, N.A., Chamberlain, S.R., Goudriaan, A.E., Stein, D.J., Vanderschuren, L.J.M.J., Gillian, C.M., Shekar, S., Gorwood, P.A.P.M., Voon, V., Morein-Zamir, S., Denys, D., Sahakian, B.J., Moeller, F.G., Robbins, T.W., Potenza, M.N., 2014. New Developments in Human Neurocognition: Clinical, Genetic and Brain Imaging Correlates of Impulsivity and Compulsivity. CNS Spectr 19, 69-89. https://doi.org/10.1038/jid.2014.371

Fischer, S., Breithaupt, L., Wonderlich, J., Westwater, M.L., Crosby, R.D., Engel, S.G., Thompson, J., Lavender, J., Wonderlich, S., 2017. Impact of the neural correlates of stress and cue reactivity on stress related binge eating in the natural environment. J. Psychiatr. Res. 92, 15-23. https://doi.org/10.1016/j.jpsychires.2017.03.017

Fischer, S., Smith, G.T., Anderson, K.G., 2003. Clarifying the role of impulsivity in bulimia nervosa. Int. J. Eat. Disord. 33, 406-411. https://doi.org/10.1002/eat.10165

Fischer, S., Wonderlich, J., Breithaupt, L., Byrne, C., Engel, S. 2018. Negative urgency and expectancies increase vulnerability to binge eating in bulimia nervosa. Eat Disorders, 26(1), 3951. https://doi.org/10.1080/10640266.2018.1418253

Frank, G.K.W., Shott, M.E., Riederer, J., Pryor, T.L., 2016. Altered structural and effective connectivity in anorexia and bulimia nervosa in circuits that regulate energy and reward homeostasis. Transl. Psychiatry 6, e932-10. https://doi.org/10.1038/tp.2016.199

Frank, K.G., Shott, E.M., Hagman, O.J., A.V., M., 2013. Alterations in brain structures related to taste 
1154

1155

1156

1157

1158

1159

1160

1161

1162

1163

1164

1165

1166

1167

1168

1169

1170

1171

1172

1173

1174

1175

1176

1177

1178

1179

1180

1181

1182

1183

1184

1185

1186

1187

1188

1189

1190

reward circuitry in ill and recovered anorexia nervosa and in bulimia nervosa. Am. J. Psychiatry 170, 1152-1160. https://doi.org/10.1176/appi.ajp.2013.12101294

Galanti, K., Gluck, M.E., Geliebter, A., 2007. Test Meal Intake in Obese Binge Eaters in Relation to Impulsivity and Compulsivity. Int. J. Eat. Disord. 40, 727-732. https://doi.org/10.1002/eat

García-garcía, I., Michaud, A., Dadar, M., Zeighami, Y., Neseliler, S., Collins, D.L., Evans, A.C., Dagher, A., 2019. Neuroanatomical differences in obesity: meta-analytic findings and their validation in an independent dataset. Int. J. Obes. 43, 943-951. https://doi.org/10.1038/s41366018-0164-4

Gasbarri, A., Pompili, A., Packard, M.G., Tomaz, C., 2014. Habit learning and memory in mammals: Behavioral and neural characteristics. Neurobiol. Learn. Mem. 114, 198-208. https://doi.org/10.1016/j.nlm.2014.06.010

Georgiou, P., Zanos, P., Bhat, S., Tracy, J.K., Merchenthaler, I.J., Mccarthy, M.M., Gould, T.D., 2017. Dopamine and Stress System Modulation of Sex Differences in Decision Making 43, 313-324. https://doi.org/10.1038/npp.2017.161

Gibson, E.L., 2012. The psychobiology of comfort eating: Implications for neuropharmacological interventions. Behav. Pharmacol. 23, 442-460. https://doi.org/10.1097/FBP.0b013e328357bd4e

Giel, K.E., Teufel, M., Junne, F., Zipfel, S., Schag, K., 2017. Food-related impulsivity in obesity and binge eating disorder - a systematic update of the evidence. Nutrients 9. https://doi.org/10.3390/nu9111170

Gil-Lievana, E., Balderas, I., Moreno-Castilla, P., Luis-Islas, J., McDevitt, R. A., Tecuapetla, F., Gutierrez, R., Bonci, A., Bermúdez-Rattoni, F., 2020. Glutamatergic basolateral amygdala to anterior insular cortex circuitry maintains rewarding contextual memory. Comm Biol. 3, 139. https://doi.org/10.1038/s42003-020-0862-z

Gillies, G.E., Virdee, K., McArthur, S., Dalley, J.W., 2014. Sex-dependent diversity in ventral tegmental dopaminergic neurons and developmental programing: A molecular, cellular and behavioral analysis. Neuroscience. https://doi.org/10.1016/j.neuroscience.2014.05.033

Ginty, A.T., Phillips, A.C., Higgs, S., Heaney, J.L.J., Carroll, D., 2012. Disordered eating behaviour is associated with blunted cortisol and cardiovascular reactions to acute psychological stress. Psychoneuroendocrinology 37, 715-724. https://doi.org/10.1016/j.psyneuen.2011.09.004

Gluck, M.E., 2006. Stress response and binge eating disorder. Appetite, 46, 26-30. https://doi.org/ 10.1016/j.appet.2005.05.004

Gluck, M.E., Geliebter, A., Hung, J., Yahav, E., 2004. Cortisol, Hunger, and Desire to Binge Eat Following a Cold Stress Test in Obese Women With Binge Eating Disorder. Psychosom. Med. 66, 876-881. https://doi.org/10.1097/01.psy.0000143637.63508.47

Gluck, M.E., Yahav, E., Hashim, S.A., Geliebter, A., 2014. Ghrelin Levels After a Cold Pressor Stress Test in Obese Women With Binge Eating Disorder. Psychosom. Med. 76, 74-79. https://doi.org/10.1097/PSY.0000000000000018.Ghrelin 
1191

1192

1193

1194

1195

1196

1197

1198

1199

1200

1201

1202

1203

1204

1205

1206

1207

1208

1209

1210

1211

1212

1213

1214

1215

1216

1217

1218

1219

1220

1221

1222

1223

1224

1225

1226

1227

Grilo, C.M., Masheb, R.M., 2002. Childhood maltreatment and personality disorders in adult patients with binge eating disorder. Acta Psychiatr. Scand. 106, 183-188. https://doi.org/10.1034/j.16000447.2002.02303.x

Guerdjikova, A.I., Mori, N., Casuto, L.S., McElroy, S.L., 2017. Binge Eating Disorder. Psychiatr. Clin. North Am. 40, 255-266. https://doi.org/10.1016/j.psc.2017.01.003

Guh, D.P., Zhang, W., Bansback, N., Amarsi, Z., Birmingham, L., Anis, A.H., 2009. The incidence of co-morbidities related to obesity and overweight : A systematic review and meta-analysis $20,1-$ 20. https://doi.org/10.1186/1471-2458-9-88

Haedt-Matt, A.A., Keel, P.K., 2012. Revisiting the Affect Regulation Model of Binge Eating: A MetaAnalysis of Studies using Ecological Momentary Assessment. Psychol. Bull. 137, 660-681. https://doi.org/10.1037/a0023660.Revisiting

Hardaway, J.A., Crowley, N.A., Bulik, C.M., Kash, T.L., 2015. Integrated circuits and molecular components for stress and feeding: implications for eating disorders. Genes Brain Behav., 14(1), 85-97. https://doi.org/10.1111/gbb.12185

Harrison, A., O’Brien, N., Lopez, C., Treasure, J., 2010. Sensitivity to reward and punishment in eating disorders. Psychiatry Res. 177, 1-11. https://doi.org/10.1016/j.psychres.2009.06.010

Hartogsveld, B., van Ruitenbeek, P., Quaedflieg, C.W.E.M., Smeets, T., 2020. Balancing between goal-directed and habitual responding following acute stress. Experimental Psychology, 67(2), 99-111. https://doi.org/10.1027/1618-3169/a000485

He, X., Stefan, M., Terranova, K., Steinglass, J., Marsh, R., 2016. Altered White Matter Microstructure in Adolescents and Adults with Bulimia Nervosa. Neuropsychopharmacology 41, 1841-1848. https://doi.org/10.1038/npp.2015.354

Hege, M.A., Stingl, K.T., Kullmann, S., Schag, K., Giel, K.E., Zipfel, S., Preissl, H., 2015. Attentional impulsivity in binge eating disorder modulates response inhibition performance and frontal brain networks. Int. J. Obes. 39, 353-360. https://doi.org/10.1038/ijo.2014.99

Herman, J.P., Figueiredo, H., Mueller, N.K., Ulrich-lai, Y., Ostrander, M.M., Choi, D.C., Cullinan, W.E., 2003. Central mechanisms of stress integration : hierarchical circuitry controlling hypothalamo - pituitary - adrenocortical responsiveness. Neuroendocrinology 24, 151-180. https://doi.org/10.1016/j.yfrne.2003.07.001

Hernádi, I., Grabenhorst, F., Schultz, W., 2015. Planning activity for internally generated reward goals in monkey amygdala neurons. Nat Neurosci. 18(3), 461-469. https://doi.org/10.1038/nn.3925

Herrmann, M.J., Tesar, A., Beier, J., Berg, M., Warrings, B., 2019. Grey matter alterations in obesity: A meta-analysis of whole-brain studies. Obes. Rev. 20, 464-471. https://doi.org/10.1111/obr.12799

Het, S., Vocks, S., Wolf, J.M., Hammelstein, P., Herpertz, S., Wolf, O.T., 2015a. Blunted neuroendocrine stress reactivity in young women with eating disorders. J. Psychosom. Res. 78, 260-267. https://doi.org/10.1016/j.jpsychores.2014.11.001 
1228

1229

1230

1231

1232

1233

1234

1235

1236

1237

1238

1239

1240

1241

1242

1243

1244

1245

1246

1247

1248

1249

1250

1251

1252

1253

1254

1255

1256

1257

1258

1259

1260

1261

1262

1263

1264

Het, S., Vocks, S., Wolf, J.M., Hammelstein, P., Herpertz, S., Wolf, O.T., 2015b. Blunted neuroendocrine stress reactivity in young women with eating disorders. J. Psychosom. Res. 78, 260-267. https://doi.org/10.1016/j.jpsychores.2014.11.001

Hilbert, A., Vögele, C., Tuschen-Caffier, B., Hartmann, A.S., 2011. Psychophysiological responses to idiosyncratic stress in bulimia nervosa and binge eating disorder. Physiol. Behav. 104, 770-777. https://doi.org/10.1016/j.physbeh.2011.07.013

Hudson, J.I., Hiripi, E., Pope, H.G., Kessler, R.C., 2007. The Prevalence and Correlates of Eating Disorders in the National Comorbidity Survey Replication. https://doi.org/10.1016/j.biopsych.2006.03.040

Hutson, P.H., Balodis, I.M., Potenza, M.N., 2018. Binge-eating disorder : Clinical and therapeutic advances. Pharmacol. Ther. 182, 15-27. https://doi.org/10.1016/j.pharmthera.2017.08.002

Johnson, C., Larson, R., 1982. Bulimia: An analysis of moods and behavior. Psychosom. Med. 44, 341-351. https://doi.org/10.1097/00006842-198209000-00003

Jones, J. L., Day, J. J., Aragona, B. J., Wheeler, R. A., Wightman, R. M., Carelli, R. M., 2010. Basolateral amygdala modulates terminal dopamine release in the nucleus accumbens and conditioned responding. Biol Psychiatry. 67(8), 737-744. https://doi.org/10.1016/j.biopsych.2009.11.006

Joos, A., Klöppel, S., Hartmann, A., Glauche, V., Tüscher, O., Perlov, E., Saum, B., Freyer, T., Zeeck, A., van Elst, L.T., 2010. Voxel-based morphometry in eating disorders: Correlation of psychopathology with grey matter volume. Psychiatry Res. - Neuroimaging 182, 146-151. https://doi.org/10.1016/j.pscychresns.2010.02.004

Kar, B.R., Nigam, R., Pammi, V.S.C., Guleria, A., Srinivasan, N., 2019. Neurocognitive mechanisms of affective conflict adaptation: An event related fMRI study. Prog. Brain Res. 247, 149-167. https://doi.org/10.1016/BS.PBR.2019.04.002

Kaye, W.H., Gwirtsman, H.E., George, D.T., Weiss, S.R., Jimerson, D.C., 1986. Relationship of mood alterations to bingeing behaviour in bulimia. Br. J. Psychiatry 149, 479-485. https://doi.org/10.1192/bjp.149.4.479

Kessler, R.C., Berglund, P.A., Chiu, W.T., Deitz, A.C., Hudson, J.I., Shahly, V., Aguilar-Gaxiola, S., Alonso, J., Angermeyer, M.C., Benjet, C., Bruffaerts, R., De Girolamo, G., De Graaf, R., Maria Haro, J., Kovess-Masfety, V., O’Neill, S., Posada-Villa, J., Sasu, C., Scott, K., Viana, M.C., Xavier, M., 2013. The prevalence and correlates of binge eating disorder in the World Health Organization World Mental Health Surveys. Biol. Psychiatry 73, 904-914. https://doi.org/10.1016/j.biopsych.2012.11.020

Kessler, R.M., Hutson, P.H., Herman, B.K., Potenza, M.N., 2016. The neurobiological basis of bingeeating disorder. Neurosci. Biobehav. Rev. https://doi.org/10.1016/j.neubiorev.2016.01.013

Kittel, R., Brauhardt, A., Hilbert, A., 2015. Cognitive and emotional functioning in binge-eating disorder: A systematic review. Int. J. Eat. Disord. https://doi.org/10.1002/eat.22419 
1265

1266

1267

1268

1269

1270

1271

1272

1273

1274

1275

1276

1277

1278

1279

1280

1281

1282

1283

1284

1285

1286

1287

1288

1289

1290

1291

1292

1293

1294

1295

1296

1297

1298

1299

1300

1301
Klatzkin, R.R., Gaffney, S., Cyrus, K., Bigus, E., Brownley, K.A., 2018. Stress-induced eating in women with binge-eating disorder and obesity. Biol. Psychol. 131, 96-106. https://doi.org/10.1016/j.biopsycho.2016.11.002

Koo-Loeb, J.H., Pedersen, C., Girdler, S.S., 1998. Blunted cardiovascular and catecholamine stress reactivity in women with bulimia nervosa. Psychiatry Res. 80, 13-27. https://doi.org/10.1016/S0165-1781(98)00057-2

Krantz, D.S., 1979. A naturalistic study of social influences on meal size among moderately obese and nonobese subjects. Psychosom. Med. 41, 19-27. https://doi.org/10.1097/00006842-19790200000003

Laessle, R.G., Schulz, S., 2009. Stress-Induced Laboratory Eating Behavior in Obese Women with Binge Eating Disorder 505-510. https://doi.org/10.1002/eat.20648

Laquitaine, S., Piron, C., Abellanas, D., Loewenstein, Y., Boraud, T., 2013. Complex population response of dorsal putamen neurons predicts the ability to learn. PLoS One 8, 1-13. https://doi.org/10.1371/journal.pone.0080683

Lavagnino, L., Arnone, D., Cao, B., Soares, J.C., Selvaraj, S., 2016. Inhibitory control in obesity and binge eating disorder: A systematic review and meta-analysis of neurocognitive and neuroimaging studies. Neurosci. Biobehav. Rev. 68, 714-726. https://doi.org/10.1016/j.neubiorev.2016.06.041

Lee, S., Ran Kim, K., Ku, J., Lee, J.H., Namkoong, K., Jung, Y.C., 2014. Resting-state synchrony between anterior cingulate cortex and precuneus relates to body shape concern in anorexia nervosa and bulimia nervosa. Psychiatry Res. - Neuroimaging 221, 43-48. https://doi.org/10.1016/j.pscychresns.2013.11.004

Lichtenberg, N.T., Pennington, Z.T., Holley, S.M., Greenfield, V.Y., Cepeda, X., Levine, M.S., Wassum, K.M., 2017. Basolateral Amygdala to Orbitofrontal Cortex Projections Enable CueTriggered Reward Expectations 37, 8374-8384. https://doi.org/10.1523/JNEUROSCI.048617.2017

Liefooghe, B., de Houwer, J., 2016. A functional approach for research on cognitive control: analysing cognitive control tasks and their effects in terms of operant conditioning. Int J Psychol., 51(1), 28-32. https://doi.org/10.1002/ijop.12179

Liu, X., Hairston, J., Schrier, M., Fan, J., 2011. Common and distinct networks underlying reward valence and processing stages: a meta-analysis of functional neuroimaging studies. Neurosci Biobehav Rev. 35(5), 1219-1236. https://doi.org/10.1016/j.neubiorev.2010.12.012

Lock, J., Garrett, A., Beenhakker, J., Reiss, A., 2011. Aberrant Brain Activation During a Response Inhibition Task in Adolescent Eating Disorder Subtypes. Am J Psychiatry 168, 55-64. https://doi.org/10.1038/jid.2014.371

Loxton, N.J., Tipman, R.J., 2017. Reward sensitivity and food addiction in women. Appetite 115, 2835. https://doi.org/10.1016/j.appet.2016.10.022 
1302

1303

1304

1305

1306

1307

1308

1309

1310

1311

1312

1313

1314

1315

1316

1317

1318

1319

1320

1321

1322

1323

1324

1325

1326

1327

1328

1329

1330

1331

1332

1333

1334

1335

1336

1337

1338

Lyu, Z., Jackson, T., 2016. Acute stressors reduce neural inhibition to food cues and increase eating among binge eating disorder symptomatic women. Front. Behav. Neurosci. 10, 1-11. https://doi.org/10.3389/fnbeh.2016.00188

Mahlberg, J., Seabrooke, T., Weidemann, G., Hogarth, L., Mitchell, C.J., Moustafa, A.A., 2019. Human appetitive Pavlovian-to-instrumental transfer: a goal-directed account. Psychol. Res. https://doi.org/10.1007/s00426-019-01266-3

Malvaez, M., Shieh, C., Murphy, M.D., Greenfield, V.Y., Wassum, K.M., 2019. Distinct corticalamygdala projections drive reward value encoding and retrieval. Nat. Neurosci. 22, 762-769. https://doi.org/10.1038/s41593-019-0374-7

Manasse, S.M., Goldstein, S.P., Wyckoff, E., Forman, E.M., Juarascio, A.S., Butryn, M.L., Ruocco, A.C., Nederkoorn, C., 2016. Slowing down and taking a second look: Inhibitory deficits associated with binge eating are not food-specific. Appetite 96, 555-559. https://doi.org/10.1016/j.appet.2015.10.025

Marle, H. J. F., Hermans, E. J., Qin, S., Fernández, G., 2009. From specificity to sensitivity: how acute stress affects amygdala processing of biologically salient stimuli. Biol Psychiatry. 66(7), 649655. https://doi.org/10.1016/j.biopsych.2009.05.014

Marsh, R., Horga, G., Wang, Z., Wang, P., Klahr, K., Berner, L.A., Walsh, B.T., Peterson, B.S., 2011. An fMRI Study of self-regulatory control and conflict resolution in adolescents with bulimia nervosa. Am J Psychiatry 168, 1210-1220.

Marsh, R., Stefan, M., Bansal, R., Hao, X., Walsh, B.T., Peterson, B.S., 2015. Anatomical characteristics of the cerebral surface in bulimia nervosa. Biol. Psychiatry 77, 616-623. https://doi.org/10.1016/j.biopsych.2013.07.017

Marsh, R., Steinglass, J.E., Gerber, A.J., O’Leary, K.G., Wang, Z., Murphy, D., Walsh, B.T., Peterson, B.S., 2009. Deficient activity in the neural systems that mediate self-regulatory control in bulimia nervosa. Arch Gen Psychiatry 66, 51-63. https://doi.org/doi:10.1001/archgenpsychiatry.2008.504

McRae, A.L., Saladin, M.E., Brady, K.T., Upadhyaya, H., Back, S.E., Timmerman, M.A., 2006. Strees reactivity: Biological and subjective responses to the cold pressor and Trier Social stressors. Hum. Psychopharmacol. 21, 377-385. https://doi.org/10.1002/hup.778

Mendonça-de-Souza, A.C.F., Souza, G.G.L., Vieira, A., Fischer, N.L., Souza, W.F., Rumjanek, V.M., Figueira, I., Mendlowicz, M.V., Volchan, E., 2007. Negative affect as a predisposing factor for cortisol release after an acute stress - the impact of unpleasant priming. The International Journal on the Biology of Stress, 10(4), 362-367. https://doi.org/10.1080/10253890701379999

Meredith, G.E., Baldo, B.A., Andrezjewski, M.E., Kelley, A.E., 2008. The structural basis for mapping behavior onto the ventral striatum and its subdivisions. Brain Struct Funct 213(1-2), 1727. https://doi.org/10.1007/s00429-008-0175-3

Messerli-Bürgy, N., Engesser, C., Lemmenmeier, E., Steptoe, A., Laederach-Hofmann, K., 2010. 
1339

1340

1341

1342

1343

1344

1345

1346

1347

1348

1349

1350

1351

1352

1353

1354

1355

1356

1357

1358

1359

1360

1361

1362

1363

1364

1365

1366

1367

1368

1369

1370

1371

1372

1373

1374

1375

Cardiovascular stress reactivity and recovery in bulimia nervosa and binge eating disorder. Int. J. Psychophysiol. 78, 163-168. https://doi.org/10.1016/j.ijpsycho.2010.07.005

Mettler, L.N., Shott, M.E., Pryor, T., Yang, T.T., Frank, G.K.W., 2013. White matter integrity is reduced in bulimia nervosa. Int. J. Eat. Disord. 46, 264-273. https://doi.org/10.1002/eat.22083

Meule, A., Küppers, C., Harms, L., Friederich, H.C., Schmidt, U., Blechert, J., Brockmeyer, T., 2018. Food cue-induced craving in individuals with bulimia nervosa and binge-eating disorder. PLoS One 13, 1-8. https://doi.org/10.1371/journal.pone.0204151

Miller, R., Plessow, F., Kirschbaum, C., Stalder, T., 2013. Classification criteria for distinguishing cortisol responders from nonresponders to psychosocial stress: evaluation of salivary cortisol pulse detection in panel designs. Psychosom. Med. 840, 832-840. https://doi.org/10.1097/PSY.0000000000000002

Mohr, H.M., Röder, C., Zimmermann, J., Hummel, D., Negele, A., Grabhorn, R., 2011. Body image distortions in bulimia nervosa: Investigating body size overestimation and body size satisfaction by fMRI. Neuroimage 56, 1822-1831. https://doi.org/10.1016/j.neuroimage.2011.02.069

Monteleone, A.M., Monteleone, P., Marciello, F., Pellegrino, F., Castellini, G., Maj, M., 2017. Differences in Cortisol Awakening Response between Binge- Purging and Restrictive Patients with Anorexia Nervosa. Eur. Eat. Disord. Rev. 25, 13-18. https://doi.org/10.1002/erv.2485

Monteleone, A.M., Patriciello, G., Ruzzi, V., Fico, G., Pellegrino, F., Castellini, G., Steardo, L., Monteleone, P., Maj, M., 2018. Insecure attachment and hypothalamus-pituitary-adrenal axis functioning in people with eating disorders. Psychosom. Med. 80, 710-716. https://doi.org/10.1097/PSY.0000000000000629

Monteleone, A.M., Ruzzi, V., Pellegrino, F., Patriciello, G., Cascino, G., Del Giorno, C., Monteleone, P., Maj, M., 2019. The vulnerability to interpersonal stress in eating disorders: The role of insecure attachment in the emotional and cortisol responses to the trier social stress test. Psychoneuroendocrinology 101, 278-285. https://doi.org/10.1016/j.psyneuen.2018.12.232

Monteleone, P., Maj, M., 2013. Dysfunctions of leptin, ghrelin , BDNF and endocannabinoids in eating disorders : Beyond the homeostatic control of food intake. Psychoneuroendocrinology 38, 312-330. https://doi.org/10.1016/j.psyneuen.2012.10.021

Monteleone, P., Tortorella, A., Scognamiglio, P., Serino, I., Monteleone, A.M., Maj, M., 2012. The acute salivary ghrelin response to a psychosocial stress is enhanced in symptomatic patients with bulimia nervosa: A pilot study. Neuropsychobiology 66, 230-236. https://doi.org/10.1159/000341877

Murialdo, G., Casu, M., Falchero, M., Brugnolo, A., Patrone, V., Cerro, P.F., Ameri, P., Andraghetti, G., Briatore, L., Copello, F., Cordera, R., Rodriguez, G., Ferro, A.M., 2007. Alterations in the autonomic control of heart rate variability in patients with anorexia or bulimia nervosa: Correlations between sympathovagal activity, clinical features, and leptin levels. J. Endocrinol. Invest. 30, 356-362. https://doi.org/10.1007/BF03346310 
1376

1377

1378

1379

1380

1381

1382

1383

1384

1385

1386

1387

1388

1389

1390

1391

1392

1393

1394

1395

1396

1397

1398

1399

1400

1401

1402

1403

1404

1405

1406

1407

1408

1409

1410

1411

1412

Naish, K.R., Laliberte, M., MacKillop, J., Balodis, I.M., 2018. Systematic review of the effects of acute stress in binge eating disorder. Eur. J. Neurosci. 1-15. https://doi.org/10.1111/ejn.14110

Nansel., T.R., Lipsky, L.M., Eisenberg, M.H., Haynie, D.L., Liu, D., Simons-Morton, B., 2016. Greater food reward sensitivity is associated with more frequent intake of discretionary foods in a nationally representative sample of young adults. Front. Nutr., 3, 33. https://doi.org/10.3389/fnut.2016.00033

Neveu, R., Neveu, D., Carrier, E., Gay, A., Nicolas, A., Coricelli, G., 2018. Goal Directed and SelfControl Systems in Bulimia Nervosa: An fMRI Study. EBioMedicine 34, 214-222. https://doi.org/10.1016/j.ebiom.2018.07.012

Noonan, M. P., Kolling, N., Walton, M. E., Rushworth, M. F. S., 2012. Re-evaluating the role of the orbitofrontal cortex in reward and reinforcement. Eur J Neurosci. 35(7), 997-1010. https://doi.org/10.1111/j.1460-9568.2012.08023.x

O’Doherty, J.P., Cockburn, J., Pauli, W.M., 2017. Learning, reward, and decision making. Annu. Rev. Psychol. 68, 73-100. https://doi.org/10.1146/annurev-psych-010416-044216

O'Doherty, J., Dayan, P., Schultz, J., Deichmann, R., Friston, K., Dolan, R. J., 2004. Dissociable roles of ventral and dorsal striatum in instrumental conditioning. Science. 304(5669), 452-454. https://doi.org/10.1126/science.1094285

Oberndorfer, T.A., Frank, G.K.W., Simmons, A.N., Wagner, A., McCurdy, D., Fudge, J.L., Yang, T.T., Paulus, M.P., Kaye, W.H., 2013. Altered insula response to sweet taste processing after recovery from anorexia and bulimia nervosa. Am. J. Psychiatry 170, 1143-1151. https://doi.org/10.1176/appi.ajp.2013.11111745

Oliva, R., Morys, F., Horstmann, A., Castiello, U., Begliomini, C., 2020. Characterizing impulsivity and resting-state functionalconnectivity in normal-weight binge eaters. Int. J. Eat. Disord., 53(3), 478-488. https://doi.org/10.1002/eat.23212

O'Reilly, J. X., Croxson, P. L., Jbabdi, S., Sallet, J., Noonan, M. P., Mars, R. B., Browning, P. G. F., Wilson, C. R. E., Mitchell, A. S., Miller, K. L., Rushworth, M. F. S., Baxter, M. G., 2013. Causal effect of disconnection lesions on interhemispheric functional connectivity in rhesus monkeys. Proc Natl Acad Sci U S A. 110(34), 13982-13987. https://doi.org/10.1073/pnas.1305062110

Parkes, S. L., Balleine, B. W., 2013. Incentive Memory: Evidence the Basolateral Amygdala Encodes and the Insular Cortex Retrieves Outcome Values to Guide Choice between Goal-Directed Actions. J Neurosci. 33(20), 8753-8763. https://doi.org/10.1523/JNEUROSCI.5071-12.2013

Patel, R.S., Olten, B., Patel, P., Shah, K., Mansuri, Z., 2018. Hospitalization Outcomes and Comorbidities of Bulimia Nervosa : A Nationwide Inpatient Study Data source. Cureus 10, e2583. https://doi.org/10.7759/cureus.2583

Peschel, S.K.V., Feeling, N.R., Vögele, C., Kaess, M., Thayer, J.F., Koenig, J., 2016. A systematic review on heart rate variability in Bulimia Nervosa. Neurosci. Biobehav. Rev. 63, 78-97. https://doi.org/10.1016/j.neubiorev.2016.01.012 
1413

1414

1415

1416

1417

1418

1419

1420

1421

1422

1423

1424

1425

1426

1427

1428

1429

1430

1431

1432

1433

1434

1435

1436

1437

1438

1439

1440

1441

1442

1443

1444

1445

1446

1447

1448

1449

Postuma, R.B., Dagher, A., 2006. Basal ganglia functional connectivity based on a meta-analysis of 126 positron emission tomography and functional magnetic resonance imaging publications. Cereb. Cortex 16, 1508-1521. https://doi.org/10.1093/cercor/bhj088

Quaedflieg, C.W.E.M., Meyer, T., van Ruitenbeek, P., Smeets, T., 2017. Examining habituation and sensitization across repetitive laboratory stress inductions using the MAST.

Psychoneuroendocrinology 77, 175-181. https://doi.org/10.1016/j.psyneuen.2016.12.009

Quaedflieg, C.W.E.M., Stoffregen, H., Sebalo, I., Smeets, T., 2019. Stress-induced impairment in goal-directed instrumental behaviour is moderated by baseline working memory. Neurobiol. Learn. Mem. 158, 42-49. https://doi.org/10.1016/j.nlm.2019.01.010

Racine, S.E., Martin, S.J. 2017. Integrating eating disorder-specific risk factors into the acquired preparedness model of dysregulated eating: A moderated mediation analysis. Eat Behav. 24, 5460. https://doi.org/10.1016/j.eatbeh.2016.12.007

Razzoli, M., Pearson, C., Crow, S., Bartolomucci, A., 2016. Stress, overeating and obesity: insights from human studies. Neurosci Biobehav Rev. 20, 412-426. https://doi.org/10.1016/j.neubiorev.2017.01.026

Ridderinkhof, K.R., van den Wildenberg, W.P.M., Segalowitz, S.J., Carter, C.S., 2004. Neurocognitive mechanisms of cognitive control: The role of prefrontal cortex in action selection, response inhibition, performance monitoring, and reward-based learning. Brain Cogn. 56, 129-140. https://doi.org/10.1016/J.BANDC.2004.09.016

Robinson, T.E., Berridge, K.C., 1993. The neural basis of drug craving: An incentive-sensitization theory of addiction. Brain Res. Rev. 18, 247-291. https://doi.org/10.1016/0165-0173(93)90013-P

Roefs, A., Franssen, S., Jansen, A., 2018. The dynamic nature of food reward processing in the brain. Curr Opin Clin Nutr Metab Care. 21(6), 444-448. https://doi.org/10.1097/MCO.0000000000000504

Rogers, P.J., 2017. Food and drug addictions: Similarities and differences. Pharmacol. Biochem. Behav. https://doi.org/10.1016/j.pbb.2017.01.001

Rogers, P.J., Hardman, C.A., 2015. Food reward. What it is and how to measure it. Appetite 90, 1-15. https://doi.org/10.1016/j.appet.2015.02.032

Rojo, L., Conesa, L., Bermudez, O., Livianos, L., 2006. Influence of stress in the onset of eating disorders: Data from a two-stage epidemiologic controlled study. Psychosom. Med. 68, 628-635. https://doi.org/10.1097/01.psy.0000227749.58726.41

Rolls, E. T., 2016. Functions of the anterior insula in taste, autonomic, and related functions. Brain Cogn. 110, 4-19. https://doi.org/10.1016/j.bandc.2015.07.002

Rolls, E.T., 2019. The cingulate cortex and limbic systems for emotion, action, and memory. Brain Struct. Funct. 224, 3001-3018. https://doi.org/10.1007/s00429-019-01945-2

Rosenberg, N., Bloch, M., Ben Avi, I., Rouach, V., Schreiber, S., Stern, N., Greenman, Y., 2013. Cortisol response and desire to binge following psychological stress: Comparison between obese 
1450

1451

1452

1453

1454

1455

1456

1457

1458

1459

1460

1461

1462

1463

1464

1465

1466

1467

1468

1469

1470

1471

1472

1473

1474

1475

1476

1477

1478

1479

1480

1481

1482

1483

1484

1485

1486

subjects with and without binge eating disorder. Psychiatry Res. 208, 156-161.

https://doi.org/10.1016/j.psychres.2012.09.050

Rosval, L., 2006. Impulsivity in ED: problem of response inhibition, planning, or attention. Ijed 32, 66-70. https://doi.org/10.1002/eat

Salvy, S.J., Coelho, J.S., Kieffer, E., Epstein, L.H., 2007. Effects of social contexts on overweight and normal-weight children's food intake. Physiol. Behav. 92, 840-846. https://doi.org/10.1016/j.physbeh.2007.06.014

Salzman, C.D., Fusi, S., 2010. Emotion, Cognition, and Mental State Representation in Amygdala and Prefrontal Cortex. Annu. Rev. Neurosci. 33, 173-202. https://doi.org/10.1146/annurev.neuro.051508.135256

Schäfer, A., Vaitl, D., Schienle, A., 2010. Regional grey matter volume abnormalities in bulimia nervosa and binge-eating disorder. Neuroimage 50, 639-643. https://doi.org/10.1016/j.neuroimage.2009.12.063

Schag, K., Teufel, M., Junne, F., Preissl, H., Hautzinger, M., Zipfel, S., Giel, K.E., 2013. Impulsivity in Binge Eating Disorder: Food Cues Elicit Increased Reward Responses and Disinhibition. PLoS One 8, 4-11. https://doi.org/10.1371/journal.pone.0076542

Schepers, R., Markus, C.R., 2015. Gene x cognition interaction on stress-induced eating: Effect of rumination. Biol. Psychol., 54, 41-53. https://doi.org/10.1016/j.psyneuen.2015.01.013

Schienle, A., Schäfer, A., Hermann, A., Vaitl, D., 2009. Binge-Eating Disorder: Reward Sensitivity and Brain Activation to Images of Food. Biol. Psychiatry 65, 654-661. https://doi.org/10.1016/j.biopsych.2008.09.028

Schulz, S., Laessle, R.G., 2012. Stress-induced laboratory eating behavior in obese women with binge eating disorder. Appetite 58, 457-461. https://doi.org/10.1016/j.appet.2011.12.007

Schwabe, L., Haddad, L., Schachinger, H., 2008. HPA axis activation by a socially evaluated coldpressor test. Psychoneuroendocrinology 33, 890-895. https://doi.org/10.1016/j.psyneuen.2008.03.001

Schwabe, L., Tegenthoff, M., Hoffken, O., Wolf, O.T., 2012. Simultaneous Glucocorticoid and Noradrenergic Activity Disrupts the Neural Basis of Goal-Directed Action in the Human Brain. J. Neurosci. 32, 10146-10155. https://doi.org/10.1523/JNEUROSCI.1304-12.2012

Schwabe, L., Wolf, O.T., 2010. Socially evaluated cold pressor stress after instrumental learning favors habits over goal-directed action. Psychoneuroendocrinology 35, 977-986. https://doi.org/10.1016/j.psyneuen.2009.12.010

Schwabe, L., Wolf, O.T., 2009. Stress prompts habit behavior in humans. J. Neurosci. 29, 7191-7198. https://doi.org/10.1523/JNEUROSCI.0979-09.2009

Seghier, M. L., 2013. The angular gyrus: Multiple functions and multiple subdivisions. Neuroscientist. 19(1), 43-61. https://doi.org/ 10.1177/1073858412440596

Sescousse, G., Redouté, J., Dreher, J.C., 2010. The architecture of reward value coding in the human 
1487

1488

1489

1490

1491

1492

1493

1494

1495

1496

1497

1498

1499

1500

1501

1502

1503

1504

1505

1506

1507

1508

1509

1510

1511

1512

1513

1514

1515

1516

1517

1518

1519

1520

1521

1522

orbitofrontal cortex. J. Neurosci. 30, 13095-13104. https://doi.org/10.1523/JNEUROSCI.350110.2010

Setogawa, T., Mizuhiki, T., Matsumoto, N., Akizawa, F., Kuboki, R., Richmond, B.J., Shidara, M., 2019. Neurons in the monkey orbitofrontal cortex mediate reward value computation and decision-making. Commun. Biol. 2, 1-9. https://doi.org/10.1038/s42003-019-0363-0

Shiflett, M. W., Balleine, B. W., 2010. At the limbic-motor interface: Disconnection of basolateral amygdala from nucleus accumbens core and shell reveals dissociable components of incentive motivation. Eur J Neurosci. 32(10), 1735-1743. https://doi.org/10.1111/j.14609568.2010.07439.x

Shilton, A.L., Laycock, R., Crewther, S.G., 2017. The Maastricht Acute Stress Test (MAST): physiological and subjective responses in anticipation, and post-stress 8,567 . https://doi.org/10.3389/fpsyg.2017.00567

Simon, J.J., Skunde, M., Walther, S., Bendszus, M., Herzog, W., Friederich, H.C., 2016. Neural signature of food reward processing in bulimic-type eating disorders. Soc. Cogn. Affect. Neurosci. 11, 1393-1401. https://doi.org/10.1093/scan/nsw049

Sinha, R., 2018. Role of addiction and stress neurobiology on food intake and obesity. Biol. Psychol. 131, 5-13. https://doi.org/10.1016/j.biopsycho.2017.05.001

Sinha, R., Lacadie, C.M., Constable, R.T., Seo, D., 2016. Dynamic neural activity during stress signals resilient coping. Proc. Natl. Acad. Sci. U. S. A. 113, 8837-8842. https://doi.org/10.1073/pnas.1600965113

Smeets, T., Cornelisse, S., Quaedflieg, C.W.E.M., Meyer, T., Jelicic, M., Merckelbach, H., 2012. Introducing the Maastricht Acute Stress Test (MAST): a quick and non-invasive approach to elicit robust autonomic and glucocorticoid stress responses. Psychoneuroendocrinology 37, 1998-2008. https://doi.org/10.1016/j.psyneuen.2012.04.012

Smeets, T., van Ruitenbeek, P., Hartogsveld, B., Quaedflieg, C.W.E.M., 2019. Stress-induced reliance on habitual behavior is moderated by cortisol reactivity. Brain Cogn. 133, 60-71. https://doi.org/10.1016/j.bandc.2018.05.005

Smink, F. R., van Hoeken, D., \& Hoek, H. W., 2012. Epidemiology of eating disorders: incidence, prevalence and mortality rates. Curr. Psychiatry. Rep., 14(4), 406-14. https://doi.org/10.1007/s11920-012-0282-y

Smith, K.E., Mason, T.B., Johnson, J.S., Lavender, J.M., Wonderlich, S.A., 2018. A systematic review of reviews of neurocognitive functioning in eating disorders : The state-of-the-literature and future directions 798-821. https://doi.org/10.1002/eat.22929

Solowij, N., Zalesky, A., Lorenzetti, V., Yücel, M., 2017. Chronic cannabis use and axonal fiber connectivity. Handbook of Cannabis and Related Pathologies, 391-400. https://doi.org/10.1016/B978-0-12-800756-3.00046-6 
1523

1524

1525

1526

1527

1528

1529

1530

1531

1532

1533

1534

1535

1536

1537

1538

1539

1540

1541

1542

1543

1544

1545

1546

1547

1548

1549

1550

1551

1552

1553

1554

1555

1556

1557

1558

1559
Sominsky, L., Spencer, S. J., 2014. Eating behavior and stress: a pathway to obesity. Front Psychol. 5, 434. https://doi.org/10.3389/fpsyg.2014.00434

Spalatro, A. V., Amianto, F., Huang, Z., D’Agata, F., Bergui, M., Abbate Daga, G., Fassino, S., Northoff, G., 2019. Neuronal variability of Resting State activity in Eating Disorders: increase and decoupling in Ventral Attention Network and relation with clinical symptoms. Eur. Psychiatry 55, 10-17. https://doi.org/10.1016/j.eurpsy.2018.08.005

Stalnaker, T.A., Liu, T.L., Takahashi, Y.K., Schoenbaum, G., 2018. Orbitofrontal neurons signal reward predictions, not reward prediction errors. Neurobiol. Learn. Mem. 153, 137-143. https://doi.org/10.1016/j.nlm.2018.01.013

Stern, S., A., Azevedo, E. P., Pomeranz, L. E., Doerig, K. R., Ivan, V. J., Friedman, J. M., 2021. Topdown control of conditioned overconsumption is mediated by insular cortex Nos 1 neurons. Cell Metab. 33(7), 1418-1432. https://doi.org/10.1016/j.cmet.2021.03.001

Stice, E., Agras, W.S., Telch, C.F., Halmi, K.A., Mitchell, J.E., Wilson, T., 2001. Subtyping binge eating-disordered women along dieting and negative affect dimensions. Int. J. Eat. Disord. 30, 11-27. https://doi.org/10.1002/eat.1050

Stice, E., Marti, C.N., Rohde, P., 2013. Prevalence, incidence, impairment, and course of the proposed DSM-5 eating disorder diagnoses in an 8-year prospective community study of young women. $\mathrm{J}$ Abnorm Psychol 122(2), 445-457. https://doi.org/10.1037/a0030679

Stopyra, M.A., Simon, J.J., Skunde, M., Walther, S., Bendszus, M., Herzog, W., Friederich, H.C., 2019. Altered functional connectivity in binge eating disorder and bulimia nervosa: A restingstate fMRI study. Brain Behav. e01207. https://doi.org/10.1002/brb3.1207

Striegel-Moore, R.H., Dohm, F.A., Kraemer, H.C., Schreiber, G.B., Taylor, C.B., Daniels, S.R., 2007. Risk Factors for Binge-Eating Disorders: An Exploratory Study. Int J Eat Disord 40, 481-487. https://doi.org/10.1002/eat

Svaldi, J., Brand, M., Tuschen-Caffier, B., 2010. Decision-making impairments in women with binge eating disorder. Appetite 54, 84-92. https://doi.org/10.1016/j.appet.2009.09.010

Svaldi, J., Naumann, E., Trentowska, M., Schmitz, F., 2014. General and food-specific inhibitory deficits in binge eating disorder. Int. J. Eat. Disord. 47, 534-542. https://doi.org/10.1002/eat.22260

Symmonds, M., Emmanuel, J. J., Drew, M. E., Batterham, R. L., Dolan, R. J., 2010. Metabolic state alters economic decision making under risk in humans. PLoS One. 5(6), e11090. https://doi.org/10.1371/journal.pone.0011090

Tricomi, E., Lempert, K. M., 2015. Value and probability coding in a feedback-based learning task utilizing food rewards. J Neurophysiol. 113(1), 4-13. https://doi.org/10.1152/jn.00086.2014

Troop, N.A., Holbrey, A., Treasure, J.L., 1998. Stress, coping, and crisis support in eating disorders. Int. J. Eat. Disord. 24, 157-166. https://doi.org/10.1002/(SICI)1098108X(199809)24:2<157::AID-EAT5>3.0.CO;2-D 
1560

1561

1562

1563

1564

1565

1566

1567

1568

1569

1570

1571

1572

1573

1574

1575

1576

1577

1578

1579

1580

1581

1582

1583

1584

1585

1586

1587

1588

1589

1590

1591

1592

1593

1594

1595

1596

Uddin, L.Q., Nomi, J.S., Hébert-Seropian, B., Ghaziri, J., Boucher, O., 2017. Structure and Function of the Human Insula. J. Clin. Neurophysiol. 34, 300-306. https://doi.org/10.1097/WNP.0000000000000377

Ulrich-Lai, Y.M., Herman, J.P., 2009. Neural regulation of endocrine and autonomic stress responses. Nat. Rev. Neurosci. 10, 397-409. https://doi.org/10.1038/nrn2647

Vainik, U., García-García, I., Dagher, A., 2019. Uncontrolled eating : a unifying heritable trait linked with obesity, overeating, personality and the brain. Eur. J. Neurosci. 50, 2430-2445. https://doi.org/10.1111/ejn.14352

Val-Laillet, D., Aarts, E., Weber, B., Ferrari, M., Quaresima, V., Stoeckel, L.E., Alonso-Alonso, M., Audette, M., Malbert, C.H., Stice, E., 2015. Neuroimaging and neuromodulation approaches to study eating behavior and prevent and treat eating disorders and obesity. NeuroImage Clin. 8, 131. https://doi.org/10.1016/j.nicl.2015.03.016

van den Akker, K., Schyns, G., Jansen, A., 2018. Learned Overeating: Applying Principles of Pavlovian Conditioning to Explain and Treat Overeating. Curr. Addict. Reports 5, 223-231. https://doi.org/10.1007/s40429-018-0207-x

van den Eynde, F., Suda, M., Broadbent, H., Guillaume, S., Van Den Eynde, M., Steiger, H., Israel, M., Berlim, M., Giampietro, V., Simmons, A., Treasure, J., Campbell, I., Schmidt, U., 2012. Structural magnetic resonance imaging in eating disorders: A systematic review of voxel-based morphometry studies. Eur. Eat. Disord. Rev. 20, 94-105. https://doi.org/10.1002/erv.1163

van Ruitenbeek, P., Quaedflieg, C.W.E.M., Hernaus, D., Hartogsveld, B., Smeets, T., 2021.

Dopaminergic and noradrenergic modulation of stress-induced alterations in brain activation associated with goal-directed behaviour. J Psychopharmacol. 2698811211044679. https://doi.org/10.1177/02698811211044679

Vannucci, A., Nelson, E.E., Bongiorno, D.M., Pine, D.S., Yanovski, J.A., Tanofsky-Kraff, M., 2015. Behavioral and neurodevelopmental precursors to binge-type eating disorders: Support for the role of negative valence systems. Psychol. Med. 45, 2921-2936. https://doi.org/10.1017/S003329171500104X

Vaz-Leal, F.J., Ramos-Fuentes, M.I., Rodríguez-Santos, L., Chimpén-López, C., Fernández-Sánchez, N., Zamora-Rodríguez, F.J., Beato-Fernández, L., Rojo-Moreno, L., Guisado-Macías, J.A., 2018. Blunted cortisol response to stress in patients with eating disorders: Its association to bulimic features. Eur. Eat. Disord. Rev. 26, 207-216. https://doi.org/10.1002/erv.2581

Voon, V., Derbyshire, K., Rück, C., Irvine, M.A., Worbe, Y., Enander, J., Schreiber, L.R.N., Gillan, C., Fineberg, N.A., Sahakian, B.J., Robbins, T.W., Harrison, N.A., Wood, J., Daw, N.D., Dayan, P., Grant, J.E., Bullmore, E.T., 2015. Disorders of compulsivity: a common bias towards learning habits. Mol. Psychiatry 20, 345-352. https://doi.org/10.1038/mp.2014.44

Voon, V., Reiter, A., Sebold, M., Groman, S., 2017. Model-Based Control in Dimensional Psychiatry. Biol. Psychiatry. https://doi.org/10.1016/j.biopsych.2017.04.006 
1597

1598

1599

1600

1601

1602

1603

1604

1605

1606

1607

1608

1609

1610

1611

1612

1613

1614

1615

1616

1617

1618

1619

1620

1621

1622

1623

1624

1625

1626

1627

1628

1629

1630

1631

1632

1633

Wagner, A., Greer, P., Bailer, U.F., Frank, G.K., Henry, S.E., Putnam, K., Meltzer, C.C., Ziolko, S.K., Hoge, J., McConaha, C., Kaye, W.H., 2006. Normal brain tissue volumes after long-term recovery in anorexia and bulimia nervosa. Biol. Psychiatry 59, 291-293. https://doi.org/10.1016/j.biopsych.2005.06.014

Wallace, G.L., Richard, E., Peng, C.S., Knodt, A.R., Hariri, A.R., 2020. Subclinical eating disorder traits are correlated with cortical thickness in regions associated with food reward and perception. Brain Imaging Behav. https://doi.org/10.1007/s11682-018-0007-x

Wallis, J. D., Kennerley, S. W., 2011. Contrasting reward signals in the orbitofrontal cortex and anterior cingulate cortex. Ann N Y Acad Sci. 1239, 33-42. https://doi.org/10.1111/j.1749$6632.2011 .06277 . \mathrm{x}$

Wang, L., Bi, K., An, J., Li, M., Li, K., Kong, Q.M., Li, X.N., Lu, Q., Si, T.M., 2019. Abnormal structural brain network and hemisphere-specific changes in bulimia nervosa. Transl. Psychiatry, 9(1), 206. https://doi.org/10.1038/s41398-019-0543-1

Wang, L., Bi, K., Song, Z., Zhang, Z., Li, K., Kong, Q.M., Li, X.N., Lu, Q., Si, T.M., 2020. Disturbed Resting-State Whole-Brain Functional Connectivity of Striatal Subregions in Bulimia Nervosa. Int. J. Neuropscychopharmacol., 23(6), 356-365. https://doi.org/10.1093/ijnp/pyaa023.

Wang, G.J., Geliebter, A., Volkow, N.D., Telang, F.W., Logan, J., Jayne, M.C., Galanti, K., Selig, P.A., Han, H., Zhu, W., Wong, C.T., Fowler, J.S., 2011. Enhanced striatal dopamine release during food stimulation in binge eating disorder. Obesity 19, 1601-1608. https://doi.org/10.1038/oby.2011.27

Wang, K. S., Smith, D. V., Delgado, M. R., 2016. Using fMRI to study reward processing in humans: past, present, and future. J Neurophysiol. 115(3), 1664-1678. https://doi.org/10.1152/jn.00333.2015

Wassum, K. M., Izquierdo, A., 2015. The basolateral amygdala in reward learning and addiction. Neurosci Biobehav Rev. 57, 271-283. https://doi.org/10.1016/j.neubiorev.2015.08.017

Watson, P., de Wit, S., 2018. Current limits of experimental research into habits and future directions. Curr. Opin. Behav. Sci. 20, 33-39. https://doi.org/10.1016/j.cobeha.2017.09.012

Watson, P., van Wingen, G., de Wit, S., 2018. Conflicted between goal-directed and habitual control an fMRI investigation. eNeuro 5, 1-11. https://doi.org/10.1523/ENEURO.0240-18.2018

Watson, P., Wiers, R. W., Hommel, B., \& De Wit, S. (2014). Working for food you don't desire. Cues interfere with goal-directed food-seeking. Appetite, 79, 139-148. https://doi.org/10.1016/j.appet.2014.04.005

Watson, P., Wiers, R. W., Hommel, B., Gerdes, V. E. A., \& de Wit, S. (2017). Stimulus control over action for food in obese versus healthy-weight individuals. Frontiers in Psychology, 8(APR), 113. https://doi.org/10.3389/fpsyg.2017.00580

Waxman, S.E., 2009. A systematic review of impulsivity in eating disorders. Eur. Eat. Disord. Rev. 17, 408-425. https://doi.org/10.1002/erv.952 
1634

1635

1636

1637

1638

1639

1640

1641

1642

1643

1644

1645

1646

1647

1648

1649

1650

1651

1652

1653

1654

1655

1656

1657

1658

1659

1660

1661

1662

1663

1664

1665

1666

1667

1668

1669

1670

Wellman, X.C.L., Bangasser, D.A., Bollinger, J.L., Coutellier, X.L., Logrip, X.M.L., Moench, X.K.M., Urban, X.K.R., 2018. Sex Differences in Risk and Resilience : Stress Effects on the Neural Substrates of Emotion and Motivation 38, 9423-9432. https://doi.org/10.1523/JNEUROSCI.1673-18.2018

Wemm, S.E., Wulfert, E., 2017. Effects of acute stress on decision making. Appl Psychophysiol Biofeedback, 42(1), 1-12. https://doi.org/10.1007/s10484-016-9347-8

Westwater, M.L., Seidlitz, J., Diederen, K.M.J., Fischer, S., Thompson, J.C. 2018. Associations between cortical thickness, structural connectivity and severity of dimensional bulimia nervosa symptomatology. Psych Res: Neuroimaging, 271, 118-225. https://doi.org/10.1016/j.psychresns.2017.11.006

Weygandt, M., Schaefer, A., Schienle, A., Haynes, J.D., 2012. Diagnosing different binge-eating disorders based on reward-related brain activation patterns. Hum. Brain Mapp. 33, 2135-2146. https://doi.org/10.1002/hbm.21345

Wierenga, C.E., Lavender, J.M., Hays, C.C., 2018. The potential of calibrated fMRI in the understanding of stress in eating disorders. Neurobiol. Stress 9, 64-73. https://doi.org/10.1016/j.ynstr.2018.08.006

Wirz, L., Bogdanov, M., Schwabe, L., 2018. Habits under stress: mechanistic insights across different types of learning. Curr. Opin. Behav. Sci. 20, 9-16. https://doi.org/10.1016/j.cobeha.2017.08.009

Wolters, A.F., van de Weijer, S.C.F., Leentjes, A.F.G., Duits, A.A., Jacobs, H.I.L., Kuijf, M.L. 2019. Resting-state fMRI in Parkinson's disease patients with cognitive impairment: a meta-analysis. Parkinsonism Relat Disord., 62, 16-27. https://doi.org/10.1016/j.parkreldis.2018.12.016

Wonderlich, J.A., Breithaupt, L., Thompson, J.C., Crosby, R.D., Engel, S.G., Fischer, S., 2018. The impact of neural responses to food cues following stress on trajectories of negative and positive affect and binge eating in daily life. J. Psychiatr. Res. 102, 14-22. https://doi.org/10.1016/j.jpsychires.2018.03.005

Wu, M., Brockmeyer, T., Hartmann, M., Skunde, M., Herzog, W., Friederich, H.C., 2016. Rewardrelated decision making in eating and weight disorders: A systematic review and meta-analysis of the evidence from neuropsychological studies. Neurosci. Biobehav. Rev. 61, 177-196. https://doi.org/10.1016/j.neubiorev.2015.11.017

Wu, M., Brockmeyer, T., Hartmann, M., Skunde, M., Herzog, W., Friederich, H.C., 2014. Set-shifting ability across the spectrum of eating disorders and in overweight and obesity: A systematic review and meta-analysis. Psychol. Med. 44, 3365-3385. https://doi.org/10.1017/S0033291714000294

Wunderlich, K., Dayan, P., Dolan, R.J., 2012. Mapping value based planning and extensively trained choice in the human brain 15, 786-791. https://doi.org/10.1038/nn.3068.Mapping

Yan, C., Su, L., Wang, Y., Xu, T., Yin, D.Z., Fan, M.X., Deng, C.P., Hu, Y., Wang, Z.X., Cheung, E.F.C., Lim, K.O., Chan, R.C.K., 2016. Multivariate Neural Representations of Value during 
1671 Reward Anticipation and Consummation in the Human Orbitofrontal Cortex. Sci. Rep. 6, 1-12.

1672 https://doi.org/10.1038/srep29079

1673 Zhang, X., Ge, T. T., Yin, G., Cui, R., Zhao, G., Yang, W., 2018. Stress-induced functional alterations

1674 in amygdala: implications for neuropsychiatric diseases. Front Neurosci. 12, 367.

1675 https://doi.org/10.3389/fnins.2018.00367

1676 Zhang-Molina, C., Schmit, M. B., Cai, H., 2020. Neural Circuit Mechanism Underlying the Feeding

1677 Controlled by Insula-Central Amygdala Pathway. iScience. 23(4), 101033.

1678 https://doi.org/10.1016/j.isci.2020.101033

1679 


\section{Figure captions}

\section{Figure 1. Differences in activity in bulimia nervosa (BN) and binge eating disorder (BED) in} passive food viewing tasks and active food tasting tasks compared with matched controls. For each area, the bar graph indicates the number of studies that found a decrease in activity (= red), or an increase in activity (= green), and the studies that found no difference in activity (= gray), during passive food viewing tasks (i.e., studies using paradigms where participants had to merely view food stimuli; shown in the two images on top) and active food tasting tasks (i.e., studies where participants had to actively taste food in the scanner; represented in the two images at the bottom). All of the included studies found at least one brain area that was significantly different in activation in $\mathrm{BN}$ and/or BED compared with HC. Abbreviations are as follows: $\mathrm{PCC}=$ posterior cingulate cortex, $\mathrm{ACC}=$ anterior cingulate cortex, ventr. striatum $=$ ventral striatum, med. $\mathrm{OFC}=$ medial orbitofrontal cortex, ant. med. PFC $=$ anterior medial prefrontal cortex, ang. gyr. angular gyrus. If no indication of lateralization is given (either left or right), differences are observed bilaterally.

\section{Figure 2. Differences in activity in bulimia nervosa (BN) and binge eating disorder (BED) in} cognitive control tasks compared with matched controls. For each area, the bar graph indicates the number of studies that found a decrease in activity (= red), or an increase in activity (= green), and the studies that found no difference in activity (= gray), during cognitive control tasks. All of the included studies found at least one brain area that was significantly different in activation in $\mathrm{BN}$ and/or BED compared with HC. Abbreviations are as follows: med. front. gyr. = medial frontal gyrus, $\mathrm{PCC}=$ posterior cingulate cortex, $\mathrm{ACC}=$ anterior cingulate cortex, $\mathrm{IFG}=$ inferior frontal gyrus, sup. front. gyr. $=$ superior frontal gyrus, $\mathrm{dlPFC}=$ dorsolateral prefrontal cortex, med PFC $=$ medial prefrontal cortex, temp. gyr. $=$ temporal gyrus, lingual gyr. = lingual gyrus, occ. gyr. $=$ occipital gyrus. If no indication of lateralization is given (either left or right), differences are observed bilaterally. 
1706

1707

1708

1709

1710

1711

1712

1713

1714

1715

1716

1717

1718

1719

1720

1721

1722

1723

1724

1725

1726

1727

1728

1729

1730

1731

Figure 3. Differences in activity in bulimia nervosa (BN) and binge eating disorder (BED) under acute stress / negative affect, using passive food viewing tasks, compared with matched controls. For each area, the bar graph indicates the number of studies that found a decrease in activity (= red), or an increase in activity (= green), and the studies that found no difference in activity (= gray), during passive food viewing tasks under acute stress. All of the included studies found at least one brain area that was significantly different in activation in BN and/or BED compared with HC. Abbreviations are as follows: $\mathrm{vmPFC}=$ ventromedial prefrontal cortex, amyg. $=$ amygdala, ant. vermis $=$ anterior vermis of cerebellum, $\mathrm{ACC}=$ anterior cingulate cortex, paracing. $=$ paracingulate gyrus, $\mathrm{IFG}=$ inferior frontal gyrus. If no indication of lateralization is given (either left or right), differences are observed bilaterally.

\section{Figure 4. Volumetric differences in bulimia nervosa (BN) and binge eating disorder (BED)} compared with matched controls. For each area, the bar graph indicates the number of studies that found a reduction in volume (= red), or an increase in volume (= green), and the studies that found no difference in activity (= gray). For BN, 10 of the 14 included studies found at least one brain area that was significantly different compared with HC. Four studies did not find any significant differences between $\mathrm{BN}$ and $\mathrm{HC}$. Abbreviations are as follows: caudate $=$ caudate nucleus, $\mathrm{OFC}=$ orbitofrontal cortex, sup. par. $=$ superior parietal cortex, $\mathrm{IFG}=$ inferior frontal gyrus, ventr. striatum $=$ ventral striatum, $\mathrm{ACC}=$ anterior cingulate cortex. If no indication of lateralization is given (either left or right), differences are observed bilateral. For the left part (BN) of this figure only, areas with one study indicating differences are not displayed, due to the large number of areas found in BN. For the right part (BED) all studies are displayed. For a full overview for differences in BN, please see Table 2.

\section{Figure 5. Summary of quality assessment performed for all included MR studies (related to the} three cognitive constructs, volumetric, or connectivity). The studies were evaluated by two independent raters, based on 12 criteria (see Quality assessment). Each criterion was scored with 1 
1732 point $(+), 0.5$ point $( \pm)$ or 0 points (-). The corrected average score ((total points/number of applicable

1733 criteria*10)/2) is presented in this figure, with yellow indicating a rating of 'fair' (<7.5) and green a

1734 rating of 'good' $(>=7.5)$.

1735

1736 
1737

\begin{tabular}{|c|c|c|c|c|c|c|c|c|}
\hline Study & Subjects & $\begin{array}{l}\text { Gender } \\
\left(+/ \delta^{\wedge}\right)\end{array}$ & $\begin{array}{l}\text { Age } \\
\overline{\mathrm{X}}(S D)\end{array}$ & $\begin{array}{l}\text { BMI } \\
\overline{\mathrm{X}}(S D)\end{array}$ & Diagnosis & Task & Methods & Findings \\
\hline \multicolumn{9}{|c|}{ REWARD SENSITIVITY } \\
\hline \multicolumn{9}{|l|}{$B N$} \\
\hline \multirow[t]{2}{*}{$\begin{array}{l}\text { Oberndorfer, } \\
\text { Frank, Simmons } \\
\text { et al. }(2013)^{\mathrm{f}}\end{array}$} & $\begin{array}{l}\mathrm{BN} \\
\text { recovered } \\
(14)\end{array}$ & $14 / 0$ & $26.6(5.7)$ & $22.9(2.1)$ & $\begin{array}{l}\text { SCID DSM- } \\
\text { IV-TR }\end{array}$ & $\begin{array}{l}\text { Taste of sucrose } \\
\text { and sucralose }\end{array}$ & $\begin{array}{l}\text { MRI, whole } \\
\text { brain, ROI }\end{array}$ & $\begin{array}{l}\text { Increased activation right } \mathrm{AI} \text { during sucrose in } \\
\mathrm{BN} \text { compared with } \mathrm{HC}\end{array}$ \\
\hline & $\mathrm{HC}(14)$ & $14 / 0$ & $27.4(5.5)$ & $22.6(1.5)$ & & & & \\
\hline \multicolumn{9}{|l|}{$B E D$} \\
\hline \multirow[t]{3}{*}{ 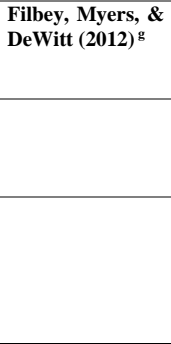 } & $\begin{array}{l}\text { BED- } \\
\text { spectrum } \\
(26)\end{array}$ & $14 / 12$ & $\begin{array}{l}32.88 \\
(11.04)\end{array}$ & $32.72(5.98)$ & BES $>8$ & $\begin{array}{l}\text { Food cue exposure } \\
\text { task }\end{array}$ & $\begin{array}{l}\text { MRI, whole } \\
\text { brain; PPI }\end{array}$ & $\begin{array}{l}\text { Taste cues high-caloric food vs neutral } \\
\text { mOFC, VTA, NAc, insula, caudate, putamen, } \\
\text { precuneus, CG, thalamus, amygdala, } \\
\text { hippocampus }\end{array}$ \\
\hline & & & & & & & & $\begin{array}{l}\text { Positive correlation compulsive overeating } \\
\text { scores with activity in: amygdala, putamen, } \\
\text { insula, PCC, precuneus, hippocampus, } \\
\text { thalamus, CG, VTA, MFG }\end{array}$ \\
\hline & & & & & & & & $\begin{array}{l}\text { Functional connectivity during high-caloric } \\
\text { cues vs. neutral } \\
\text { NAc more positively correlated with mOFC } \\
\text { and DS } \\
\text { NAc connectivity with PCC/precuneus } \\
\text { positively correlated with BES scores }\end{array}$ \\
\hline \multirow[t]{3}{*}{$\begin{array}{l}\text { Balodis, Kober, } \\
\text { Worhunsky et al. } \\
(2013 a)^{f}\end{array}$} & BED (19) & $14 / 5$ & $\begin{array}{l}43.7 \\
(12.7)\end{array}$ & $36.7(4.05)$ & DSM-5 & $\begin{array}{l}\text { Monetary Incentive } \\
\text { Delay task }\end{array}$ & $\begin{array}{l}\text { MRI, whole- } \\
\text { brain }\end{array}$ & $\begin{array}{l}\text { HC,OB>BED, decreased activity } \\
\text { VS (anticipation of reward) } \\
\text { PFC and insula (outcome phase) }\end{array}$ \\
\hline & OB (19) & $10 / 9$ & $38.3(7.5)$ & $34.6(3.5)$ & & & & \\
\hline & HC (19) & $10 / 9$ & $\begin{array}{ll}34.8 \\
(10.7)\end{array}$ & $23.3(1.1)$ & & & & \\
\hline $\begin{array}{l}\text { Balodis, } \\
\text { Kober, Grilo, } \\
(\mathbf{2 0 1 4})^{\mathrm{f}}\end{array}$ et al. & $\begin{array}{l}\text { remain BED } \\
(10)\end{array}$ & $\begin{array}{l}14 / 5, \\
\text { difference } \\
\text { N.S. }\end{array}$ & $\begin{array}{l}43.7 \\
(12.7) \\
\text { difference, } \\
\text { N.S. }\end{array}$ & $\begin{array}{l}36.7(4.05) \text {, } \\
\text { difference } \\
\text { N.S. }\end{array}$ & $\begin{array}{l}\text { DSM-5, re- } \\
\text { analysis of } \\
\text { data Balodis } \\
\text { et al. (2013). }\end{array}$ & $\begin{array}{l}\text { Monetary Incentive } \\
\text { Delay task }\end{array}$ & $\begin{array}{l}\text { MRI, whole- } \\
\text { brain }\end{array}$ & $\begin{array}{l}\text { Remain BED group diminished VS and IFG in } \\
\text { anticipation, reduced activity in medial PFC } \\
\text { during outcome phase }\end{array}$ \\
\hline
\end{tabular}




\begin{tabular}{|c|c|c|c|c|c|c|c|c|}
\hline & $\begin{array}{l}\text { recovered } \\
\text { BED (9) }\end{array}$ & $\begin{array}{l}14 / 5, \\
\text { difference } \\
\text { N.S. }\end{array}$ & $\begin{array}{l}43.7 \\
(12.7) \text {, } \\
\text { difference } \\
\text { N.S. }\end{array}$ & $\begin{array}{l}36.7(4.05) \text {, } \\
\text { difference } \\
\text { N.S. }\end{array}$ & $\begin{array}{l}\text { Recovered } \\
\text { is no binge } \\
\text { eating last } \\
28 \text { days }\end{array}$ & & & \\
\hline \multirow[t]{2}{*}{$\begin{array}{l}\text { Wang, Geliebter, } \\
\text { Volkow et al. } \\
(\text { (2011) g }\end{array}$} & BED (10) & $8 / 2$ & $\begin{array}{l}38.5 \\
(13.3)\end{array}$ & $43.4(13.5)$ & $\begin{array}{l}\text { DSM-IV, } \\
\text { EDE }\end{array}$ & $\begin{array}{l}\text { Food cue and taste } \\
\text { task } \\
\text { (smell/view/taste); } \\
\text { administered } \\
\text { methylphenidate } \\
\text { (MPH) }\end{array}$ & $\begin{array}{l}\text { PET, } \\
{[11 \mathrm{C}] \text { raclopride }}\end{array}$ & $\begin{array}{l}\text { N.S., in placebo } \\
\text { Food stimuli in MPH condition increased } \\
\text { dopamine in caudate and putamen in BED, not } \\
\text { in OB } \\
\text { Dopamine increases caudate positively } \\
\text { correlated binge eating scores, not BMI }\end{array}$ \\
\hline & OB (8) & $5 / 3$ & $41.8(8.9)$ & $36.5(9.4)$ & & & & \\
\hline \multicolumn{9}{|l|}{$B N \& B E D$} \\
\hline \multirow[t]{5}{*}{$\begin{array}{l}\text { Schienle, } \\
\text { Schäfer, } \\
\text { Hermann, \& } \\
\text { Vaitl (2009) g }\end{array}$} & BED (17) & $17 / 0$ & $26.4(6.4)$ & $32.2(4)$ & $\begin{array}{l}\text { DSM-IV, } \\
\text { EDI }\end{array}$ & $\begin{array}{l}\text { Passive food } \\
\text { viewing, } \\
\text { food/disgust/neutral } \\
\text { pictures }\end{array}$ & $\begin{array}{l}\text { MRI, whole } \\
\text { brain/ROI }\end{array}$ & $\begin{array}{l}\text { Between-subject, Food }>\text { Neutral } \\
\text { BED>OB, mOFC } \\
\text { BED>HC, right mOFC } \\
\text { BED>BN, right lOFC, right mOFC } \\
\text { BN>OB, ACC, right insula } \\
\text { BN>HC, right ACC, insula } \\
\text { BN>BED, ACC, right insula }\end{array}$ \\
\hline & BN (14) & $14 / 0$ & $23.1(3.8)$ & $22.1(2.5)$ & & & & $\begin{array}{l}\text { Within-subject, Food }>\text { Neutral } \\
\text { Occipital cortex, OFC, ACC, insula }\end{array}$ \\
\hline & OB (17) & $17 / 0$ & $25(4.7)$ & $31.6(4.7)$ & & & & $\begin{array}{l}\text { Reward sensitivity scores positively correlated } \\
\text { with activity to Food }>\text { Neutral } \\
\text { In BED: left ACC, right mOFC } \\
\text { In BN: insula, ACC, mOFC }\end{array}$ \\
\hline & HC (19) & $19 / 0$ & $22.3(2.6)$ & $21.7(1.4)$ & & & & $\begin{array}{l}\text { Arousal scores positively correlated with } \\
\text { activity to Food }>\text { Neutral } \\
\text { In BED: ACC, mOFC }\end{array}$ \\
\hline & & & & & & & & $\begin{array}{l}\text { EDI binge eating scores positively correlated } \\
\text { with activity to Food>Neutral } \\
\text { In BN: right insula }\end{array}$ \\
\hline \multirow[t]{2}{*}{$\begin{array}{l}\text { Simon, Skunde, } \\
\text { Walther et al. } \\
(2016)^{\mathrm{g}}\end{array}$} & BED (27) & N.R. & $\begin{array}{l}38.26 \\
(13.75)\end{array}$ & $32.61(4.55)$ & $\begin{array}{l}\text { SCID DSM- } \\
5\end{array}$ & $\begin{array}{l}\text { Monetary and Food } \\
\text { Delay task }\end{array}$ & MRI, ROI & $\begin{array}{l}\text { Anticipation of reward (high vs no-food } \\
\text { reward) } \\
\text { ROI: N.S. in striatum } \\
\text { Whole-brain: decreased } \mathrm{PCC}, \mathrm{HC}>\mathrm{BN} \text { and } \\
\text { HC>BED }\end{array}$ \\
\hline & $\begin{array}{l}\text { controls } \\
\text { BED (28) }\end{array}$ & matched & $38(10.85)$ & $34.02(4.5)$ & & & & $\begin{array}{l}\text { Receipt of reward (high vs no-food reward) } \\
\text { ROI: increased mOFC, BN>HC and BED>HC }\end{array}$ \\
\hline
\end{tabular}




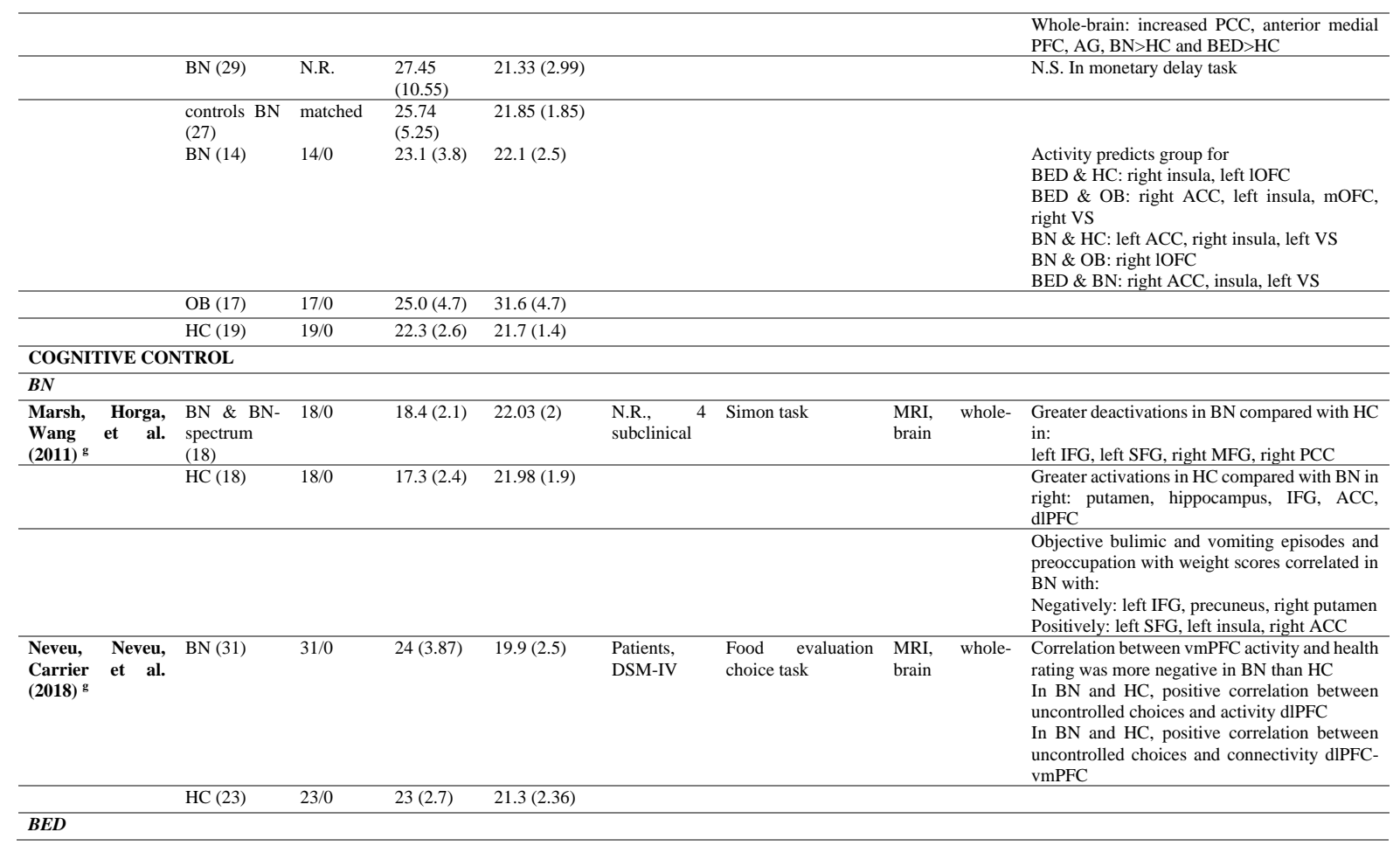




\begin{tabular}{|c|c|c|c|c|c|c|c|c|}
\hline \multirow[t]{4}{*}{$\begin{array}{l}\text { Balodis, Molina, } \\
\text { Kober et al. } \\
(\mathbf{2 0 1 3 b})^{g}\end{array}$} & BED (11) & $9 / 2$ & $\begin{array}{l}47.6 \\
(12.7)\end{array}$ & $37.1(3.9)$ & $\begin{array}{l}\text { SCID DSM- } \\
5 \text {, EDE-Q }\end{array}$ & Stroop task & $\begin{array}{l}\text { MRI, whole- } \\
\text { brain }\end{array}$ & $\begin{array}{l}\text { All groups showed consistent Stroop-related } \\
\text { differences in incongruent }>\text { congruent } \\
\text { e.g. insula, cingulate, striatum, thalamus, } \\
\text { frontal gyri, cerebellum, cuneus }\end{array}$ \\
\hline & OB (13) & $5 / 8$ & $35.4(9.3)$ & $34.6(4.1)$ & & & & $\begin{array}{l}\text { Group differences on incongruent }>\text { congruent } \\
\text { OB>BED, decreased activity } \\
\text { IFG, MFG, SFG, OFG, MOG, IOG, LG, } \\
\text { STG, insula, PreCG }\end{array}$ \\
\hline & & & & & & & & $\begin{array}{l}\text { HC>BED, decreased activity } \\
\text { SOG, MOG, STG, insula }\end{array}$ \\
\hline & $\mathrm{HC}(11)$ & $5 / 6$ & $\begin{array}{l}32.7 \\
(11.3)\end{array}$ & $23.2(1.1)$ & & & & \\
\hline \multirow[t]{2}{*}{$\begin{array}{l}\text { Hege, Stingl, } \\
\text { Kullmann, } \\
\text { Schag, Giel, } \\
\text { Zipfel, \& Preissl } \\
(\text { (2015) }\end{array}$} & BED (13) & $13 / 0$ & $\begin{array}{l}41.15 \\
(9.14)\end{array}$ & $33.45(5.38)$ & $\begin{array}{l}\text { SCID, } \\
\text { DSM-IV- } \\
\text { TR, EDE-Q }\end{array}$ & $\begin{array}{l}\text { Food-related visual } \\
\text { Go/noGo }\end{array}$ & MEG & $\begin{array}{l}\text { Successful withholds during no-go trials } \\
\text { associated with SFG and right SMG } \\
\text { BIS- } 11 \text { negatively correlated with right MFG } \\
\text { activity. BED showed decreased activity on } \\
\text { food stimuli on successful withholds in no-go } \\
\text { trials }\end{array}$ \\
\hline & OB (16) & $16 / 0$ & $\begin{array}{l}40.19 \\
(11.73)\end{array}$ & $36.38(5.02)$ & & & & \\
\hline \multirow[t]{2}{*}{$\begin{array}{l}\text { Voon, } \\
\text { Derbyshire, } \\
\text { Rück et al. (2015) } \\
\text { g }\end{array}$} & BED (31) & $19 / 12$ & $\begin{array}{l}42.79 \\
(9.02)\end{array}$ & $34.97(5.56)$ & $\begin{array}{l}\text { DMS-IV- } \\
\text { TR }\end{array}$ & $\begin{array}{l}\text { Sequential } \\
\text { instrumental } \\
\text { learning task }\end{array}$ & MRI, VBM & $\begin{array}{l}\text { In non-related HC group, bias toward goal- } \\
\text { related responding positively correlated with } \\
\text { volume in left mOFC, caudate, and lateral PFC. } \\
\text { In subsample, adding HAB/GD as covariate, } \\
\text { previously described differences (see Table 2) } \\
\text { disappeared }\end{array}$ \\
\hline & OB (31) & $12 / 19$ & $\begin{array}{l}44.24 \\
(9.39)\end{array}$ & $31.49(3.6)$ & & & & \\
\hline
\end{tabular}

NEGATIVE AFFECT

$$
\text { BN }
$$

\begin{tabular}{|c|c|c|c|c|c|c|c|}
\hline $\begin{array}{l}\text { Collins, et al } \\
(2017) \mathrm{g}\end{array}$ & Sample & & & & & & $\begin{array}{l}\mathrm{HC}>\mathrm{BN} \text {, decreased activity: Precuneus, PaCG, } \\
\text { anterior vermis }\end{array}$ \\
\hline & $\mathrm{BN}(10)$ & $10 / 0$ & $21(2.5)$ & $21.75(1.59)$ & $\begin{array}{l}\text { DSM-5, } \\
\text { SCID, EDE }\end{array}$ & $\begin{array}{l}\text { Visual food cue Whole-brain } \\
\text { processing task }\end{array}$ & $\begin{array}{l}\text { BN pre-stress> BN post-stress, decreased } \\
\text { activity: Precuneus, } \mathrm{PaCG} \text {, anterior vermis }\end{array}$ \\
\hline & $\mathrm{HC}(10)$ & $10 / 0$ & $24(5.5)$ & $22.21(1.28)$ & & $\begin{array}{l}\text { TSST (only } \\
\text { mathematical part) }\end{array}$ & \\
\hline
\end{tabular}




\begin{tabular}{|c|c|c|c|c|c|c|c|c|}
\hline \multirow{2}{*}{$\begin{array}{l}\text { Collins } \\
(2017)^{\mathrm{g}}\end{array}$ et al. } & \multicolumn{6}{|l|}{ Sample 2} & \multirow{2}{*}{\multicolumn{2}{|c|}{ Replicated findings study 1}} \\
\hline & $\begin{array}{l}\text { BN \& \& } \\
\text { OSFED-BN } \\
(17)\end{array}$ & $17 / 0$ & $\begin{array}{l}22.85 \\
(5.42)\end{array}$ & $24.47(3.25)$ & $\begin{array}{l}\text { DSM-5, } \\
\text { SCID, EDE }\end{array}$ & $\begin{array}{l}\text { Visual food cue } \\
\text { processing task } \\
\text { TSST (only } \\
\text { mathematical part) }\end{array}$ & & \\
\hline $\begin{array}{l}\text { Fischer, } \\
\text { Breithaupt, } \\
\text { Wonderlich et al. } \\
(2017)^{g}\end{array}$ & $\begin{array}{l}\text { BN \& BN- } \\
\text { spectrum } \\
\text { (16) }\end{array}$ & $16 / 0$ & $\begin{array}{l}22.85 \\
(5.42)\end{array}$ & $24.47(3.25)$ & $\begin{array}{lr}\text { DSM-5, } & 12 \\
\text { BN, } & 4 \\
\text { OSFED } & \& \\
\text { BN } & \\
\text { symptoms, } \\
\text { EDE }\end{array}$ & $\begin{array}{lr}\text { Visual palatable } \\
\text { food rue } \\
\text { processing, TSST }\end{array}$ & WS, ROI & $\begin{array}{l}\text { BN pre-stress > BN post-stress, decreased } \\
\text { activity: vmPFC, right ACC, left amygdala }\end{array}$ \\
\hline $\begin{array}{l}\text { Wonderlich, } \\
\text { Breithaupt, } \\
\text { Thompson, } \\
\text { Crosby, Engel, } \\
\text { Fischer (2018) } \mathrm{g}\end{array}$ & $\begin{array}{l}\text { BN \& BN- } \\
\text { spectrum } \\
\text { (16) }\end{array}$ & $16 / 0$ & $\begin{array}{l}22.85 \\
(5.42)\end{array}$ & $24.47(3.25)$ & $\begin{array}{lr}\text { DSM-5, } & 12 \\
\text { BN, } & 4 \\
\text { OSFED \& } \\
\text { BN } \\
\text { symptoms, } \\
\text { EDE, re- } \\
\text { analysis of } \\
\text { data Fischer } \\
\text { et al. (2017). }\end{array}$ & $\begin{array}{lr}\text { Visual palatable } \\
\text { food rue } \\
\text { processing, TSST }\end{array}$ & $\begin{array}{l}\text { EMA-fMRI } \\
\text { integration, } \\
\text { WS, ROI }\end{array}$ & $\begin{array}{l}\text { Predictive of negative affect (high just before } \\
\text { binge): right amygdala, vmPFC } \\
\text { Predictive of positive affect (high before and } \\
\text { after binge): Left amygdala, right ACC, } \\
\text { vmPFC }\end{array}$ \\
\hline \multirow[t]{6}{*}{$\begin{array}{l}\text { Lyu \& } \text { Jackson } \\
(2016)^{g}\end{array}$} & $\begin{array}{l}\text { BED - stress } \\
\text { (9) }\end{array}$ & $9 / 0$ & $\begin{array}{l}19.22 \\
(0.44)\end{array}$ & $20.8(1.48)$ & DSM-IV & $\begin{array}{l}\text { Visual food cue } \\
\text { processing } \\
\text { (high/low-caloric, } \\
\text { neutral images) }\end{array}$ & BS, ROI & $\begin{array}{l}\text { Stress condition - HC>BED, decreased activity } \\
\text { High-caloric vs. Neutral: IFG, insula, } \\
\text { hippocampus }\end{array}$ \\
\hline & $\begin{array}{l}\text { BED - no- } \\
\text { stress (9) }\end{array}$ & & $\begin{array}{l}19.89 \\
(1.54)\end{array}$ & $20.72(2.34)$ & & CPT & & Low-caloric vs. Neutral: hippocampus \\
\hline & $\begin{array}{l}\mathrm{HC}-\text { stress } \\
(12)\end{array}$ & $12 / 0$ & $20(1.41)$ & $19.19(1.52)$ & & & & $\begin{array}{l}\text { High-caloric vs. Low-caloric: } \\
\text { hippocampus, amygdala }\end{array}$ \\
\hline & $\begin{array}{l}\mathrm{HC}-\text { no- } \\
\text { stress }(14)\end{array}$ & $14 / 0$ & $\begin{array}{l}19.43 \\
(1.34)\end{array}$ & $19.22(2.16)$ & & & & $\begin{array}{l}\text { Control condition - HC>BED, decreased } \\
\text { activity } \\
\text { High-caloric vs. Neutral: SFG, ACC }\end{array}$ \\
\hline & & & & & & & & Low caloric vs. Neutral: SFG, ACC, putamen \\
\hline & & & & & & & & High-caloric vs. low-caloric: $\mathrm{PaCG}$ \\
\hline
\end{tabular}

. Overview of publications on reward sensitivity, cognitive control, and negative affect in BN and BED. Abbreviations general: N.S. = not

significant, N.R. = not reported. Abbreviations subjects: $\mathrm{BN}=$ bulimia nervosa, $\mathrm{BED}=$ binge eating disorder, $\mathrm{HC}=$ healthy control, $\mathrm{OB}=\mathrm{obese}$ control, 
OSFED = Other Specified Feeding or Eating Disorders. Abbreviations diagnosis: SCID = Structured Clinical Interview for the DSM, DSM $=$ Diagnostic and Statistical Manual of Mental Disorders, DSM-IV-TR = DSM IV textual revision, EDE $=$ Eating Disorder Examination Interview, EDE-Q $=$ EDE questionnaire, EDI = Eating Disorder Inventory, QWEP = Questionnaire on Eating and Weight Patterns, BES = Binge Eating Scale. Abbreviations task: TSST $=$ Trier Social Stress Task, CPT = Cold Pressor Test. Abbreviations method: VBM = voxel-based morphometry, ROI = region-of-interest analysis, PPI = psychophysiological interaction, $\mathrm{WS}=$ within-subject, $\mathrm{BS}=$ between=subject, EMA = Ecological Momentary Assessment. Abbreviations findings general: $\mathrm{HAB} / \mathrm{GD}=$ habitual/goal-directed responding. Abbreviations findings areas: $\mathrm{AI}=$ anterior insula, $\mathrm{VTA}=$ ventral tegmental area, $\mathrm{NAc}=$ nucleus accumbens, DS = dorsal striatum, VS = ventral striatum. Abbreviations findings cortex: $\mathrm{mOFC}=$ medial orbitofrontal cortex, $1 \mathrm{OFC}=1$ ateral $\mathrm{OFC}, \mathrm{vmPFC}=$ ventromedial prefrontal cortex, dIPFC $=$ dorsolateral PFC. Abbreviations findings gyri: $\mathrm{CG}=$ cingulate gyrus, $\mathrm{MFG}=$ medial frontal gyrus, IFG $=$ inferior frontal gyrus, $\mathrm{SFG}=$ superior frontal gyrus, $\mathrm{OFG}=$ orbitofrontal gyrus, $\mathrm{PreCG}=$ precentral gyrus, $\mathrm{AG}=$ angular gyrus, $\mathrm{LG}=$ lingual gyrus, $\mathrm{MOG}=$ middle occipital gyrus, $\mathrm{IOG}=$ inferior occipital gyrus, $\mathrm{SOG}=$ superior occipital gyrus, $\mathrm{STG}=$ superior temporal gyrus, $\mathrm{SMG}=$ superior medial gyrus, $\mathrm{PaCG}=$ paracingulate gyrus. ${ }^{\mathrm{g}, \mathrm{f}}$ Refers to the quality assessment done by two independent raters (see 'Quality assessment' for more details). Represents a good (=>7.5) or a fair (4-7.5; out of 10) rating respectively. 
1754

\begin{tabular}{|c|c|c|c|c|c|c|c|}
\hline Study & Subjects & $\begin{array}{l}\text { Gender } \\
\left(+/ \delta^{\lambda}\right)\end{array}$ & $\begin{array}{l}\text { Age } \\
\overline{\mathrm{X}}(S D)\end{array}$ & $\begin{array}{l}\text { BMI } \\
\overline{\mathrm{X}}(S D)\end{array}$ & Diagnosis & Method & Findings \\
\hline \multicolumn{8}{|l|}{ VOLUMETRIC } \\
\hline \multicolumn{8}{|l|}{$B N$} \\
\hline \multirow[t]{2}{*}{$\begin{array}{l}\text { Amianto, Caroppo, } \\
\text { D'Agata et al. (2013a) } \mathrm{g}\end{array}$} & $\mathrm{BN}(13)$ & $13 / 0$ & $22(3)$ & $22(2)$ & $\begin{array}{l}\text { SCID DSM-IV- } \\
\text { TR }\end{array}$ & VBM & $\begin{array}{l}\text { BN }>\text { HC, increased volume } \\
\text { GM: left PCL, precuneus, left putamen, left insula }\end{array}$ \\
\hline & $\mathrm{HC} \mathrm{(14)}$ & $14 / 0$ & $24(3)$ & $21(2)$ & & & $\begin{array}{l}\mathrm{HC}>\mathrm{BN} \text {, reduced volume } \\
\text { GM: caudate, right thalamus }\end{array}$ \\
\hline \multirow[t]{2}{*}{$\begin{array}{l}\text { Berner, Stefan, Lee et al. } \\
(2018)^{\mathrm{g}}\end{array}$} & $\begin{array}{l}\text { BN \& BN- } \\
\text { spectrum } \\
(60)\end{array}$ & $60 / 0$ & $18.8(4.1)$ & $22.4(2.4)$ & Patients, N.R. & $\begin{array}{l}\text { Cortical } \\
\text { thickness, } \\
\text { ROI }\end{array}$ & $\begin{array}{l}\mathrm{BN}>\mathrm{HC} \text {, increased } \\
\text { Cortical thickness: left ventral PCC }\end{array}$ \\
\hline & $\mathrm{HC}(54)$ & $54 / 0$ & $19.2(5.5)$ & $21.9(2.1)$ & & & $\begin{array}{l}\mathrm{HC}>\mathrm{BN} \text {, reduced } \\
\text { Cortical thickness: pars triangularis, right SPC, left dorsal PCC }\end{array}$ \\
\hline \multirow[t]{2}{*}{$\begin{array}{l}\text { Berner, Wang, Stefan et } \\
\text { al. (2019) } \mathrm{g}\end{array}$} & $\begin{array}{l}\text { BN \& BN- } \\
\text { spectrum } \\
\text { (62) }\end{array}$ & $62 / 0$ & $18.8(4)$ & $22.4(2.5)$ & $\begin{array}{l}\text { SCID DSM-IV- } \\
\text { TR, EDE }\end{array}$ & VBM & $\begin{array}{l}\mathrm{HC}>\mathrm{BN} \text {, inward deformations (vertex indices) } \\
\text { right anterior lateral and medial pallidum; internal and external GP }\end{array}$ \\
\hline & $\mathrm{HC}(65)$ & $65 / 0$ & $19.3(5.7)$ & $22.6(2.8)$ & & & N.S. \\
\hline \multirow[t]{2}{*}{$\begin{array}{l}\text { Canna, Prinster, } \\
\text { Monteleone et al. (2017) }{ }^{\mathrm{g}}\end{array}$} & $\mathrm{BN}(13)$ & $13 / 0$ & $27.2(2)$ & N.R. & $\begin{array}{l}\text { Patients, SCID } \\
\text { DSM-5 }\end{array}$ & VBM & N.S. \\
\hline & $\mathrm{HC}(16)$ & $16 / 0$ & $26.1(3.5)$ & $21.1(1.6)$ & & & \\
\hline \multirow[t]{2}{*}{$\begin{array}{l}\text { Coutinho, Ramos, Maia } \\
\text { et al. }(\mathbf{2 0 1 5})^{\mathrm{g}}\end{array}$} & $\mathrm{BN}(21)$ & $21 / 0$ & $31.57(8.27)$ & $21.39(2.36)$ & $\begin{array}{l}\text { Patients, DSM- } \\
\text { IV }\end{array}$ & $\begin{array}{l}\text { Drawn } \\
\text { ROIs }\end{array}$ & $\begin{array}{l}\text { HC>BN, reduced volume } \\
\text { GM: caudate nucleus }\end{array}$ \\
\hline & HC (20) & $20 / 0$ & $30.9(8.79)$ & $22.11(3.2)$ & & & \\
\hline \multirow[t]{2}{*}{$\begin{array}{l}\text { Cyr, Kopala-Sibley, Lee } \\
\text { et al. }(2017)^{*} \mathrm{f}\end{array}$} & $\mathrm{BN}(33)$ & $33 / 0$ & $\begin{array}{l}16.5(1.5)- \\
18.1(1.5)- \\
19.3(1.5)\end{array}$ & $\begin{array}{ll}22.1 & (2.8)- \\
23.2(2.8)- \\
23.8(2.7)\end{array}$ & $\begin{array}{ll}\text { Patients, } & 22 \\
\text { DSM-5, } & 11 \\
\text { OSFED-BN } & \end{array}$ & $\begin{array}{l}\text { Cortical } \\
\text { thickness, } \\
\text { ROI, } \\
\text { follow-up }\end{array}$ & $\begin{array}{l}\text { HC>BN, reduced thickness } \\
\text { Right inferior frontal gyrus pars opercularis and pars orbitalis } \\
\text { (OFC), consistent over all time points } \\
\text { IFG opercularis on baseline, } 12 \text { months, } 24 \text { months, but not } 36 \\
\text { months follow-up }(\text { N.S.) }\end{array}$ \\
\hline & $\mathrm{HC}(28)$ & $28 / 0$ & $\begin{array}{l}16.2(2.1)- \\
17.3(2.1)- \\
18.8(2.3)\end{array}$ & $\begin{array}{ll}21.4(3.5)- \\
22.6(3.5)- \\
23.9(4.9)\end{array}$ & & & $\begin{array}{l}\text { Correlations } \\
\text { Thickness frontal pole correlated negatively with objective binge } \\
\text { eating episode frequency, baseline only } \\
\text { Average thickness lateral OFC and IFC orbitalis correlated } \\
\text { negatively with frequency vomiting, over all time points }\end{array}$ \\
\hline
\end{tabular}




\begin{tabular}{|c|c|c|c|c|c|c|c|}
\hline $\begin{array}{l}\text { Frank, Shott, Hagman, \& } \\
\text { Mittal (2013) }\end{array}$ & $\mathrm{BN}(19)$ & $19 / 0$ & $25.2(5.3)$ & $22.6(5.7)$ & $\begin{array}{l}\text { Patients, SCID } \\
\text { DSM-IV }\end{array}$ & VBM & $\begin{array}{l}\text { BN>HC, increased volume } \\
\text { GM: left OFC, left anterior ventral insula, GR }\end{array}$ \\
\hline & HC (24) & $24 / 0$ & $27.4(6.3)$ & $21.6(1.3)$ & & & $\begin{array}{l}\text { HC>BN, reduced volume } \\
\text { GM: dorsal caudate, right dorsal putamen } \\
\text { WM: right MTL, right IFG }\end{array}$ \\
\hline \multirow[t]{2}{*}{$\begin{array}{l}\text { Joos, Klöppel, Hartmann } \\
\text { et al. (2010) } \mathrm{g}\end{array}$} & $\mathrm{BN}(17)$ & $17 / 0$ & $24.5(4.8)$ & $21.1(2.5)$ & DSM-IV & VBM & N.S. \\
\hline & HC (18) & $18 / 0$ & $26.9(5.7)$ & $21.2(2)$ & & & \\
\hline \multirow[t]{2}{*}{$\begin{array}{l}\text { Marsh, Stefan, Bansal et } \\
\text { al. (2015) } \mathrm{g}\end{array}$} & $\mathrm{BN}(34)$ & $34 / 0$ & $21.6(6)$ & $22.1(2)$ & $\begin{array}{l}\text { SCID DSM-IV- } \\
\text { TR }\end{array}$ & $\begin{array}{l}\text { Cortical } \\
\text { thickness }\end{array}$ & $\begin{array}{l}\text { BN>HC, increased volume } \\
\text { GM: MOG, IOG, LG, right IPL } \\
\text { WM: reflective of these results }\end{array}$ \\
\hline & $\mathrm{HC}(34)$ & $34 / 0$ & $22.08(6.5)$ & $22.13(2.3)$ & & & $\begin{array}{l}\text { HC>BN, reduced volume } \\
\text { GM: MFG, PreCG, ITG, PCC, right PostCG, right SPG, right } \\
\text { cuneus, left IFG, left LSG, left precuneus, left FG } \\
\text { WM: reflective of these results }\end{array}$ \\
\hline \multirow[t]{2}{*}{$\begin{array}{l}\text { Mettler, Shott, Pryor, } \\
\text { Yang, \& Frank (2013) g }\end{array}$} & BN (20) & $20 / 0$ & $25.2(5.3)$ & $22.59(5.69)$ & $\begin{array}{l}\text { Patients, DSM- } \\
\text { IV-TR }\end{array}$ & VBM & N.S. \\
\hline & HC (21) & $21 / 0$ & 27.5 (6.6) & $21.55(1.19)$ & & & \\
\hline \multirow[t]{2}{*}{$\begin{array}{l}\text { Wagner, Greer, Bailer et } \\
\text { al. (2006) }{ }^{f}\end{array}$} & $\begin{array}{l}\mathrm{BN}, \\
\text { recovered } \\
(10)\end{array}$ & $10 / 0$ & $24(6.1)$ & $23.1(2.4)$ & $\begin{array}{l}\text { Ex-patients, } \\
\text { recovery } 29.8 \\
\text { (18.1) months. }\end{array}$ & VBM & $\begin{array}{l}\text { N.S. } \\
\text { When covarying for age, } \mathrm{BN}>\mathrm{HC} \text { GM insula }\end{array}$ \\
\hline & $\mathrm{HC}(31)$ & $31 / 0$ & $26.8(7.3)$ & $21.9(2)$ & & & \\
\hline $\begin{array}{l}\text { Wallace, Richard, Peng, } \\
\text { Knodt, Hariri (2020) }{ }^{\mathrm{f}}\end{array}$ & $\begin{array}{l}\text { BN- } \\
\text { spectrum } \\
(247)\end{array}$ & $169 / 78$ & $19.43(1.23)$ & N.R. & $\begin{array}{l}\text { EDI-3 Bulimia } \\
\text { subtest, score }>0\end{array}$ & $\begin{array}{l}\text { Cortical } \\
\text { thickness }\end{array}$ & $\begin{array}{l}\text { Negative correlation with bulimia scores in thickness } \\
\text { GM: OFC, insula, left S1/S2, left IPC }\end{array}$ \\
\hline 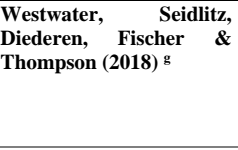 & $\begin{array}{l}\text { BN \& BN- } \\
\text { spectrum } \\
\text { (33) }\end{array}$ & $33 / 0$ & $22.6(4.13)$ & $23.9(3.1)$ & $\begin{array}{ll}\text { N.R., } & \text { EDE, } \\
\text { EDE-Q } & \end{array}$ & $\begin{array}{l}\text { Cortical } \\
\text { thickness, \& } \\
\text { per vertex } \\
\text { connectivity }\end{array}$ & $\begin{array}{l}\text { Negative correlation EDE-Q BN symptoms with cortical thickness } \\
\text { GM: rPostCG, right rostral MFG, rITG, rSFG, IOFC, IIPC, IMTG, } \\
\text { left caudal MFG } \\
\text { areas with reduced cortical thickness show increase in structural } \\
\text { connectivity estimation (per vertex, T1 MPRAGE) }\end{array}$ \\
\hline \multicolumn{8}{|l|}{$B N+B E D$} \\
\hline \multirow[t]{2}{*}{$\begin{array}{l}\text { Voon, Derbyshire, Rück } \\
\text { et al. (2015) }{ }^{\mathrm{g}}\end{array}$} & BED (20) & $12 / 8$ & 43.95 (9.47) & $34.12(5.49)$ & DMS-IV-TR & VBM, ROI & $\begin{array}{l}\text { HC>BED, reduced volume } \\
\text { GM: medial OFC, caudate, left VS, left lateral OFC }\end{array}$ \\
\hline & OB (20) & $9 / 11$ & 44.7 (10.12) & $32.88(3.53)$ & & & \\
\hline $\begin{array}{l}\text { Schafer, Vaitl, \& Schienle } \\
(2010)^{g}\end{array}$ & BED (17) & $17 / 0$ & $26.4(6.4)$ & $32.2(4)$ & DSM-IV-TR & VBM & $\begin{array}{l}\text { BED>HC, increased volume } \\
\text { GM: ACC, medial OFC }\end{array}$ \\
\hline
\end{tabular}




\begin{tabular}{|c|c|c|c|c|c|c|c|}
\hline & $\mathrm{BN}(14)$ & $14 / 0$ & $23.1(3.8)$ & $22.1(2.5)$ & & & $\begin{array}{l}\text { BN>HC, increased volume } \\
\text { GM: medial OFC, VS }\end{array}$ \\
\hline & HC (19) & $19 / 0$ & $22.3(2.6)$ & $21.7(1.4)$ & & & $\begin{array}{l}\text { BN>BED, volume } \\
\text { GM: VS, DS, left lateral OFC, left medial OFC }\end{array}$ \\
\hline \multicolumn{8}{|c|}{ STRUCTURAL CONNECTIVITY*** } \\
\hline \multicolumn{8}{|l|}{$B N$} \\
\hline \multirow[t]{2}{*}{$\begin{array}{l}\text { Canna, Prinster, } \\
\text { Monteleone et al. (2017) } \mathrm{g}\end{array}$} & $\mathrm{BN}(13)$ & $13 / 0$ & $27.2(2)$ & N.R. & $\begin{array}{l}\text { Patients, SCID } \\
\text { DSM-5 }\end{array}$ & DTI & FA: N.S. \\
\hline & $\mathrm{HC}(16)$ & $16 / 0$ & $26.1(3.5)$ & $21.1(1.6)$ & & & \\
\hline \multirow[t]{4}{*}{$\begin{array}{l}\text { Frank, Shott, Riederer, } \\
\text { Pryor (2016) }\end{array}$} & $\mathrm{BN}(25)$ & $25 / 0$ & $24.64(4.22)$ & $23.56(5.89)$ & $\begin{array}{l}\text { Patients, SCID } \\
\text { DSM-IV }\end{array}$ & $\begin{array}{l}\text { Diffusion, } \\
\text { PFT }\end{array}$ & $\begin{array}{l}\text { BN>HC, increased connectivity, left hemisphere } \\
\text { pI an dAI to: medial PFC, middle OFC, VS } \\
\text { vAI to: middle OFC, VS } \\
\text { VS to: inferior OFC, GR }\end{array}$ \\
\hline & $\mathrm{HC} \mathrm{(26)}$ & $26 / 0$ & $24.39(3.49)$ & $21.61(1.21)$ & & & $\begin{array}{l}\text { BN>HC, increased connectivity, right hemisphere } \\
\text { pI to: VS } \\
\text { dAI to: medial PFC, middle OFC } \\
\text { VS to: medial OFC }\end{array}$ \\
\hline & & & & & & & $\begin{array}{l}\text { HC>BN, reduced, left hemisphere } \\
\text { vAI to: inferior OFC, CeA } \\
\text { Hypothalamus to: middle OFC } \\
\text { Medial PFC to: GR }\end{array}$ \\
\hline & & & & & & & $\begin{array}{l}\text { HC>BN, reduced, right hemisphere } \\
\text { BLA to: dAI, VS } \\
\text { CeA to: hypothalamus }\end{array}$ \\
\hline \multirow[t]{2}{*}{$\begin{array}{l}\text { He, Stefan, Terranova, } \\
\text { Steinglass, Marsh (2016) }{ }^{\mathrm{g}}\end{array}$} & $\mathrm{BN}(28)$ & $28 / 0$ & $21.32(6.11)$ & $21.95(2.13)$ & $\begin{array}{l}\text { SCID DSM-IV- } \\
\text { TR }\end{array}$ & DTI, TBSS & $\begin{array}{l}\text { HC>BN, reduced } \\
\text { FA: FMajor, Fminor, SLF, IFOF, ATR, CST, UF, cingulate gyrus }\end{array}$ \\
\hline & $\mathrm{HC}(28)$ & $28 / 0$ & $20.61(6.12)$ & $22.18(2.14)$ & & & $\begin{array}{l}\text { BN>HC, increased } \\
\text { RD: FMajor, Fminor, IFOF, ATR, CST, cingulate gyrus, left SLF }\end{array}$ \\
\hline \multirow[t]{2}{*}{$\begin{array}{l}\text { Mettler, Shott, Pryor, } \\
\text { Yang, \& Frank (2013) } \mathrm{g}\end{array}$} & $\mathrm{BN}(20)$ & $20 / 0$ & $25.2(5.3)$ & $22.59(5.69)$ & $\begin{array}{l}\text { Patients, DSM- } \\
\text { IV-TR }\end{array}$ & DTI & $\begin{array}{l}\text { BN>HC, increased } \\
\text { ADC: CR into ALIC, corpus callosum, left IFOF, left UF, left EC }\end{array}$ \\
\hline & $\mathrm{HC}(21)$ & $21 / 0$ & $27.5(6.6)$ & $21.55(1.19)$ & & & $\begin{array}{l}\text { HC>BN, reduced } \\
\text { FA: CR into PLIC, corpus callosum }\end{array}$ \\
\hline $\begin{array}{l}\text { Wang, Bi, An, Li, Kong } \\
\text { et al. (2019) }{ }^{g}\end{array}$ & $\mathrm{BN}(48)$ & $48 / 0$ & $22.0(3.4)$ & $21.0(2.6)$ & $\begin{array}{l}\text { Patients, DSM- } \\
\text { IV, MINI }\end{array}$ & $\begin{array}{l}\text { DTI, nodal, } \\
\text { NBS }\end{array}$ & $\begin{array}{l}\text { BN>HC, increased } \\
\text { nodal strength: left superior OFC, ITG, insula, hippocampus, PHG, } \\
\text { thalamus } \\
\text { local efficiency: left superior OFC, STG, ITG, superior temporal } \\
\text { pole, thalamus, amygdala }\end{array}$ \\
\hline
\end{tabular}




\begin{tabular}{|c|c|c|c|c|c|c|}
\hline & HC (44) & $44 / 0$ & $23.1(1.7)$ & $20.5(1.4)$ & & $\begin{array}{l}\text { HC>BN, reduced } \\
\text { nodal strength: left ACC, right precuneus } \\
\text { global efficiency: left GR, right OFC, insula, putamen, pallidum, } \\
\text { amygdala, PreCG, PostCG, SMG, precuneus, FG } \\
\text { local efficiency: right PreCG, precuneus }\end{array}$ \\
\hline \multicolumn{7}{|l|}{ BED } \\
\hline \multirow[t]{3}{*}{$\begin{array}{l}\text { Estella, Sanches, } \\
\text { Maranhão et al. (2020) g }\end{array}$} & BED (17) & $17 / 0$ & $33.82(7.2)$ & $36.07(0.8)$ & DSM-5, EDE & $\begin{array}{l}\text { BED>OB, increased } \\
\text { FA: Fminor } \\
\text { AD: left SLF, cingulum (ACC, PCC), corpus callosum }\end{array}$ \\
\hline & $\begin{array}{l}\text { OB (BED } \\
\text { controls) } \\
\text { (13) }\end{array}$ & $13 / 0$ & $38.03(9.7)$ & $33.64(4.7)$ & & $\begin{array}{l}\text { BED>HC, increased } \\
\text { AD: } \\
\text { right Fminor, SLF } \\
\text { left ILF, Fmajor, IFOF } \\
\text { bilateral ATR }\end{array}$ \\
\hline & $\begin{array}{l}\text { HC (non- } \\
\text { OB) }(17)\end{array}$ & $17 / 0$ & $34.70(11.0)$ & $22.50(2.0)$ & & \\
\hline \multicolumn{7}{|c|}{ FUNCTIONAL CONNECTIVITY } \\
\hline \multicolumn{7}{|l|}{$B N$} \\
\hline \multirow[t]{2}{*}{$\begin{array}{l}\text { Amianto, D'Agata, } \\
\text { Lavagnino et al. (2013b) }\end{array}$} & $\mathrm{BN}(12)$ & $12 / 0$ & $23(5)$ & $21.57(2.38)$ & $\begin{array}{l}\text { Patients, DSM- RS, ICA } \\
\text { IV }\end{array}$ & $\begin{array}{l}\text { BN }>\mathrm{HC} \text {, increased connectivity } \\
\text { Cerebellum (IX, X) to: left insula, TL } \\
\text { Lateral cerebellum, ACC, precuneus }\end{array}$ \\
\hline & $\mathrm{HC}(10)$ & $10 / 0$ & $24(3)$ & $21.35(3.16)$ & & $\begin{array}{l}\mathrm{HC}>\mathrm{BN} \text {, reduced connectivity } \\
\text { Cerebellum (IX, X) with PL } \\
\text { Right IFG }\end{array}$ \\
\hline \multirow[t]{2}{*}{$\begin{array}{l}\text { Canna, Prinster, } \\
\text { Monteleone et al. (2017) } \mathrm{g}\end{array}$} & $\mathrm{BN}(13)$ & $13 / 0$ & $27.2(2)$ & N.R. & $\begin{array}{l}\text { Patients, SCID RS, VMHC } \\
\text { DSM-5 }\end{array}$ & $\begin{array}{l}\text { HC>BN, reduced } \\
\text { VMHC: FL, from OFC to dlPFC } \\
\text { Coherence: Slow- } 4 \text { and Slow- } 5 \text { for OFC-dlPFC cluster }\end{array}$ \\
\hline & $\mathrm{HC}(16)$ & $16 / 0$ & $26.1(3.5)$ & $21.1(1.6)$ & & \\
\hline \multirow[t]{2}{*}{$\begin{array}{l}\text { Lee, Kim, Ku, } \\
\text { Namkoong, } \\
(2014)^{g}\end{array}$} & $\mathrm{BN}(20)$ & $20 / 0$ & $22.9(3.9)$ & $21.6(2.3)$ & $\begin{array}{ll}\text { Patients, SCID, } & \begin{array}{l}\text { RS, ROI, } \\
\text { seed-based }\end{array}\end{array}$ & $\begin{array}{l}\mathrm{BN}>\mathrm{HC} \text {, increased synchrony } \\
\text { dACC to: left OFC, right precuneus, medial OFC }\end{array}$ \\
\hline & $\mathrm{HC}(20)$ & $20 / 0$ & $23.3(1.8)$ & $19.9(1.9)$ & & $\begin{array}{l}\mathrm{HC}>\mathrm{BN} \text {, reduced synchrony } \\
\text { dACC to: left PHG }\end{array}$ \\
\hline $\begin{array}{l}\text { Spalatro, Amianto, } \\
\text { Huang et al., (2019) }{ }^{\mathrm{f}}\end{array}$ & $\mathrm{BN}(16)$ & $16 / 0$ & $21.56(2.35)$ & $21.84(2.35)$ & $\begin{array}{l}\text { Patients, SCID } \\
\text { DSM-IV-TR \&OI } \\
\text { DSM-5 }\end{array}$ & $\begin{array}{l}\text { BN>HC, increased neural variability }(S D) \\
\text { Slow-4: ventral attention network } \\
\text { Slow-5: N.S. }\end{array}$ \\
\hline
\end{tabular}




\begin{tabular}{|c|c|c|c|c|c|c|c|}
\hline & HC (17) & $17 / 0$ & $23.27(2.19)$ & $21.42(1.85)$ & & & \\
\hline \multirow[t]{2}{*}{$\begin{array}{l}\text { Wang, Bi, Song, Zhang, } \\
\text { Li, Kong et al., (2020) }\end{array}$} & $\mathrm{BN}(51)$ & $51 / 0$ & N.S. & $20.8(2.2)$ & $\begin{array}{l}\text { Patients, DSM- } \\
\text { IV, MINI }\end{array}$ & $\begin{array}{l}\text { RS, ROI, } \\
\text { seed-based }\end{array}$ & $\begin{array}{l}\text { BN>HC, increased connectivity } \\
\text { Right DC to bilateral putamen, GP, caudate, thalamus } \\
\text { Putamen (DCP, DRP, VRP) to thalamus, GP, putamen }\end{array}$ \\
\hline & $\mathrm{HC}(53)$ & $53 / 0$ & N.S. & $20.4(1.7)$ & & & $\begin{array}{l}\text { HC>BN, reduced connectivity } \\
\text { VS to PreCG, PostCG, OG } \\
\text { Putamen (DCP, DRP, VRP) to right SFG/MFG }\end{array}$ \\
\hline \multicolumn{8}{|l|}{$B E D$} \\
\hline \multirow[t]{2}{*}{$\begin{array}{l}\text { Oliva, Morys, Horstmann } \\
\text { et al., (2019) }{ }^{\mathrm{f}}\end{array}$} & $\begin{array}{l}\text { BED \& } \\
\text { BED- } \\
\text { spectrum } \\
(19)\end{array}$ & $15 / 4$ & $23.89(3.4)$ & $22.53(2.04)$ & $\begin{array}{l}\text { Eating attitude } \\
\text { test (EAT-26), } \\
>1 \text { episode per } \\
\text { month }\end{array}$ & $\begin{array}{l}\text { RS, ROI, } \\
\text { seed-based }\end{array}$ & $\begin{array}{l}\text { BED>HC, increased } \\
\text { N.S. for seeds left putamen, ITG, SPL } \\
\text { N.S. correlation with impulsivity scores }\end{array}$ \\
\hline & HC (20) & $15 / 5$ & $25.31(3.2)$ & $21.25(2.07)$ & & & $\begin{array}{l}\mathrm{HC}>\mathrm{BED} \text {, reduced } \\
\text { Degree centrality: right MFG, left MTL/ITL, SPL, insula } \\
\text { Connectivity: right MFG to right anterior insula, rMFG to } \\
\text { rMFG/IFG }\end{array}$ \\
\hline \multicolumn{8}{|r|}{ 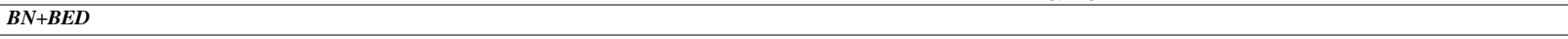 } \\
\hline \multirow[t]{6}{*}{$\begin{array}{l}\text { Stopyra, Simon, Skunde } \\
\text { et al. (2019) } \mathrm{g}\end{array}$} & BN (29) & $29 / 0$ & $\begin{array}{l}27.45 \\
(10.55)\end{array}$ & $21.33(2.99)$ & $\begin{array}{l}\text { Patients, SCID } \\
\text { DSM-IV }\end{array}$ & $\begin{array}{l}\text { RS, ICA, } \\
\text { ROI, seed- } \\
\text { based }\end{array}$ & $\begin{array}{l}\mathrm{BN}>\mathrm{HC} \text {, increased connectivity } \\
\text { ICA: right dorsal medial PFC }\end{array}$ \\
\hline & $\begin{array}{l}\text { HC } \quad(B N \\
\text { controls) } \\
(30)\end{array}$ & $30 / 0$ & $26.86(6.59)$ & $21.85(1.80)$ & & & $\begin{array}{l}\text { OB }>B E D \text {, reduced connectivity } \\
\text { ICA: right medial dACC, right dorsal medial PFC }\end{array}$ \\
\hline & BED (27) & $23 / 4$ & $\begin{array}{l}38.39 \\
(13.06)\end{array}$ & $32.64(4.13)$ & & & $\begin{array}{l}\text { BED>OB, increased connectivity } \\
\text { seed-based with dACC: right cerebellum, right LG }\end{array}$ \\
\hline & $\begin{array}{l}\text { OB (BED } \\
\text { controls) } \\
(28)\end{array}$ & $24 / 4$ & $\begin{array}{l}39.40 \\
(10.48)\end{array}$ & $33.58(4.54)$ & & & $\begin{array}{l}\mathrm{HC}>\mathrm{BN} \text {, reduced connectivity } \\
\text { ICA: left medial dACC, left ventral medial PFC }\end{array}$ \\
\hline & & & & & & & $\begin{array}{l}\text { BN>BED } \\
\text { ICA: right dorsal medial PFC, left MFG, left AG } \\
\text { seed-based with dACC: RSC }\end{array}$ \\
\hline & & & & & & & $\begin{array}{l}\text { BED>BN } \\
\text { ICA: left medial dorsal PCC } \\
\text { seed-based with dACC: left PreCG, right PostCG, left SMA }\end{array}$ \\
\hline
\end{tabular}


Table 2. Overview of publications on volumetric, functional connectivity, and structural connectivity in bulimia nervosa (BN) and binge eating disorder (BED). Abbreviations general: N.S. = not significant, N.R. = not reported. Abbreviations subjects: $\mathrm{BN}=$ bulimia nervosa, $\mathrm{BED}=$ binge eating disorder, $\mathrm{HC}=$ healthy control, $\mathrm{OB}=$ obese control, $\mathrm{EDIBul}=$ bulimia symptoms on Eating Disorder Inventory. Abbreviations diagnosis: SCID = Structured Clinical Interview for the DSM, DSM = Diagnostic and Statistical Manual of Mental Disorders, DSM-IV-TR = DSM IV textual revision, OSFED = Other Specified Feeding or Eating Disorders, EDE $=$ Eating Disorder Examination Interview, EDI $=$ Eating Disorder Inventory. Abbreviations method: VBM = voxel-based morphometry, $\mathrm{ROI}=$ region-of-interest analysis, $\mathrm{ICA}=$ independent component analysis, $\mathrm{RS}=$ resting state, $\mathrm{VMHC}=$ voxel-mirrored homotopic connectivity, DTI = diffusion tensor imaging, TBSS = tract-based spatial statistics, PFT = probabilistic fiber tractography, NBS $=$ network-based statistic. Abbreviations findings general: $\mathrm{GM}=$ gray matter, $\mathrm{WM}=$ white matter, $\mathrm{FA}=$ fractional anisotropy, $\mathrm{ADC}=$ apparent diffusion coefficient, $\mathrm{RD}=$ radial diffusivity. Abbreviations findings gyri: $M O G=$ middle occipital gyrus, $I O G=$ inferior occipital gyrus, $L G=$ lingual gyrus, $A G=$ angular gyrus, $M F G=$ middle frontal gyrus, IFG = inferior frontal gyrus, $\mathrm{SFG}=$ superior frontal gyrus, $\mathrm{PreCG}=$ precentral gyrus, PostCG $=$ postcentral gyrus, $\mathrm{ITG}=$ inferior temporal gyrus, $\mathrm{MTG}=$ middle temporal gyrus, $\mathrm{STG}=$ superior temporal gyrus, $\mathrm{SPG}$ superior parietal gyrus, $\mathrm{LSG}=$ lateral superior gyrus, $\mathrm{FG}=$ fusiform gyrus, $\mathrm{PHG}=$ parahippocampal gyrus, $\mathrm{GR}=$ gyrus rectus, $\mathrm{SMG}=$ supramarginal gyrus. Abbreviations findings cortex: $\mathrm{PCC}=$ posterior cingulate cortex, (d) $\mathrm{ACC}=($ dorsal $)$ anterior cingulate cortex, $\mathrm{OFC}=$ orbitofrontal cortex, $\mathrm{PFC}=$ prefrontal cortex, $\mathrm{SPC}=$ superior parietal cortex, $\mathrm{RSC}=$ retrosplenial cortex, $\mathrm{S} 1 / \mathrm{S} 2=$ somatosensory cortex, IPC $=$ inferior parietal cortex. Abbreviations findings other areas: SMA $=$ supplementary motor area, $\mathrm{PCL}=$ paracentral lobule, $\mathrm{TL}=$ temporal lobe, $\mathrm{PL}=$ parietal lobe, $\mathrm{FL}=$ frontal lobe, $\mathrm{MTL}=$ medial temporal lobe, $\mathrm{ITL}=$ inferior temporal lobe, $\mathrm{IPL}=$ inferior parietal lobe, $\mathrm{SPL}$ $=$ superior parietal lobe, $\mathrm{VS}=$ ventral striatum, $\mathrm{DS}=$ dorsal striatum,, $\mathrm{DC}=$ dorsal caudate, $\mathrm{GP}=$ globus pallidus, $\mathrm{DCP}=$ dorsal caudal putamen, $\mathrm{DRP}=$ dorsal rostral put., $\mathrm{VRP}=$ ventral rostral put., $\mathrm{CeA}=$ central nucleus amygdala, $\mathrm{BLA}=$ basolateral amygdala, $\mathrm{pI}=$ posterior insula, $\mathrm{dAI}=\mathrm{dorsal}$ anterior insula, vAI = ventral anterior insula, Cerebellum $(\mathrm{IX}, \mathrm{X})=$ vermis and paravermis of cerebellum, lobule IX/X. Abbreviations findings WM: SLF $=$ superior longitudinal fasciculus, ILF $=$ inferior longitudinal fasciculus, IFOF $=$ inferior fronto-occipital fasciculus, $\mathrm{UF}=$ uncinate fasciculus, ATR $=$ anterior thalamic radiation, $\mathrm{CST}=$ corticospinal tract, $\mathrm{FMajor}=$ major forceps, Fminor $=$ minor forceps, $\mathrm{CR}=$ corona radiata, ALIC $=$ anterior limb of internal capsule, $\mathrm{PLIC}=$ posterior limb of internal capsule, EC = external capsule. *Age and BMI are displayed as baseline, follow-up 1, and follow-up 2. ** Structural connectivity can be measured with a number of different techniques (e.g. diffusion tensor imaging, probability tracking, TBSS), and do not necessarily give perfectly comparable results. Values such as FA and MD are not specific (increase in FA and decrease in MD reflects reduction in white matter integrity), and differences could be attributed to myelin integrity, axonal diameter, axonal density, less coherent orientation of axons, etc. Higher RD is however more specific to myelin loss, and lower AD to axonal degradation (though there are exceptions; see Solowij et al., 2017; Aung et al., 2013). ${ }^{\mathrm{g}, \mathrm{f}}$ Refers to the quality assessment done by two independent raters (see 'Quality assessment' for more details). Represents a good (=>7.5) or a fair (4-7.5; out of 10) rating respectively. 


\section{Reward sensitivity}

anticipation phase
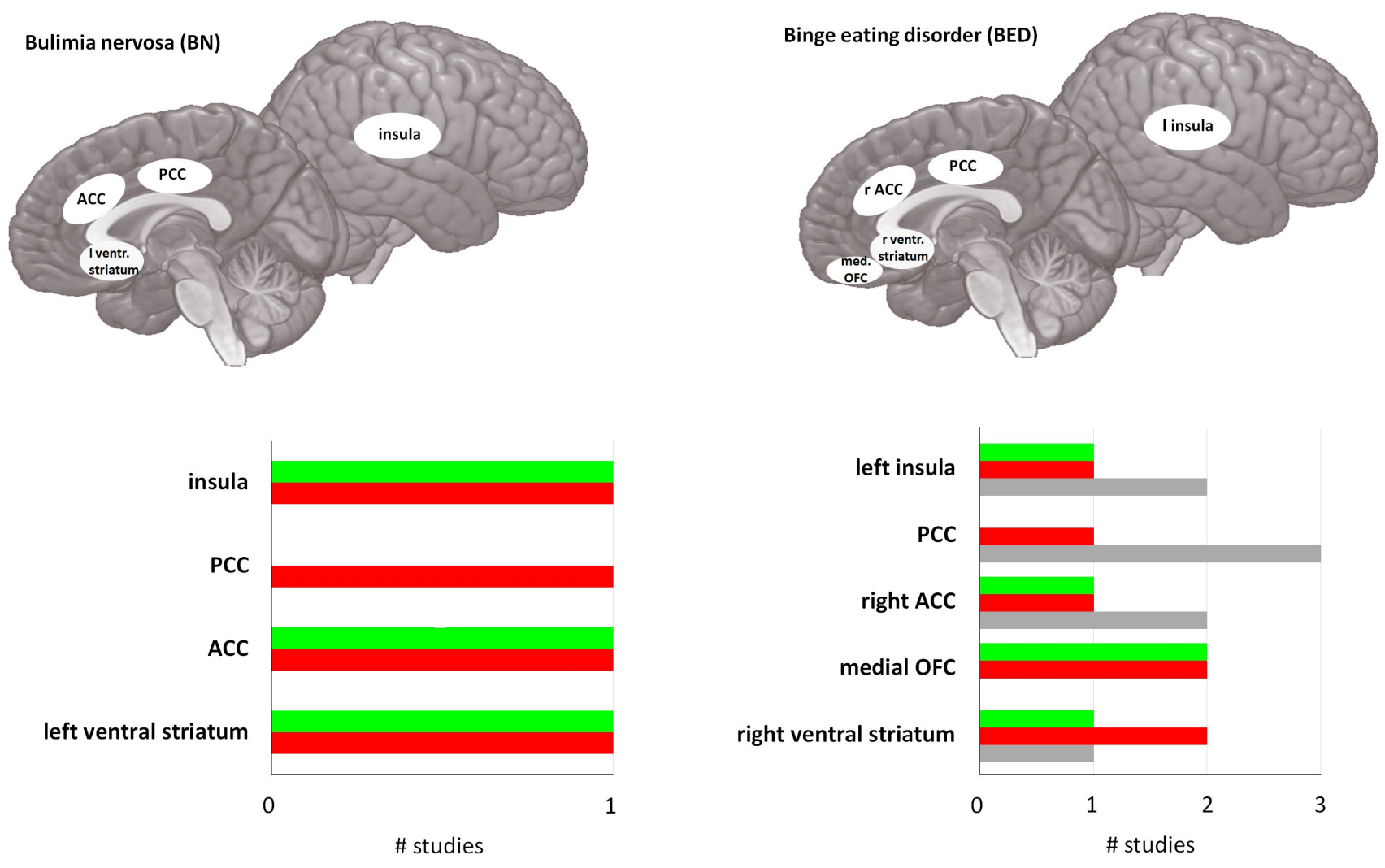

- Increased activity $\quad$ Decreased activity

- Increased activity Decreased activity No activity difference

outcome phase
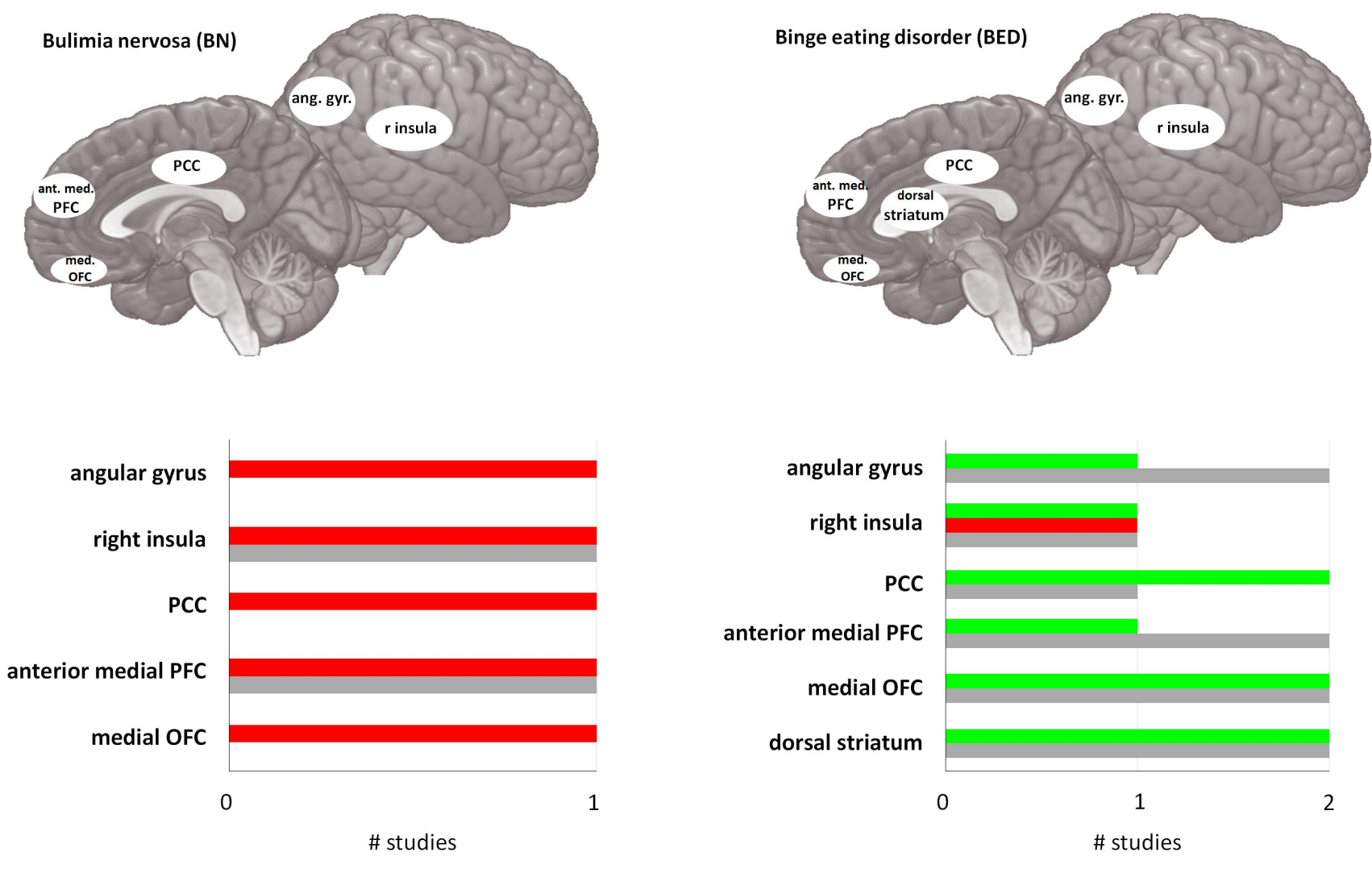

- Increased activity Decreased activity No activity difference

- Increased activity Decreased activity No activity difference 


\section{Cognitive control}
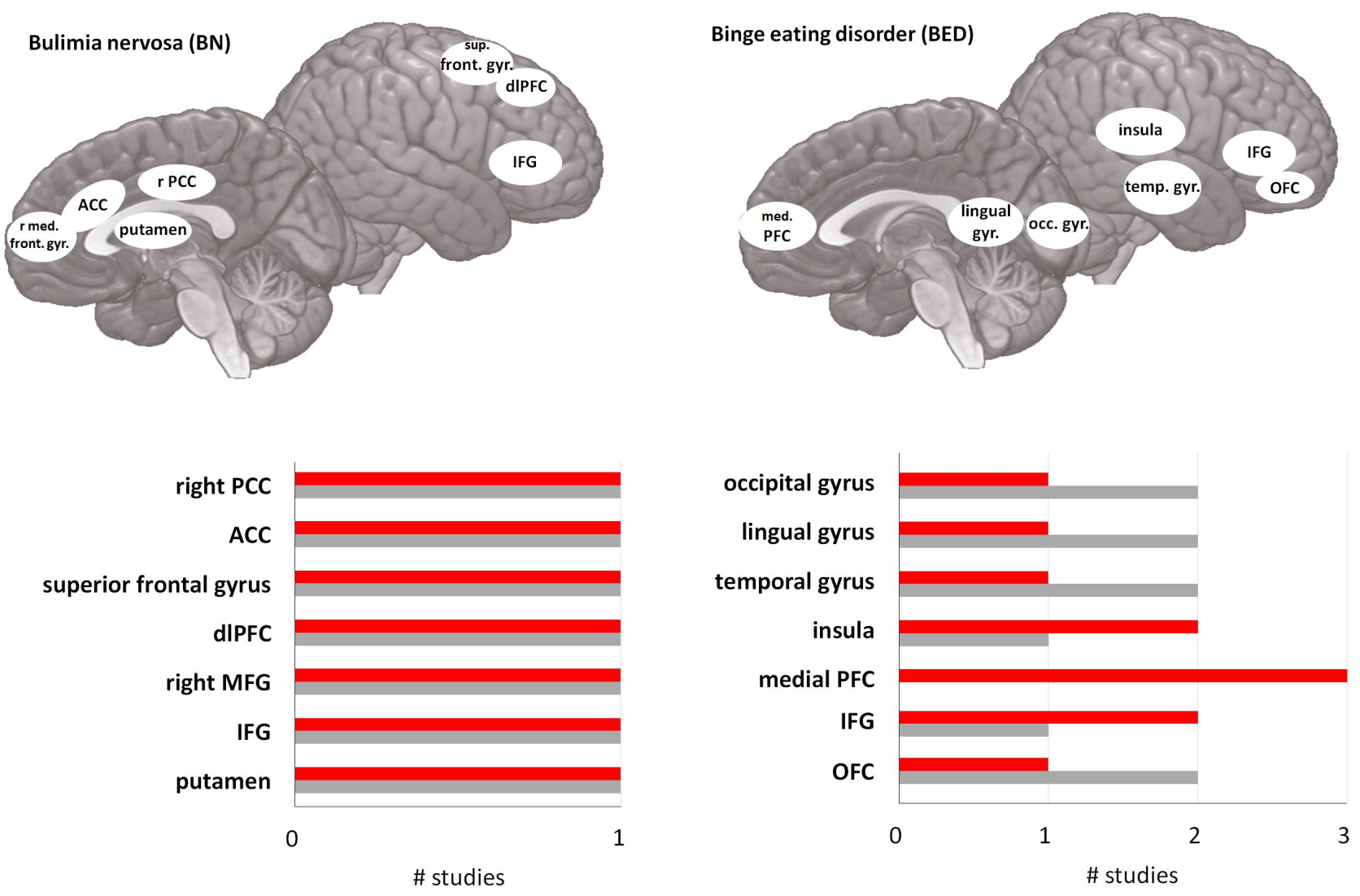

- Increased activity Decreased activity No activity difference

- Increased activity $\square$ Decreased activity No activity difference 

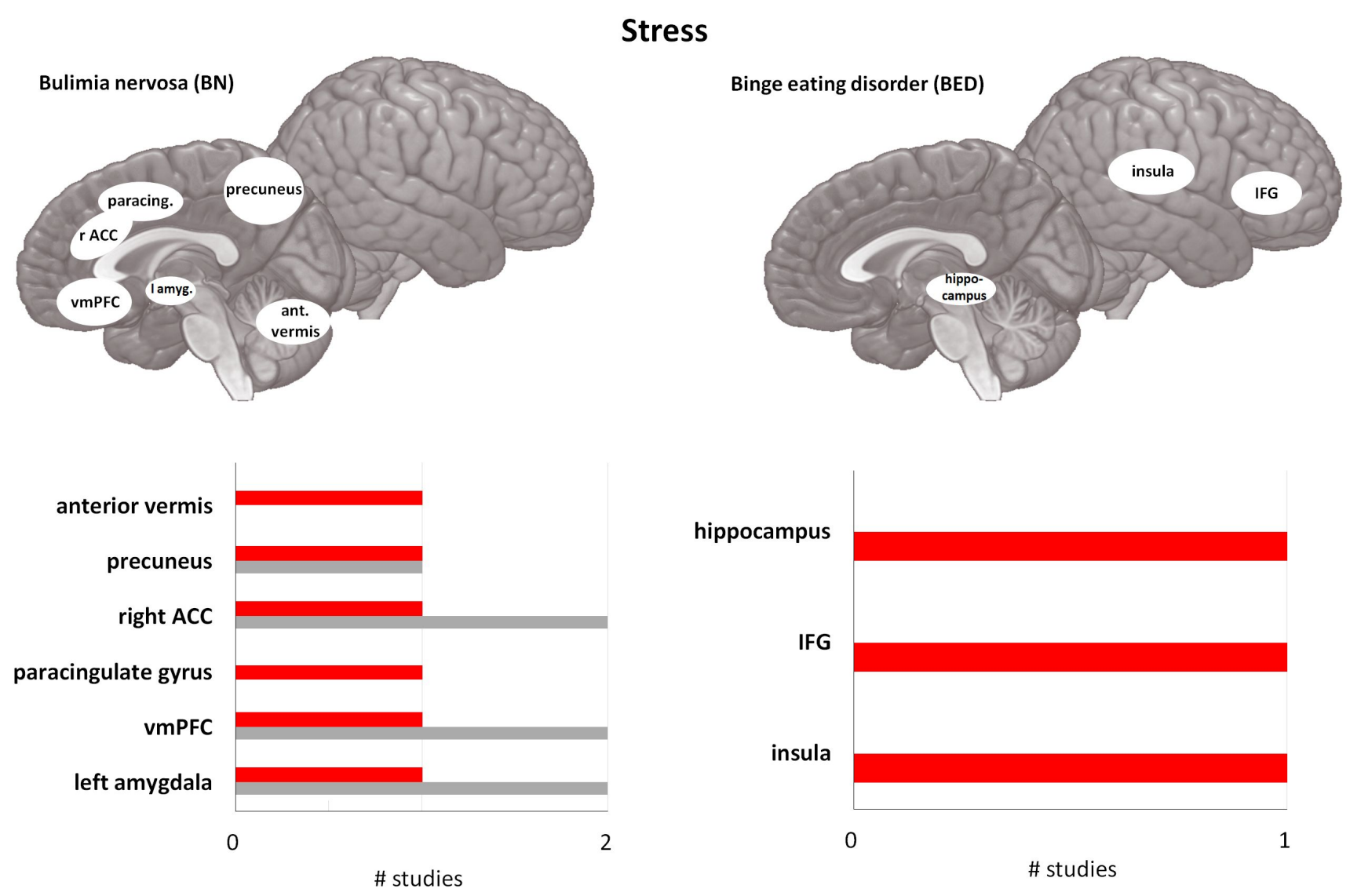

- Increased activity Decreased activity No activity difference

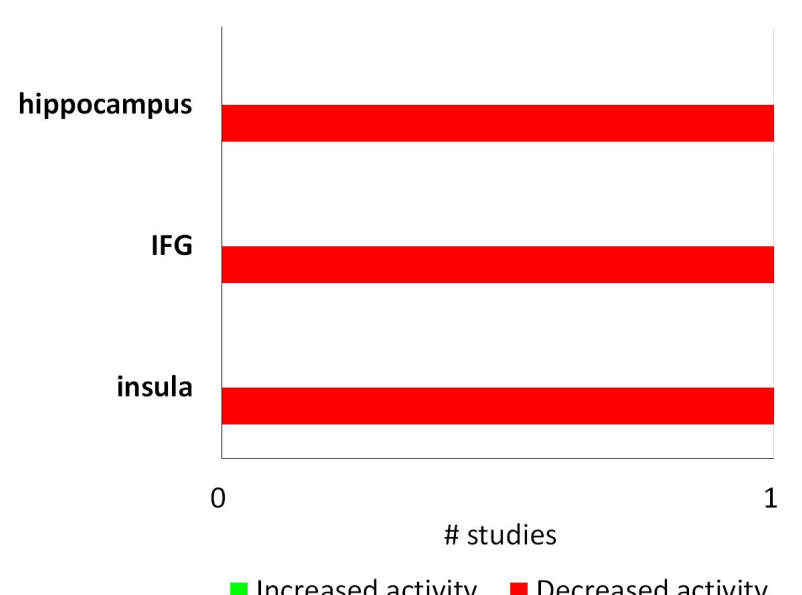




\section{Volumetric}
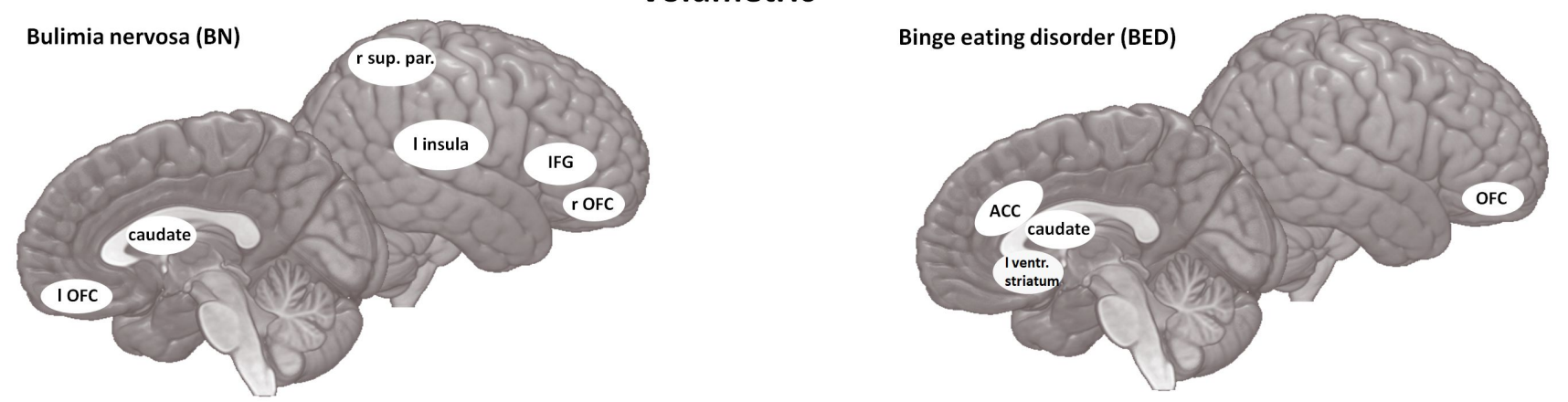

right sup. par.
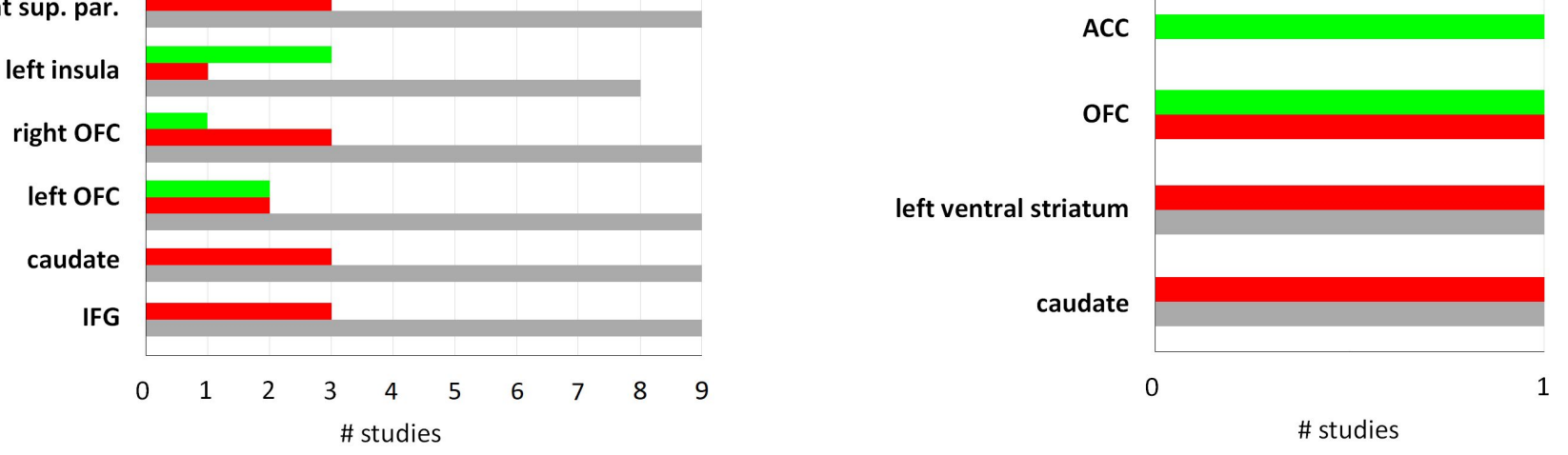

- Increased volume Decreased volume No volume difference

- Increased volume Decreased volume No volume difference 


\section{Quality Assessment}

REWARD SENSITIVITY

Balodis, Grilo, Kober 2014

Balodis, Kober, Worhunsky 2013

Filbey, Meyers, DeWitt 2012

Oberndorfer, Frank, Simmons, 2013

Schienle, Shafer, Hermann, Vaitl 2009

Simon, Skunde, Walther 2016

Wang, Geliebter, Volkow 2011

COGNITIVE CONTROL

Balodis, Molina, Kober et al 2013

Hege, Stingl, Kullman, Schag, Giel 2015

Marsh, Horga, Wang 2011

Neveu, Neveu, Carrier 2018

Voon, Derbyshire, Ruck 2015

NEGATIVE AFFECT

Collins 2017

Fischer 2017

Lyu, Jackson 2016

Wonderlich 2018

VOLUMETRIC

Amianto, Caroppo, D'agata 2013

Berner, Stefan, Lee 2018

Berner, Wang, Stefan 2019

Canna, Prinster, Monteleone 2017

Coutinho, Ramos, Maia 2015

Cyr, Kopala-Sibley, Lee 2017

Frank, Shott, Hagman, Mittal 2013

Joos, Kloppel, Harmann 2010

Marsh, Stefan, Bansal 2015

Mettler, Shott, Pryor, Yang, Frank 2013

Shafer, Vaitl, Schienle 2010

Voon, Derbyshire, Ruck 2015

Wagner, Greer, Bailer, 2006

Wallace, Richard, Peng, Knodt, Hariri 2019

Westwater et al., 2018

STRUCTURAL CONNECTIVITY

Canna, Prinster, Monteleone 2017

Estella, Sanches, Maranhão, Hoexter 2020

Frank, Shott, Riederer, Pryor 2016

He, Stefan, Terranova, Steinglass, Marsh 2016 Mettler, Shott, Pryor, Yang, Frank 2013

Wang, Bi, An, Li, Li, Kong 2019

FUNCTIONAL CONNECTIVITY

Amianto, D'agata, Lavagnino 2013

Canna, Prinster, Monteleone 2017

Lee, Kim, Ku, Lee, Namkoong, Jung 2014

Oliva, Morys, Horstmann, Castiello 2019

Spalatro, Amianto, Huang 2019

Stopyra, Simon, Skunde 2019

Wang, Bi, Song, Zhang, Li 2020
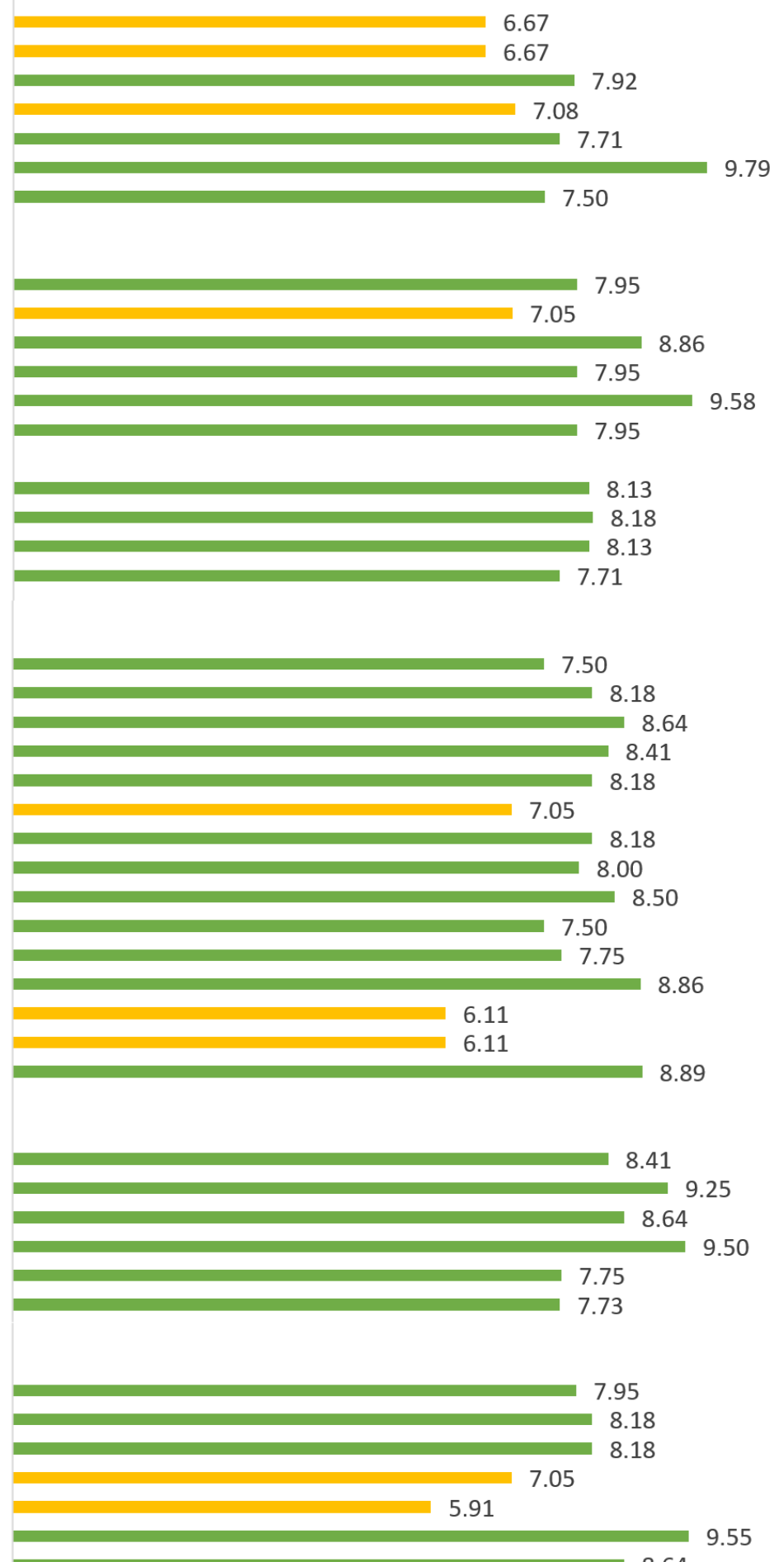